Article

\title{
Solving Problems like Maria: A Case Study and Review of Collaborative Hurricane-Resilient Solar Energy and Autogestión in Puerto Rico
}

\author{
David Krantz ${ }^{1,2,3}$ \\ 1 School of Sustainability, College of Global Futures, Julie Ann Wrigley Global \\ Futures Laboratory, Arizona State University, Tempe, AZ 85281, USA; \\ Email: krantz@asu.edu \\ 2 Center for Energy \& Society, School for the Future of Innovation in Society, \\ College of Global Futures, Julie Ann Wrigley Global Futures Laboratory, \\ Arizona State University, Tempe, AZ 85281, USA \\ 3 Quantum Energy and Sustainable Solar Technologies Engineering Research \\ Center, Arizona State University, Tempe, AZ 85281, USA
}

\begin{abstract}
After Hurricane Maria, Puerto Rico experienced the second-largest blackout in modern history, with parts of the island left without power for up to 18 months. Because the problems of Maria are multifold, this case study and review presents the historical, political, social, economic and cultural context of Puerto Rico, including a review of post-Maria solar interventions, along with two novel unconventional hybrid approaches to solving the problems of Maria: (i) Solar de Autogestión, a solar-energy racking that permits panel removal and storage in advance of a storm's arrival and reinstallation after the storm passes-a system that was developed through (ii) collaboratory-action parachuting, a novel community-interaction method developed as an oral history-based applied-scholarship hybrid of conventional parachuting research and community-based participatory research. This paper finds that addressing the problems of Maria involves understanding the holistic context of a place and its people; working in partnership with communities to form collaborations; and providing disaster response, addressing climate change, and expressing allyship and solidarity with communities through hurricane-resilient solar energy to help create energy citizenship and an energy community. Befitting its unconventional methodologies, this transdisciplinary paper-which by its nature may not fit neatly into any single discipline-also takes an unabridged, critical and hybrid descriptive-normative approach to subject matter and style, coupling academic sourcing and discourse with quotes, narrative details and fluid writing in order to be accessible to academics, policymakers and practitioners alike.
\end{abstract}

\section{Open Access}

Received: 10 June 2020

Accepted: 13 December 2020

Published: 21 December 2020

Copyright $(02020$ by the author(s). Licensee Hapres, London, United Kingdom. This is an open access article distributed under the terms and conditions of Creative Commons Attribution 4.0 International License.

KEYWORDS: applied scholarship; community engagement; disaster response; energy citizenship; energy democracy; energy sovereignty; 
environmental history; hurricane resilience; solar power; transdisciplinary scholarship

\section{ABBREVIATIONS}

CAP, collaboratory-action parachuting; CBPR, community-based participatory research; CIGS, copper, indium, gallium and selenium; PREPA, Puerto Rico Electric Power Authority; PV, photovoltaic; SolAu, Solar de Autogestión; UNDP, United Nations Development Programme

\section{INTRODUCTION}

In September 2017-exactly two weeks after Hurricane Irma, a category-five storm, passed north of Puerto Rico but still caused extensive damage to the island ${ }^{i}$, including a blackout for two thirds of Puerto Ricans-Hurricane Maria, a category-four storm when it arrived with winds blasting up to 155 miles ( $249 \mathrm{~km}$ ) per hour, ripped through Puerto Rico, resulting in the loss of electric power across the island [1] and the world's second-largest blackout in the history of electricity production [2]. Relying on electric transmission via overhead wires after centralized production of power through the burning of imported fossil fuels that generate 98 percent of Puerto Rico's electricity ${ }^{\text {ii }}$ [3] —what has been called "fossil colonialism" [4] and "energy colonialism" [5], although "energy imperialism" may be more apt-some parts of Puerto Rico remained without power for up to 18 months ${ }^{\text {iii }}$ after Maria [6], revealing weaknesses in the island's electric-grid architecture, its resilience to hurricanes, and its relationship with the federal government of the United States.

Following the work of researchers who found that "the domain of energy, and in particular electricity, opens up important questions at the interface of social-ecological relations and the organization of collective life" in post-Maria Dominica [7], this case study and review of post-Maria Puerto Rico calls for new approaches to energy production-allowing for greater resilience to hurricanes-as well as the way that engagement is conducted with communities as part of disaster response in the Global South. These new pathways may help to develop energy citizenship for energy democracy and to illuminate post-colonial energy transitions in the anthropocene epoch, when climate change-induced warming leads to stronger cyclones, hurricanes and typhoons iv [8-12], and when ever-higher levels of carbon pollution from energy production necessitate an urgent and systematic transition to renewables [13-16] such as PV (solar photovoltaics).

Maria may have been a natural disaster, but its disastrous impact was "an unnatural disaster resulting from a long history of colonial subjugation, economic hardship, environmental injustice, [and] infrastructural neglect” [17]. Subsequently, Maria was not a Black Swan event-improbable, only explainable with the benefit of hindsight and 
likely unrepeatable [18]. Puerto Rico's location in the Caribbean Sea, along the western edge of the Atlantic Ocean's Hurricane Alley and at the junction of the North American and Caribbean tectonic plates, makes it vulnerable to hurricanes as well as earthquakes-and both types of natural disasters often destroy buildings and energy infrastructure, leading to island-wide blackouts. Across Puerto Rico, people do not talk about what will happen if they encounter another Maria-like event, but when. That there will be more Marias is considered a foregone conclusion [19-21]. The question is: How do we solve the problems exposed by Maria?

In response to inadequate government attention to their needs, many Puerto Ricans have developed a do-it-yourself ethos of communal-governance entrepreneurship (utilizing what is alternatively called do-it-yourself adaptation [22], do-it-yourself urbanism [23-26], guerilla urbanism [27], informal urbanism [28], participatory urbanism [29] and tactical urbanism [30-32]) to tackle small-scale public-services and public-works projects-such as building sidewalk stairways on public land, providing humanitarian disaster relief in the wake of Maria [33,34], or even repairing a town's public power lines and utility poles [35,36] - tasks that typically are the responsibility of government and public utilities. In Puerto Rico there is a special term for it: autogestión. Borrowed from the French, meaning self-management, and meaning self-gestation based on its Latin and Greek roots, and in practice meaning self-reliance, autogestión was coined in the late 19th century and became popularly used through much of Latin America beginning in the 1950s [37,38]. Puerto Ricans may have learned to be self-reliant by necessity (and out of a desire for the territory's independence [33]), and although they may not need validation of the injustices they have suffered, that does not mean that they do not need support. The likely best way to learn if they need support is to ask them, and if they do need support, the challenge becomes how to partner with Puerto Ricans to achieve their own goals.

Interweaving work from the humanities, the social sciences and engineering, this paper will discuss two imperfect but pragmatic and novel solutions that I and the project group ${ }^{v}$ with which I worked have developed to address the problems of Maria: hurricane-resilient disaster-response solar PV, or what I call Solar de Autogestión (or SolAu), meaning "Self-Reliance Solar," and what I call CAP, collaboratory-action parachuting, so named because it incorporates communal collaboration in a partnership working toward a defined action for the betterment of the host community-and in recognition of CAP as an outgrowth of action research as well as computer scientist William Wulf's vision of a collaboratory as an interdisciplinary "center without walls" for collaborative work [39].

"By placing values, normative commitments, experiential and plural ways of knowing from around the world at the centre of climate 
knowledge" [40], this paper aims to incorporate the lessons of Andrea Joslyn Nightingale and others who promote confronting "climate change with contested politics and the everyday foundations of action, rather than just data" [40], recognizing that "[a]ll issues are political issues" [41]. Additionally, in taking a normative, transdisciplinary approach grounded in the field of sustainability, this paper recognizes that "confronting the climate crisis beyond slogans requires us to go beyond technical fixes, [to instead] navigate between descriptive and normative tasks, while also confronting energy injustices with contested politics" [42].

Sustainability as a field commonly is considered to have three parts - the environment, the economy, and society [43-65] —also known in business circles as the "triple bottom line" of people, planet, and profit [65]. Correspondingly, this paper will address all three parts of sustainability through first presenting the historical, political, social, economic and cultural context-what I call holistic context-for post-Maria Puerto Rico (Section "HOLISTIC (HISTORICAL, POLITICAL, SOCIAL, ECONOMIC AND CULTURAL) CONTEXT”) as part of understanding the social value of energy [66], then providing reviews (Section "REVIEW OF LITERATURE, INTERVENTIONS AND METHODOLOGIES”) for energy democracies, community-engagement methodologies (including conventional parachuting, community-based participatory research, and collaborative rationality), and solar interventions in Puerto Rico, followed by methodologies (Section "METHODS") and case-study outcomes (Section "CASE-STUDY OUTCOMES") for the novel unconventional hybrid approaches of CAP and SolAu, a type of solar-energy racking that permits panel removal and storage in advance of a storm's arrival as well as reinstallation after the storm passes. After a discussion (Section "DISCUSSION"), this paper will offer conclusions (Section "CONCLUSIONS") on three central interdependent arguments-(i) that holistic context matters, (ii) that work to support communities should be conducted collaboratively, and (iii) that energy interventions should be renewable and resilient to natural disasters. Taken together, these solutions may begin to solve the problems of Maria.

\section{HOLISTIC (HISTORICAL, POLITICAL, SOCIAL, ECONOMIC AND CULTURAL) CONTEXT}

Because "all history is current" [67] —in that the waves of past events reverberate forward into the present ${ }^{\mathrm{vi}}$-and because "[w]ithout an understanding of Puerto Rico's social contexts any transformation initiative risks failure” [68], addressing the problems of Maria requires reviewing Puerto Rico's post-Columbian history. Following several thousand years of inhabitance by the Ortoiroid, Saladoid, Igneri (Arawak), Kalinago (Island Carib) and, most prominently, the Taíno, peoples, and about 400 years of on-again, off-again revolts against the Spanish crown, in 1897 a bellicose Puerto Rico gained autonomy under Spain, but not 
independence from it. Less than a year later, the United States invaded and successfully snared Puerto Rico-along with Cuba, Guam and the Philippines-from Spain as spoils of the Spanish-American War, thereby transferring Puerto Rico from a European empire on the descent to an American empire on the rise [69]. The U.S. invasion also began 23 years after the end of the American Civil War, and defeated Confederates saw the successful conquest of Puerto Rico and the other territories from Spain as a "vindication of the 'Old Cause" [70], also known as the "Lost Cause”-White supremacy [71-73]—and a Confederate victory.

Since passage of the Jones-Shafroth Act ${ }^{\mathrm{vii}}$ in March 1917, Puerto Rico's residents born after the United States seized the island in 1898 have been granted American citizenship, and the island has limited self-rule while belonging to the United States. Yet Puerto Rico still features many of the trappings of colonialism, including partial (and ultimate) political control resting with a remote parent entity and taxation without representation. The latter marks a major difference between Puerto Rico and American states that formerly were Spanish colonies, such as California, Florida and Texas, because residents of Puerto Rico pay many federal taxes ${ }^{\text {viii }}$ and serve in the U.S. military but do not have voting representation in Congress and cannot vote for the offices of president and vice president ${ }^{\mathrm{ix}}$. Even after an estimated loss of about 130,000 people-mostly through emigration, but also from about 3000 storm-related deaths [74] —following Maria, Puerto Rico's population of about 3.2 million ${ }^{\mathrm{x}}$ makes the number of disenfranchised U.S. citizens living in Puerto Rico greater than the population of 21 U.S. states [75]. They comprise more than two thirds of the estimated 4.4 million U.S. citizens living in disenfranchised territories ${ }^{\mathrm{xi}}$ [76]. The disenfranchisement of Puerto Rico and other U.S. territories also has its roots in slavery, albeit indirectly. Before the Civil War, legislators from Southern states blocked the creation of new, free states in the North unless slave states were added as well, and vice versa. Today it is assumed that Puerto Rico and other U.S. territories, if given voting representation, would support the Democratic Party, and without the potential of conservative-leaning territories to join as states to provide a right-wing political counterweight, Republicans block attempts for Puerto Rican statehood [77].

Beginning in 1967, Puerto Ricans have voted in six non-binding referendums or plebiscites (plebiscitos in Spanish) on the island's political status. The referendums in 1967 and 1993 resulted in preferences for the status quo (with 60 percent and 49 percent of the vote, respectively); "none of the above" won the third referendum in 1998 with 51 percent of the vote; and the next two referendums, in 2012 and 2017, resulted in preferences for statehood (With 61 percent ${ }^{x i}$ and 97 percent of the vote, respectively), although the methodology of each referendum was deemed problematic, and voter turnout in the 2017 referendum was only 23 percent-fairly low for a population whose voter-participation rate is usually around 80 percent, meaning that those opposed to statehood may 
have abstained from voting [78-80]. But the referendums have offered a false choice in that the outcomes of the referendums do not alter the unequal power dynamic between the island and the rest of the United States because ultimately the choice of Puerto Rico's legal status, no matter how its residents vote, rests in Washington. Correspondingly, before the latest referendum was even held-in November 2020 as this paper was undergoing its final revision-the referendum already was labeled a "sham" and mere "pageantry" by some Puerto Rican academics and political leaders who favor independence for the island [81,82]. Rather than offer the choice between the status quo, statehood, independence, free association ${ }^{\text {xiii }}$ or "none of the above," as most prior referendums had done, the 2020 referendum was simply a yes-no vote of preference for statehood. Additionally, because a seven-member commission would have been appointed to negotiate for independence or free association if the majority voted "no," the referendum effectively removed the status quo and "none of the above" from the options, making it a vote between preference for statehood and sovereignty. Previously, the presence of up to five choices split the vote, providing a convenient excuse for politicians to dismiss the results [80] and possibly contributing to the decision by Puerto Rican politicians to go with a simple yes-no choice in 2020-which subsequently was dismissed in advance of the referendum as invalid by some, including the U.S. Department of Justice, because of the lack of the full suite of options [83]. Essentially, those who support the status quo and those who support independence find common cause in dismissing referendums that result in preference for statehood. Nonetheless, the 2020 vote resulted in a 52 percent preference for statehood xiv, with a voter turnout of, coincidentally, 52 percent [84]. Statehood requires approval of the president as well as both chambers of Congress by a simple majority; with Republicans maintaining control of the Senate, congressional approval of Puerto Rican statehood seems unlikely until whatever point in the future that Democrats control not just the House of Representatives and the White House but the Senate as well ${ }^{\mathrm{xv}}$. However, even a fully Democratic-controlled Washington may not enfranchise residents of Puerto Rico-after all, it never has previously.

The subjugation of Puerto Ricans leads many to label Puerto Rico as an American colony [4,5,69,85-98], regardless of whether its legal status is that of a colony or that of an unincorporated commonwealth, as it is classified by the U.S. federal government. Either way, Puerto Rico has a much lower per-capita gross domestic product $-\$ 39,400$, ranked 47 th worldwide - than the rest of the United States $(\$ 59,800,19$ th worldwide) [99], has a much lower ranking in the Human Development Index (33rd ${ }^{\text {xvi }}$ vs. 13th) [100-102], and is classified by many as part of the Global South. It also is estimated that about half of all Americans outside of Puerto Rico do not even know that Puerto Ricans-99 percent of whom are Hispanic/Latinx ${ }^{\text {xvii }}$ [103]—are Americans [104], probably detracting from 
public will to support the island financially. Even government officials, including the president, occasionally (and mistakenly) have said or implied that Puerto Rico is foreign and not American [105].

The rhetoric from the 45th American president, Donald John Trump, is particularly illuminating of Washington's attitude toward Puerto Rico. While he mulled selling Puerto Rico ${ }^{\text {xviii }}$ in order to divest the U.S. government of responsibility in the wake of Maria [106], his "insulting and paternalistic" statements ${ }^{\text {xix }}$ [34] repeatedly have referred to Puerto Rico as a non-American entity [105]—even suggesting that Rep. Alexandria Ocasio-Cortez, a New York legislator with Puerto Rican ancestry, should return to the country from which she came, a place that he described as "a complete and total catastrophe, the worst, most corrupt and inept" [107,108]. He simultaneously has expressed virulent disdain for immigrants, which by definition, for those who see Puerto Rico as a separate country, would include Puerto Ricans living on the U.S. mainland. And the Puerto Rican ethos of autogestion is the exact opposite of Trump's charge of laziness, that Puerto Ricans "want everything to be done for them"xx $[109,110]$.

Trump's White-nationalist, White-supremacist terminology [111-115] for immigrants_-"They're not people. They're animals”xxi,xxii [116], who will "infest" the United States [117,118] —echoes both the anti-Semitic propaganda of Nazi Germanyxxiii [119-122] as well as the language of famed Harvard-trained oncologist Cornelius P. Rhoads, who, before leading the development of chemotherapy as a treatment for cancer at Memorial Sloan-Kettering Cancer Center, worked at Presbyterian Hospital in San Juan, Puerto Rico, in 1931. Rhoads bragged that he killed eight Puerto Ricans ${ }^{\text {xxiv }}$, whom he called "experimental animals" [69] and "the dirtiest, laziest, most degenerate and thievish race of men ever inhabiting this sphere" $[69,94,123]$, while wishing for "a tidal wave or something to totally exterminate the population" [69,94,123]. Other scholars also point to racism [96,124,125], like that of Rhoads and Trump, as playing a central role in how Washington manages Puerto Rico and its inhabitants.

Like many people who are Latinx, Puerto Ricans-also known as Boricuas or Borincanos in Spanish, as adapted from Borinquen, the name of the island in Taíno, the native language of the indigenous Taíno people who lived in Puerto Rico and other Caribbean islands at the time of European colonization-descend from a variety of ethnic backgrounds, perhaps best described by Ocasio-Cortez on Twitter: "[T]o be Puerto Rican is to be the descendant of: African Moors [Crypto-Muslims ${ }^{\mathrm{xxv}}$ ] + [sic] slaves xxvi, Taino Indians, Spanish colonizers, Jewish refugees [Crypto-Jews ${ }^{\text {xxvii], and likely others }}{ }^{\text {xxviii. }}$. We are all of these things and something else all at once-we are Boricua” [126]. Essentially, even though today the vast majority of Puerto Ricans are Catholic and the island only has a small population of Jews and Muslims [127], Puerto Ricans, themselves victims of discrimination, are also the descendants of 
mixed relationships between multiple historically oppressed peoples and their colonial oppressors, the conquistadors-with assistance from a resurrection of the "marriage of Christianity and empire" [128].

All of these factors combined help to explain why legislation to provide disaster-response support to Puerto Rico has been met by fierce debate [105,129-131], reinforcing "the coloniality of disaster" [96] and illustrating how crises worsen preexisting racist and colonial structures. These factors-a "collision of historical factors and current policy [that] both produced and reproduced risk (and the realization of risk) in Puerto Rico" [132] -also may help to explain why the United States allowed parts of Puerto Rico to remain without access to electricity for a year and a half, a scenario that seems unimaginable for other hurricane-stricken but wealthier American places such as New York, where after Superstorm Sandy in 2012 power was restored to 95 percent of those who lost it within two weeks [133]. The neglectfully slow response of power restoration in Puerto Rico was even worse than the famously glacial federal response to Hurricane Katrina in 2005 [134-136], when power was not fully restored to the city at the epicenter of damage, New Orleans-whose population had the second-worst rate of extreme poverty in the country [137] and also was (and remains) majority African-American [138] - until no fewer than 14 months after the storm [139].

The island's ability to recover from Maria was exacerbated by Puerto Rico's debt crisis: At the time of Maria, the territorial government held about $\$ 130$ billion in debt ${ }^{\mathrm{xxix}}$ [140]—including $\$ 9$ billion owed by PREPA, the Puerto Rico Electric Power Authority [141], the government-owned utility responsible for the island's electricity generation and distribution since its establishment as the Puerto Rico Water Resources Authority in 1941 [68] —or a 2017 per-capita debt of about $\$ 39,000$ per person. Puerto Rico's status as a non-state that is subject to the whims of the U.S. Congress means that it "has few political mechanisms to solve its own [debt] problem, and the crisis is far beyond the reach of most of the tools that it does have" [142]. For decades, bankruptcy was not even an option because Congress explicitly prohibited Puerto Rico—and its political subdivisions and public agencies, such as PREPA-from seeking bankruptcy protection from 1984 until the 2016 passage of the Puerto Rico Oversight, Management and Economic Stability Act, more commonly known as PROMESA, which still denied Puerto Rico bankruptcy protection but permitted the territory to seek bankruptcy-like debt restructuring [143,144]. In effect, “Washington treats Puerto Rico's debts and disasters as purely local concerns, portraying federal assistance as a form of benevolence rather than as part of the nation's responsibility to its territories” [34].

Thanks to its insurmountable debt, Puerto Rico already was dealing with a public-health crisis and declining population as the island struggled to keep hospitals open ${ }^{\mathrm{xxx}}$, and its residents sought better 
economic opportunities on the U.S. mainland [145-147]. Even before Maria made landfall, the island's electric grid already was suffering from years of neglect and mismanagement. PREPA's debt load contributed to a "history of poor maintenance, poorly trained staff, allegations of corruption" and "power outages at rates four to five times higher than average U.S. customers” [148].

Puerto Rico's reliance on fossil fuels constitutes a form of "accumulated colonial violence," the layered effect of the many offenses of colonialism still felt today and worsened by the climate crisis, which in turn sharpens and deepens nearly every other crisis [149]. It is also a "slow violence"-_a violence that occurs gradually and out of sight, a violence of delayed destruction that is dispersed across time and space, an attritional violence that is typically not viewed as violence at all" [150] - the violence that manifests itself in asthma, cancer and developmental impairment from decades of exposure to the externalities of fossil fuels [151], such as air and water pollution and mountains of coal ash. Such slow violence makes PREPA complicit in the "embodied energy injustices" [152] that pollute both the island [153,154]—where "poor and mostly [B]lack communities in Puerto Rico's hinterlands are being forced to sacrifice their health and the health of their environment to support the island's energy-intensive economy and lifestyle" [154]—as well as extraction communities elsewhere that unearth the fossil fuels burned by PREPA and companies with which it contracts to build and to operate power plants, such as Virginia-based AES Corporation, the Fortune 500 firm that runs Puerto Rico's largest coal-burning facility. Effectively, these polluted areas become "sacrifice zones" where low-income residents-and plants and wildlife as well—sacrifice their health for the betterment of people elsewhere [155].

The reliance on imported fossil fuels also takes a large toll on the wallets on Puerto Ricans. As of May 2020, electricity on the island costs residential consumers about 26 cents per kilowatt-hour, or twice the U.S. average residential price of about 13 cents per kilowatt-hour [3], and commercial customers-such as community centers and other nonprofits, which are treated by utilities the same as if they were for-profit companies [156] — pay about 30 cents per kilowatt-hour, or three times the U.S. average commercial price of about 10 cents per kilowatt-hour [3]. Electricity rates in Puerto Rico are slated to continue to rise by double-digit percentages - via what is alternatively called a "debt charge" and a "transition charge"-as PREPA struggles to pay off its debt [157,158]. In 2019, Puerto Rico enacted the Public Energy Policy Law of Puerto Rico, requiring PREPA to move away from fossil fuels and to source its power fully from renewables by 2050. However, given that the White House-mirroring the assault by populist far-right political parties in Europe against renewable energy $[159,160]$ and reflecting a U.S. policy shift from energy independence to fossil-fuel-intensive energy dominance undergirded by a rhetoric of American exceptionalism and 
White victimhood while fueling energy colonialism [161,162] —has said that it prefers for Puerto Rico to continue buying fossil fuels from the U.S. mainland, Puerto Rico "may not have the biggest say in its own [energy] destiny" [163]. PREPA, meanwhile, is pressing forward with a vision for spending billions of dollars on natural-gas infrastructure and making Puerto Rico a Caribbean hub for liquefied natural gas [164]-infrastructure that "would create long-term dependence on methane gas imports, impede the adoption of onsite rooftop solar and related options, and further frustrate the potential for energy democracy and self-determination in Puerto Rico" [165]. Concerned that Puerto Rico is merely "rebuilding, rather than dramatically transforming" its energy grid, academics at the University of Puerto Rico at Mayagüez have written letters to and have attempted to meet with government officials, but their requests seeking a "just, deconcentrated, collaborative, participative, and democratic government” and energy system have gone without response or recognition [166].

\section{REVIEW OF LITERATURE, INTERVENTIONS AND METHODOLOGIES}

Starting with a review on energy democracies through collaborative-energy solutions-the methodological nexus point-and continuing with a review for CAP on community-engagement methodologies and a review for SolAu on solar interventions in Puerto Rico, I conducted three separate but related reviews of literature, interventions and methodologies.

\section{Energy Democracies through Collaborative-Energy Solutions}

Implementation of renewable energy can lead to many positive social externalities-such as communal capacity building and self-determination, improved communal participation in local politics and the development of new communal networks [167-169]—but without "attending to distributive and procedural justice in policy design, and making use of appropriate mechanisms to ensure that policy costs and benefits are fairly shared" [169], "climate and energy policies often fall short of delivering positive social outcomes" [169]. Therefore, it is not just the type of energy source that affects social impacts but also how that energy source is implemented. Although the United States is a democratic country, citizens' energy sourcing tends to be autocratic, with most energy jurisdictions governed by energy monopolies, sometimes managed by the government but typically owned by for-profit corporations, since enactment of the Public Utility Holding Company Act of 1935. Beginning in the 1990s, some states deregulated their electricity markets, with 23 states and the District of Columbia having done so by 2001 [170]. In deregulated states, utilities lost cost efficiencies and consumer prices increased, dampening interest in utility choice [171,172]. Following the California electricity crisis of 2000-2001, "concerns about market power problems there and elsewhere, phantom trading and 
fraudulent price reporting and accounting revelations, Enron's bankruptcy, and the financial collapse of many merchant generating and trading companies subsequently took the glow off of 'deregulation'” [171]. Many states returned to regulated systems, and now there are only about a dozen unregulated electricity markets remaining in the United States [173]. Today, the vast majority of the country, including Puerto Rico, remains subject to electricity monopolies, and the relative invisibility of the energy system-in that the public enjoys its benefits, but only a small percentage of people see energy infrastructure besides power lines-may allow the public to accept a lack of participation [174]. Without this public participation, the energy system has played an outsized role in the slow violence of climate change ${ }^{\mathrm{xxxi}}$ and the other negative health impacts from burning fossil fuels [151], including millions of annual deaths worldwide solely from particulate matter from fossil fuels [175], not even counting deaths from the impacts of climate change. These impacts could be called "climate colonialism" because basically the atmosphere itself is being colonized by carbon coming disproportionately from the Global North while its effects are felt disproportionately by the Global South [176].

In response, democratic forms of energy provision and governance have arisen, often seeking "more just, democratic, and sustainable energy systems" [177], or what is called "energy democracy"-a term whose usage only has begun in the past decade [178]. To many, energy democracy is rooted in social justice and climate justice as "a way to frame the international struggle of working people, low-income communities, and communities of color to take control of energy resources from the energy establishment-the large corporate energy producers, utility monopolies, and federal and state government agencies that serve their [own] interests-and to use those resources to empower their communities: literally (by providing energy), economically, and politically" [179]. This "new energy paradigm" is intended "to address the existential consequences of the extractive economy through the creation of a new regenerative economy-one based on a decentralized renewable energy model that advances ecosystem health, economic sustainability, and social justice through the empowerment of our communities and the democratization of our society" [179]. Essentially, from the perspective of those interested in social justice, energy democracy embodies solutions to humanity's failures with respect to the three parts of sustainability - the economy, society and the environment.

Researchers and practitioners who met at the Energy Democracy Symposium hosted in Salt Lake City in 2017 took a different approach to categorizing the aspects of energy democracy, selecting three key components-justice, participation and power-for use as a framework for understanding energy democracy [180]. Considering justice involves asking "who is served, what is the role of structural inequities, and how scholars and practitioners might factor justice into other sociotechnical 
factors that influence energy transitions" [180]. They see participation as working in existing democratic systems, which they acknowledge are flawed but with work can be moved closer to democracy's ideal. By using the term power, they do not mean harnessing electric energy, such as moving to renewables, but rather harnessing the "relationship between human actors and their capacities to act or not act freely" [180]. In that sense, renewable energy such as PV becomes a tool rather than a goal. Their framework also works chronologically because justice acknowledges the movement's social-justice roots, thereby representing the past; participation drives present action and can result in future power.

Others take energy democracy a bit further, dividing it into four categories [181]:

- Democratization-participation in governance and energy decision making;

- Property-public rather than private ownership of energy and its means of production achieved through community-based renewable energy managed by energy cooperatives and through remunicipalization, which is the return of privately owned utilities to public management with public participation;

- Surplus-value production-locally produced energy leading to local jobs; and

- Ecology-degrowth (reducing economic production and consumption to achieve sustainability [182-185]) through satiety, preservation of biodiversity and protection of wild animals and habitats [181].

Although it can take a variety of forms, two common attributes of energy democracy are a movement toward greater participation in energy governance and increased interest in distributed renewable energy [177,186,187] such as rooftop PV, leading to the coalescence of collaborative governance and renewable energy [188,189]. Perhaps this coalescence occurred because "for many nontraditional allies, renewable energy development has become a shared enthusiasm and a unique source of common ground" [189], meaning that "[s]iting renewable energy projects not only inspires, but also requires, a similar collaborative spirit” [189]. Collaborative rationality (which will be discussed further later in this paper) and collaborative governance-inspired work has been utilized successfully by government agencies for solar-energy projects across the United States [188,189]. For example, the U.S. Bureau of Land Management employed community collaboration in order to develop a draft environmental impact statement to help balance the concerns of solar energy with water conservation, wildlife needs, job creation and land use for recreation in Arizona, California, Colorado, Nevada, New Mexico and Utah [189]. The development of community solar-in which "multiple participants benefit directly from the energy produced by one solar array" 
[190]—may be particularly well suited for collaborative governance [191], given that it necessitates cooperation among its participants. Some lessons that have been learned about community-solar participants are that they want local control over their energy, strong financial incentives, inclusivity for those with low incomes, environmental sustainability, assurance of long-term solar maintenance, and mutual trust between them and those who initiate the PV project [191]. Of course, collaborative governance on energy issues can fail when the participants themselves fail to agree on a procedural outcome [173], which may be an effect of renewable energy's status as a politically contentious issue in the United States [192].

Given that energy democracy is such a large umbrella under which so many policies and goals fall, it can be difficult to track its agenda. However, the interdisciplinary team of Matthew Burke and Jennie Stephens identified and evaluated 26 intended outcomes and 22 policy instruments of the energy-democracy movement. They found that the priority energy-democracy outcomes include "decentralizing and distributing economic and political power; creating new alliances of social groups; normalizing the social and public control of energy production and consumption; strengthening the power and capacity for communities to control energy systems; and developing new organizations, ownership models and financial investment systems under such control" [187]. They also found that the corresponding primary policy instruments include "statutory demand reductions and distributed generation; public bond instruments; cap-and-dividends ${ }^{\mathrm{xxxii}}$; and a set of economic and new energy system institutional reforms including community energy, renewable energy cooperatives, remunicipalization, green public service banks, microgrids and democratized grid management, and sustainable energy utilities” [187]. Importantly, they note that no single policy is a magic bullet, and because the success of energy democracy depends on a basket of solutions, those policies all depend upon one another for the success of the movement [187]. The complexity of energy democracy's agenda, however-to simultaneously "resist, reclaim and restructure" energy systems [193]—is not easily operationalized, even in areas known to be politically liberal and supportive of environmental issues [194], particularly because those who work for energy democracy inevitably lead lives shaped by conventional energy infrastructure. To some extent, it is like fish trying to change the poisoned water in which they live themselves. It is necessary, but the challenge is enormous-and impossible without trying.

Lastly, although the term "energy democracy" may be seen by some Europeans as Eurocentric and therefore not necessarily resonant in the Global South [195], the ideas behind energy democracy clearly are reflective of autogestión. 


\section{Community-Engagement Methodologies}

Which community-engagement methodologies enable, and which hinder, energy democracies? Parachuting-the conventional research method for community engagement-also known as drive-by research or helicopter research, is perhaps the most commonly used (and most commonly derided) method of research for those seeking interventions in communities, often in the Global South. Seen by some as "semicolonial" [196], conventional parachuting, at its most basic, entails researchers and/or aid donors who jump into a situation, institute an intervention and leave. For example, researchers could fly to a country, install solar panels and return home. Maybe the researchers stay for a few days or longer. One even can parachute by mail-postal research-by requesting samples from a remote site, or by sending the intervention, such as solar panels, as a parcel and never even setting foot at the installation site.

The strengths of conventional parachuting are its common usage, relative ease, scalability and speed with which it can be implemented. Conventional parachuting requires minimal time investment and typically is not tailored to individual communities, allowing the same intervention to be applied anywhere the intervention is deemed necessary by the researchers and/or aid providers.

Unfortunately, because conventional parachuting typically does not involve anything more than a minimal relationship with recipients of the intervention, it is accompanied by a host of potential problems:

- Recipients may not know how to use the intervention and subsequently may use it incorrectly (for example, see the high breakage rates of condoms among those who did not receive training in using them [197]);

- Recipients may not know how to repair the intervention, which subsequently falls into disrepair (for example, see the third of broken water hand pumps in some sub-Saharan nations because community members do not know how to maintain or fix them [198]);

- The recipients may not know how to use the intervention and subsequently not use it (for example, see telecommunications devices for the deaf left untouched in their boxes because medical staff never received training on how to use them with deaf patients [199]);

- The intervention actually may be unwanted by the recipients and therefore may go unused (for example, see biomass cooking stoves that sit in their original boxes [200], piles of unused solar lanterns in the offices of nonprofit offices in Africa [201], or the seemingly infinite supply of used clothes no one wants that are sent as "aid" [202,203]);

- The intervention may be wanted but the recipients may not be capable of utilizing it well (for example, see the donation of technology transfers and laboratory equipment to countries without 
trained researchers to use them-or even $\mathrm{PhD}$ programs to train researchers [204]);

- The intervention may be wanted but is coopted by others in a way that defeats its purpose (for example, see how men took the extra income raised by women/womxn xxxiii after efforts to support the latter's businesses [205], or how U.S. food aid is intercepted by armed groups in order to finance violence [206]);

- The intervention may be wanted, but its implementation has other negative effects on the community (for example, see how U.S. food aid puts local farmers out of business by making them compete with a discounted or free product [207,208]);

- The intervention may be wanted by the recipients but may be cannibalized for parts to support another, typically wealthier, area (for example, see the World Bank-supported electric system in Freetown, Sierra Leone, where utility managers rip apart the power lines in the poor parts of the city in order to patch the lines in the city's rich neighborhoods [209]);

- The intervention may be wanted but not as much as something else (such as income or food), leading to reuse of the intervention for a purpose outside the original intention (for example, see mosquito nets intended to reduce malarial infections that often have been used as fishing nets instead [210]);

- Recipients may be unwilling to participate in the intervention without community involvement (for example, see that older ethnic-minority Americans who need psychosocial services are less likely than their White peers to participate in clinical research unless researchers involve ethnic-minority community leaders in the recruitment process [211]);

- Recipients may feel that the purpose of the intervention is actually to benefit the researcher or giver of aid instead of the community in need (for example, see initial resistance from Wiikwemkoong First Nation members in Canada to health research [212]); and

- Lack of follow up and an unequal power dynamic between researcher and intervention recipient, which when combined with a natural reluctance to report negative results means that the type and volume of parachuting-research failures likely is underreported.

Because conventional parachuting does not include the recipient of the intervention as a partner, there may not even be an assessment of whether an intervention even is wanted. In that sense, implementing the intervention may not be about helping the recipients as much as about fulfilling some other purpose, such as pretending to support others while actually supporting oneself (such as in the case of requiring U.S. aid recipients to spend their food aid by purchasing from U.S. farmers ${ }^{\mathrm{xxxiv}}$ [213], or in the case of using food aid to expand the market for GMO [genetically modified organism] crops [214]), or simply making the giver feel good (such as in the case of giving away unwanted clothes, as 
described above). Certainly, things can go right with conventional parachuting. This paper argues that too often things go wrong and that there are few, if any, mechanisms in place to protect against the ills of conventional parachuting-not even the institutional-review process. Institutional ethical-review boards-whose purview is restricted to biomedical and behavioral studies of human subjects and does not cover most other types of studies and interventions, including biography, criminal-justice research, historical scholarship, journalism, legal research, literary criticism, national-security research, oral history and public-health surveillance [215,216] - have proven to be ineffective at addressing many of the shortfalls of conventional parachuting. For example, all of the above examples of negative consequences of conventional parachuting occurred after the implementation of review boards. Indeed, even the attempts of review boards to rigidly apply biomedical standards to the social sciences have hindered researchers trying to avoid the perils of conventional parachuting [217-220] and effectively have protected "institutional power at the expense of community empowerment” [217]. A third party, such as a review board, cannot grant a social license to work with a community because only a community can grant such permission. Yet the review system persists because "the history of science shows that scientists often hold on tenaciously to an accepted paradigm and vigorously fight off any challenges" [221] and "the biases that are inherent in the paradigm itself are much more difficult to see and to debate" [221].

In response to the challenges of conventional parachuting, researchers in the late 20th century developed a plethora of similarly named and practiced research methodologies-including but far from limited to action inquiry [222], action science [223], collaborative action research [224,225], critical action research [226], socially critical action research [227], emancipatory research [228] and participatory research [229] - that perhaps best can be described as a "long list of terms representing this new participatory research paradigm, which links applied social science and social activism, [which] has been fairly daunting, and [where] the nuanced differences between them are often difficult to decipher" [230], likely reflecting academic battles over contested nomenclature [225].

These methodologies largely are intended to involve the recipient of the intervention and/or the subject of research in the design and/or implementation of the research, often in the interests of a positive outcome, rather than simply for the purpose of gaining knowledge itself-hence the emphasis on the words participatory and action. The roots of many of these methodologies can be traced back to the 1930s when social psychologist Kurt Lewin, with an unsuccessful attempt to launch a new program at Hebrew University in Jerusalem [231], pioneered what he would later call "action research" [232,233]-“collective reflection by participants on systematic 
objectifications of their efforts to change the way they work" [234] in order to demonstrate "that through discussion, decision, action, evaluation and revision in participatory democratic research, work became meaningful and alienation was reduced" [231]. Lewin's original action research and its academic spawn together have evolved into participatory action research [225,230,234,235] - which in turn has evolved into what has become one of the more commonly practiced alternative methodologies today: CBPR, or community-based participatory research [230], also known as, or in almost every practical sense interchangeable with, community-based participatory action research [236], community-partnered participatory research [237], community-based public health [238], community-centered research, community-involved research, and community-wide research [239]. Participatory action research differentiates itself from CBPR in emphasizing research that incorporates transformative actions and, typically, critical reflection to refine the research process. That said, neither form of research is monolithic, either in its practice or in how people understand it.

Although CBPR is not practiced the same way by everyone and has no universally agreed-upon standards, generally it involves the development of a partnership between researchers and intervention recipients (or in the case of some scholarship, a partnership between academics and the observed) for the duration of the research project. The researchers and the intervention recipients work as collaborators with shared goals and decision making and with each party contributing its expertise to the shared project for the betterment of the community being researched or receiving the intervention [239-242].

While noting that "[n]o one set of CBPR principles will help researchers avoid all potential problems," Elena Bastida and her colleagues in the public-health space-the field in which CBPR may be most commonly practiced-developed six principles that they see as a potential code of ethics for those practicing CBPR:

1. Respect for the community being researched or receiving the intervention;

2. Financial transparency-sharing budgetary details with community members;

3. Treat all stakeholders fairly;

4. Provide informed consent for community participation and emphasize participants' right to opt out at anytime;

5. Acknowledge that community members' participation is just as important as researchers' participation; and

6. Provide community members with the opportunity for equal speaking time, and keep them appraised of study results [242].

Barbara Israel and her colleagues, also in public health, delineated eight different but similar principles of CBPR: 
1. Identify and strengthen "community as a unit of identity";

2. Identify and build upon the community's strengths;

3. Initiate collaboration in every phase of research;

4. Integrate "knowledge and action for mutual benefit of all partners";

5. Promote allyship and solidarity that addresses social inequities;

6. Utilize an iterative process of "partnership development and maintenance, community assessment, problem definition, development of research methodology, data collection and analysis, interpretation of data, determination of action and policy implications, dissemination of results, action taking (as appropriate), specification of learnings, and establishment of mechanisms for sustainability";

7. Emphasize "physical, mental, and social well-being"; and

8. Share results with all partners [239].

The strengths of CBPR are that it can lead to fairer treatment of the community being researched or receiving the intervention, it is well-suited for longitudinal research, and it can lead to more effective outcomes because the research is more likely to be shaped by community input and partnership.

CBPR's biggest weakness may be how difficult it is to execute well. For example, building trust between parties and the hurdling of emotional barriers can take time-and even after much time, mutual trust and respect may not be gained. Additionally, it can be exceedingly difficult to distribute power and fiscal resources equitably, to overcome cultural misunderstandings, and even to define a community and who actually has the legitimacy to represent it [239]. The solutions to these weaknesses typically require time-more time than one reasonably might expect. Given that time often equates to money, CBPR can be a particularly resource-intensive venture when done well. Unfortunately, time and plentiful fiscal resources are luxuries in short supply for too many researchers [243,244]—as well as for community members [245].

Additionally, unlike community organizing, CBPR typically is oriented around projects and not toward building a community's power by tackling the structural causes of inequality. There also are several issues applicable to CBPR projects that require travel. The first is the carbon emissions of travel, which can be mitigated through carbon offsets. Secondly one might argue that it is unfair if only the researchers experience the joys and/or burdens of travel; this unfairness can be mitigated by bringing community members to meet with researchers at the latter's home community or communities. Lastly, the cost of researchers traveling in person to a community may be economically inefficient. The thousands of dollars typically spent on travel arguably would be better spent on purchasing more of the intervention itself. (In the case of our group's project in Puerto Rico, our travel costs could have been replaced with buying more solar panels.) Phone calls and video conferencing could be used instead of travel, but their use requires the community to have access to the technology. More importantly, although 
phone calls and video conferencing may be suitable for replacing typical corporate travel [246], they can be poor substitutes for the types of relationship building for which CBPR calls. Time-zone differentials also can be challenging to surmount remotely. Furthermore, despite advances in videoconferencing technology (and platforms such as FaceTime, FreeConference, Google Hangouts and Meet, GoToMeeting, Skype, WebEx and Zoom), face-to-face interaction-by virtue of its immediate feedback, physical presence and fuller context-empirically remains a better means to "build a personal, authentic, and trustworthy atmosphere" among people who do not know each other well [247].

Others have developed alternatives to CBPR. Planning theorists David Booher and Judith Innes have championed hybrid collaborative methodologies in public policy by expanding upon philosopher and sociologist Jürgen Habermas's concept of communicative rationality-what some have considered "the key to diagnosing the sociopathologies of modernity and a way of sorting out proposed remedies to these ills" [248] - to what they call collaborative rationality [249,250], an "alternative to the traditional model, with its reliance on expert knowledge and reasoning based upon argumentation” [250]. A form of collaborative governance, collaborative rationality consists of deliberative democracy [251-259] (aka discursive democracy) through discussions-typically ad hoc and organized by the government, sometimes in cooperation with other stakeholders, such as developers or environmentalists-“in which individuals representing differing interests engage in long-term, face-to-face dialog, seeking agreement on strategy, plans, policies, or actions" [260].

Deliberative democracy has been found to be effective in addressing environmental issues [255], and by emphasizing incorporation of discussion by members of the public into the policymaking process [249,250,261], Booher and Innes found that collaborative rationality is particularly useful as a means of utilizing inclusionary decisionmaking to address (but not to solve) wicked problems, such as those that involve sustainability. They note, however, that just because a process is collaborative does not mean that it will be effective, so they focus on the rationale behind the process for public representation and how the subsequent conversation is performed, for which they offer seven guidelines [249]:

1. Viewpoints should be diverse and participants should not be selected by government officials ${ }^{\mathrm{xxxv}}$;

2. All should be interested in the task at hand;

3. Participants should be discouraged from taking positions until they have had the opportunity to hear a diverse set of viewpoints on the issue;

4. Discussions should be held in person and conclusions should be determined for every discussion;

5. Experts and non-experts alike should be included in the discussions; 
6. All ideas should be considered; and

7. At least 80 percent of participants should agree to any decision [249].

Basically, collaborative rationality, befitting its usage in governance, represents the ideals of town-hall democracy, except instead of accepting a threshold of a simple majority for decisionmaking, it has a higher bar of 80 percent. By including the public in decisionmaking, collaborative rationality and deliberative democracy also challenge the conventional notion of expertise: Who are the experts, the people who design policies/interventions or the people who utilize policies/interventions? Perhaps both, and outcomes may be better by inclusion of both in the decisionmaking process.

Collaborative rationality is not, of course, perfect. It requires policymakers to relinquish power to the public, which simultaneously aids in the methodology's effectiveness while making it less likely for officials to be willing to engage in its practice. Including discussions of a small sample of the public in the decisionmaking process may inadvertently become a substitute for other forms of larger scale public engagement [262], and/or the public discussions may be held pro forma as a form of "participatory window dressing" [263], with group decisions discarded, and/or those in power may coopt or manipulate the process in order to achieve their desired results [263]. Collaborative rationality's tendency to rely on ad hoc mechanisms for discussion also lessens procedural visibility, "a key condition for accountability” [262].

Although Booher and Innes have found it to be effective [249,250,260,261], collaborative rationality (along with other frameworks developed by Booher and Innes, such as communicative rationality [264]) has not just many of the same strengths-such as communal self-determination and inclusion of diverse viewpoints-but also many of the same weaknesses of democracy itself, in that participation may be limited to those with the time, energy and inclination to participate. People working more than one job and/or those caring for family members may be left out of discussions. Participation may be most attractive to "representatives of collective interests" [262], such as corporations that stand to profit from the outcome, and may seek to maximize policy benefits for themselves and to externalize to others the costs of their policy choices [262]. Alternatively, people may have time, energy and inclination but may fear involvement with the state, which may make undocumented residents and members of minority groups accustomed to state-sanctioned forms of discrimination less likely to participate-and thereby may make the participatory process less representative. Those with inclination may hold extreme opinions, possibly making discussion groups less likely to reach consensus. (Although such consensus-obstructing antagonism can be valuable, or even central for democracy [265,266], Booher and Innes see consensus as one of the primary goals of collaborative work [264] —and certainly some antagonism can be productively disruptive but too much can thwart 
progress.) Additionally, groupthink may negate minority opinions and decisionmaking can take longer than relatively more top-down systems, if decisions can be made at all, because the participants might not reach agreement about particularly contentious issues, and conventional expertise can be devalued and/or ignored. More dangerously, by assuming that the majority knows best, democratic systems such as collaborative rationality are potentially vulnerable to misinformation, disinformation, populism, hatred and tragedies of the commons. For example, such a process would not prevent classist, racist, sexist, xenophobic or otherwise damaging decisions if that is upon what the group agrees (although top-down decisionmaking is not immune to such effects either). To function well, collaborative rationality requires the oxygen of a democracy, an informed (and non-hateful) public.

Still, like democracy itself, collaborative rationality may be flawed, but it also may be the best option available ${ }^{\mathrm{xxxvi}}$. Collaborative rationality offers a powerful model for community engagement and represents a successful means of expressing allyship and solidarity through governance. How could its lessons be applied outside of governance, however, and what would such a governance-oriented hybrid approach between conventional parachuting and CBPR look like for research, interventions and scholarship? Although hesitant to contribute yet another method to the morass of similarly named systems within the "new participatory research paradigm" [230], I have found that our newly developed method, collaboratory-action parachuting, combines the pragmatism of parachuting with the community-engagement and social-action facets of methods such as CBPR and its ilk. I recognize that we may not have been the first to practice what I am calling CAP_indeed, collaborative interventions have proven to be effective in addressing conflict around the world [250], and some of those may have utilized methodologies resembling CAP_but because this unconventional hybrid methodology has been absent from the academic literature until this point, if it has been practiced previously, then it has been without explicit documentation as a methodology. CAP, which will be discussed in more detail later in this paper, may fill a niche for those who do not have the resources needed to practice CBPR properly but who nonetheless want to engage a community in an action-oriented partnership, particularly toward energy independence and an energy democracy.

\section{Solar Interventions in Puerto Rico}

Although infrastructure cannot itself bring about an energy democracy, microgrids may be the closest to representing the physical manifestation of energy democracies. Basically, in an electric grid-a large-scale electric network that connects power plants, transmission lines, electric substations and consumer buildings-electricity is carried from the place of production to the place of consumption by way of power lines. Because everything within the grid is connected, failure in 
one part of the grid-such as downed power lines or inadequate production-can cause much or all of the grid to lose power. Microgrids operate similarly to conventional electric grids, except on a much smaller scale. Covering a single community or even a single building ${ }^{\mathrm{xxxvii}}$, a microgrid with its own power production can disconnect ${ }^{\mathrm{xx} x v i i}$ and run independently from the main grid when the latter fails, as it is prone to do during natural disasters. Much of the work to improve energy-system natural-disaster resilience (also called energy-system disaster preparedness) has focused on improvements in microgrid technologies. For example, in response to Hurricane Maria, Sandia National Laboratories identified 159 potential microgrid locations in Puerto Rico-including about a dozen nonresidential locations in Mayagüez-and evaluated the cost and benefit of each site [267]. To prevent the same devastating loss of power after Maria, however, microgrids alone are not enough: They need to be coupled with local power generation. Furthermore, because PV requires no input other than sunlight and is a cost-competitive technology, solar energy is an excellent energy-production candidate-and in some places the least-costly option [268] - to pair with microgrids to help make energy systems more resilient to natural disasters [269-274], particularly for an island like Puerto Rico [68,275]. Unlike typical electric generators, PV does not require inputs, such as fossil fuels, to be sent at a time when the ability to resupply those inputs may be cut off.

Yet unpredictability plays a large role for solar panels' natural-disaster resilience because the ability of PV to provide power is contingent upon the solar panels surviving the disaster. Hurricane-force winds can blow panels off their frames or can blow other objects into the panels, damaging them. A ground-based system is vulnerable to flooding. A roof-based system is vulnerable to collapse if the building on which it sits is destroyed. Studies of PV systems after hurricanes, including after Maria, show that some survive the storm and some do not [272,273,276-282]. Since PV systems are not designed to weather the worst impacts of a hurricane, and most PV systems are designed to be fixed in place once installed-and therefore cannot be moved to safety in advance of a hurricane's arrival-it seems that the determining factor in a PV system's survival is luck.

Although some solar installations in New Jersey were untouched after Superstorm Sandy devastated the state's coast [276,283], some solar panels in Puerto Rico experienced severe damage after Maria [284], and others on the island weathered the storm. Solar panels at the community center of Casa Pueblo-the acclaimed Adjuntas-based and autogestión-oriented [285] environmental-activist nonprofit founded and run by Goldman Environmental Prize-winning engineer Alexis Massol González-were almost two decades old when Maria struck, yet they survived and became the only source of power in the community for weeks following the hurricane. The presence of electricity transformed 
Casa Pueblo into a pop-up hospital, and Adjuntas's leaders, inspired, began installing solar panels on other homes and businesses [124,286]. With the help of Casa Pueblo, Michigan-based electric-vehicle manufacturer Rivian and the Honnold Foundation-the Utah-based nonprofit founded by professional rock climber Alex Honnold, subject of the Academy Award-winning documentary Free Solo, and dedicated to supporting small-scale solar projects around the world as a means of tackling inequality [287] - about 600 solar panels have been installed so far in Adjuntas, population 18,500. Complete with battery backup from repurposed 135-kilowatt batteries pulled from Rivian prototype vehicles, a community-solar microgrid is emerging in Adjuntas. By working with Casa Pueblo and the community of Adjuntas, Rivian and the Honnold Foundation avoided the perils of parachuting and now are successfully supporting what likely will become the first solar-powered town in Puerto Rico [288,289]. For Massol González, going solar is about achieving autogestión-and what he thinks of as an "energy insurrection" [164]—not just for Casa Pueblo, but for Puerto Rico.

"Inside a colony, energy independence is revolutionary", Massol González said [164].

The early success in Adjuntas and the promise of disaster-response solar energy has led others to initiate solar projects at a variety of scales in Puerto Rico after Maria. For example, Florida-based nonprofit Mutual Aid Disaster Relief, which originally was founded to help New Orleans in the wake of Katrina, and Minneapolis-based Footprint Project partnered together with a Puerto Rican grassroots group called Proyecto de Apoyo Mutuo, or Project for Mutual Aid, founded in response to Maria, to install a few PV systems in eastern Puerto Rico. In the Mariana neighborhood of Humacao, they installed a 16-kilowatt PV system to power a community center housing an art-therapy space, a kitchen, a laundry room and a library [290,291]. In Caguas, they installed a four-kilowatt PV system to power the community center's refrigerators [291,292]. By working in partnership with the local community, Mutual Aid Disaster Relief and the Footprint Project helped to ensure their projects' success.

Researchers at the University of Michigan used \$200,000 to design and to implement four hybrid PV biomass-gasification microgrids-a unique approach to addressing both increased renewable-energy penetration and the development of microgrids [286,293,294]. The project is focusing on communal participation in its microgrid development. Part of the work arose as a product of the same March 2018 event that birthed our project-RISE, the Resiliency through Innovation in Sustainable Energy xxxix workshop at the University of Puerto Rico at Mayagüez-which brought together representatives from more than 25 academic institutions and 30 local organizations to implement an interdisciplinary approach to setting long-term goals for increased resiliency [295]. Based on a design from my colleagues at Arizona State University, researchers from the University of Puerto Rico at Mayagüez 
and the University of Minnesota used the workshop to cooperate on what the former call "Oasis de Luz"-meaning "Oasis of Light"-and the latter call "Solar Oasis" $\mathrm{xl}$ : a shippable emergency-response aluminum crate that can provide solar-powered cell-phone charging and possibly energy for a small refrigerator as well. With support from the Institute of Electrical and Electronics Engineers Foundation, the U.S. Department of Energy-sponsored Consortium for Integrating Energy Systems in Engineering and Science Education, and the University of Puerto Rico at Mayagüez and its National Institute for Energy and Sustainability, four Oasis de Luz installations were installed in four rural towns in the Puerto Rican interior: Aibonito, Caguas, Jayuya and Orocovis [281,295-298].

In 2005, ecologically minded architects established the Brooklyn-based nonprofit Coastal Marine Resource Center to conduct beach cleanups and environmental education on the estuary in and around New York City. After Superstorm Sandy in October 2012, however, the Coastal Marine Resource Center refocused on disaster recovery and building resilience to future storms by providing distributed (also known as decentralized) solar power in the Rockaways neighborhoods of the city's Queens borough. After Maria, the Coastal Marine Resource Center expanded its solar work to Puerto Rico as well as to the Caribbean islands of Dominica and the U.S. Virgin Islands as part of a project it calls "iSolar Libre!" [299-301] - meaning "free solar," i.e., solar energy without hindrances. After Maria it also helped to launch a San Juan-based project called Resilient Power Puerto Rico, which has become a powerhouse of solar-energy microgrid projects in Puerto Rico, with at least 29 and another 28 in development, and with the 57 installations spread across at least 28 different municipalities spanning Puerto Rico, from Mayagüez, which has four, to Puerto Rico's easternmost island of Culebra. Resilient Power Puerto Rico has a goal of 200 solar installations in the next few years. Support for the projects is wide reaching, including from the New York-based Rockefeller Foundation, the Colorado-based Rocky Mountain Institute, individual donations from the Puerto Rican diaspora, and Fundación Banco Popular, the foundation supported by the San Juan-based financial giant Banco Popular [302-308]. By working in partnership with communities on projects both in Puerto Rico and on the U.S. mainland, a nonprofit project launched by architects in New York has been able to avoid the dangers of parachuting and instead develop PV projects that are likely to succeed.

Also in New York, Monxo López-who was born in Puerto Rico but left when he was 23-used Reddit's "Solar/DIY" thread ${ }^{\text {xli }}$ to teach himself how to make his own PV system. For a cost of $\$ 2800$ and eight months of his time, López designed, built and shipped the system to La Casa de Los Contrafuertes, an arts center in San Juan-and he hopes to build and ship many more [309]. López's work demonstrates solar energy's potential for energy democratization: With just some education and social awareness, he was able to develop a guerilla-urbanism PV project. 
To López, however, developing PV in Puerto Rico is also about yanking off the chain of energy colonialism [309].

"Given the state of the energy grid in P.R. and our over-dependence on fossil fuels", he said, "how do we think about all this renewable stuff in ways that lead towards genuine energy independence?” [309]

Many have connected health centers-particularly their need to operate during and after a disaster-to solar energy. Migrant Health Center-a Mayagüez-based nonprofit that provides medical care to migrant agricultural workers-installed PV to power its buildings in the western highlands towns of Las Marías and Maricao with financial support from Direct Relief [310], the Santa Barbara, California-based nonprofit founded in 1948 by Jewish refugee William Zimdin. In the central Puerto Rican town of Mameyes, with support from the University of Puerto Rico and nonprofits such as the Fundación Comunitaria de Puerto Rico-the Community Foundation of Puerto Rico-a slew of buildings, including the school and health clinic, are now running on solar power. Mameyes and the Comunidad Toro Negro neighborhood of Ciales are two of at least 50 small communities that are transitioning to solar energy with the Fundación Comunitaria de Puerto Rico's assistance [311,312]. Time and again, solar is seen by researchers and Puerto Ricans as a means of acting both on disaster response and toward resiliency against future Marias, while Puerto Ricans also have seen solar as key to energy independence and energy sovereignty—particularly as a way of exerting autogestión and becoming less reliant on PREPA's mismanagement.

"Many people [did not] trust in the PREPA system before the hurricane," said Juan Javier Rivera Morales, special-projects leader for the Fundación Comunitaria de Puerto Rico, which plans to help an additional 200 communities to go solar in the next few years. "People start to think about trying to find a solution, a long-term solution. And the sun is one of them" [311].

In particular, the Fundación Comunitaria de Puerto Rico has partnered with Puerto Rico Primary Care Association Network to power at least two dozen community health clinics with solar power as a hurricane-resiliency measure [312]. Others are supporting some of the organizational infrastructure needed to implement so many post-Maria solar projects. For example, the Washington-based Solar Foundation opened a San Juan office and joined with the University of Puerto Rico at Mayagüez and the San Juan office of the Rochester, N.Y.-based nonprofit PathStone Corporation to launch a program to help Puerto Rican firms address PV financing and train Puerto Ricans to work in the industry. The work is supported by the New York State Energy Research and Development Authority, the City University of New York, the State University of New York, Oxfam America, the Houston-based solar installer Sunnova Energy International, and the Coastal Marine Resource Center [313,314]. 
The Solar Foundation also has played a key role in installations across the island by partnering with foundations and solar companies from the continental United States along with local solar companies in Puerto Rico. For lack of a coordinating body for all of the solar work being done, the Solar Foundation, the New York-based Clinton Foundation and Direct Relief teamed with a host of funders, including the American Red Cross, Fundación Comunitaria de Puerto Rico, the Hispanic Federation, the Rockefeller Foundation, the New York-based Leona M. and Harry B. Helmsley Charitable Trust, and Walmart, along with Puerto Rican solar firms to coordinate, document, fund, install and/or support more than 400 solar projects across Puerto Rico, producing more than 12.6 megawatts of power and saving more than 15,000 tons of greenhouse-gas emissions and nearly $\$ 5$ million in annual utility payments [313,315].

Other PV projects in Puerto Rico have not fared as well, however-with the most high-profile failure coming from Tesla, further illustrating what can go wrong with conventional parachuting. In early November 2017, the now-\$600-billion company initiated an unsolicited plan to install 11 microgrid PV systems on Vieques [316,317], the Puerto Rican "forgotten island" [317] and "toxic paradise" [318] most famous for mass protests against a U.S. Navy bombing range that was in use for 60 years and left behind munitions remnants, including Agent Orange and depleted uranium, which may explain the island's high cancer rates and "some of the highest sickness rates in the Caribbean" [319].

In contrast to Tesla's electric-vehicle competitor Rivian's work in Adjuntas, Tesla did not engage its host community in development of its intervention. Tesla did achieve some PV-sourced electrification on Vieques, but much of its effort has resulted in creating a "solar graveyard” [317]: Many of its PV sites remain nonfunctioning, with some solar panels destroyed by rocks and horses and other solar panels installed but not connected. The sites use diesel generators instead. The result was yet another entity from the U.S. mainland treating Vieques like an industrial wasteland. Although one could argue that Tesla engaged in the project to test its own microgrid PV capabilities and/or to generate positive press, of which there was much, even if one assumes that Tesla simply wanted to help the people of Vieques, and even though Tesla indeed encountered regulatory challenges, the company's parachuting into Vieques without significant community support and involvement ultimately led to the project's failure [317]. Solar graveyards like the ones in Vieques are developing across the Global South, where well-meaning projects install PV but do not involve the host community, leaving the solar panels without plans for maintenance or even a communal sense of ownership over the gifted panels-and resulting in abandoned nonfunctioning PV [320,321]. They serve as a reminder that "[e]nergy systems can be complex beasts, and energy policy does not always generate its intended results" [156]. Solar panels installed through 
conventional parachuting while ignoring the holistic context of a community also can lead to other unintended effects, including:

- Poorly sized installations that do not generate enough energy to meet consumer expectations and demand [322];

- Poorly sited installations, such as indoors [323,324];

- Systems being jury rigged, such as the removal of charge controllers that protect batteries from overuse [322];

- Misperception of solar energy as "fake" [325];

- Jealousy-inspired vandalism and destruction when installations benefit individuals instead of the community at large [323,326];

- Misuse, such as being utilized as a clothes-drying rack or a coffee table, or the PV system being treated like a dog and taken for daily walks so it “wouldn't get tired" [323,324];

- Other misunderstandings, such as covering panels with leaves to help them become "part of nature" [323,324];

- Imposition of outside values onto the community, such as an international nonprofit's investment in solar-powered refrigeration to enable greater milk production and sales in a country without a culinary culture of fresh-milk consumption [201] (although local tastes and demand can change [327], albeit sometimes subsequently ${ }^{\text {xlii); }}$; and

- Disappointment, as solar alone can be used as a false proxy for other functions-such as autonomy and local job creation-that may not materialize without significant community engagement [201].

In the aftermath of Maria in Puerto Rico, moving away from grid-tied energy and toward resilient microgrids and off-grid renewable-energy generation [284], like in Adjuntas, has garnered increased attention. Yet the island's overall renewable-energy production declined after the storm. Prior to Maria, only about 3 percent of electricity in Puerto Rico was generated by renewables [328]. Because of storm damage to utility-scale wind-power and PV installations [277], which before Maria had constituted about three quarters of Puerto Rico's solar-energy output [279]—including a destroyed 100-megawatt system near Humacao [278,279] — as well as because of damage to the distributed PV systems that generated the remaining quarter of PV output [279], Puerto Rico's renewable-energy production fell to about 2 percent of electric generation in 2019xliii [3]. Additionally, storm damage alone was not the only culprit responsible for offline PV. Many of the PV systems that survived the storm were grid-tied systems that require power from the grid to operate properly and subsequently were left nonfunctioning [279] — a problem that would not have occurred had they been installed with their own microgrids [329].

Much more investment in PV is needed if Puerto Rico is going to decrease its reliance on the centralized burning of imported fossil fuels and increase reliance on decentralized and locally produced solar power [330]. Hurricane-resilient PV is needed to prevent Puerto Rico's 
post-Maria solar projects from being carried away by the wind. Planning for hurricane, cyclone and typhoon survivability is one of the greatest challenges facing both on-site and utility-scale PV designers.

\section{METHODS}

This paper presents two separate but interconnected methodologies—one for CAP and one for designing and implementing SolAu.

\section{Collaboratory-Action Parachuting (CAP)}

The name "collaboratory-action parachuting" reflects three of the schools of thought from which CAP draws. Wulf envisioned that his model of a collaboratory-in which people could collaborate on projects across geographic space-would be adapted in new and unanticipated ways [39]. I sought to find how his model of the wall-less collaboratory could be used "to create a transformative space where personal and organizational transformation may occur while addressing a societal issue of common concern in an entirely new way" [331] xliv to begin to solve the problems of Maria. CAP is also in the tradition of action research in that it is action oriented, with the intent to improve upon a tangible aspect of the world, because CAP is not about the theoretical but about action. Yet CAP, while representing a departure from conventional parachuting, still embraces its pragmatism. An unconventional hybrid method that values the ideals of methods such as CBPR while being more accessible and thereby more actionable, CAP is imperfect but pragmatic, and as the Italian proverb, misattributed to Voltaire [332], is commonly paraphrased, the perfect is the enemy of the good.

Our first step toward initiating a post-Maria collaboratory was selecting a community. In order to identify local partners in Puerto Rico for our work, initial members of our group attended the 2018 RISE workshop-the same workshop that led to the Oasis de Luz project. Workshop organizers suggested that we work with community leaders in the Salud neighborhood of Mayagüez [333] (meaning "Site of Clean Waters" in Taíno), a city with a population of about 72,000 [334,335] on Puerto Rico's western coast and the eponym of the S.S. Mayaguez, whose 1975 capture by the Khmer Rouge precipitated the last major battle of the Vietnam War. Founded in 1760 by brothers from Spain's Canary Islands off Morocco's western coast and originally named Nuestra Señora de la Candelaria (meaning "Our Lady of the Candlemas xlv ," the green-candle-bearing patron saint of the Canaries archipelago), Mayagüez ${ }^{\text {xlvi }}$, like most Puerto Rican municipalities, had dismal economic statistics ${ }^{\text {xlvii }}$ even before the negative economic impact of the novel coronavirus, SARS-CoV-2: 
- Mayagüez's pre-pandemic median household annual income was about $\$ 14,000$, compared to a pre-pandemic Puerto Rican average of about $\$ 20,000$ and a pre-pandemic U.S. average of about $\$ 58,000$;

- Mayagüez had a pre-pandemic employment rate xlviii of about 30 percent (about 70 percent of the working-age population not working), compared to a pre-pandemic Puerto Rican average of about 44 percent (about 56 percent of the working-age population not working) and a pre-pandemic U.S. average of about 60 percent (about 40 percent of the working-age population not working);

- Mayagüez had a pre-pandemic poverty rate of about 50 percent, compared to a pre-pandemic Puerto Rican average of about 43 percent and a pre-pandemic U.S. average of about 12 percent; and

- Poverty in Mayagüez disproportionately affects children: Pre-pandemic, about 67 percent of children in Mayagüez lived in households below the poverty line, compared to a pre-pandemic U.S. average of about 20 percent [103,334-336].

Mayagüez - seen as a ripe location for developing innovative solar technologies because it hosts a large campus of the University of Puerto Rico [98]—consists of 21 barrios, or neighborhoods, including Mayagüez Pueblo, the downtown area, which is subdivided into six sub-neighborhoods (or sub-barrios), including Salud xlix. Meaning "health" in Spanish, Salud is one of 19 communities in Mayagüez and one of 858 communities $^{1}$ in Puerto Rico that were selected by the territorial government's Office of the General Coordinator for Social Financing and Autogestión for inclusion in the Comunidades Especiales de Puerto Rico ("Special Communities of Puerto Rico") program for disadvantaged neighborhoods and sub-neighborhoods that nonetheless have shown capacity for autogestión, as noted in survey responses from 76,306 community members [337,338]. Salud's leaders essentially were preselected as ripe for autogestión. Additionally, of the more than 400 post-Maria solar projects underway in Puerto Rico, none had been planned for Salud [315].

At the outset of our project, I did not intend to develop a new methodology. An initial group member intended for us to conduct a community-wide survey in Mayagüez to assess individual needs and to follow it up with CBPR-like community engagement for development of the project. The survey plan was approved by the project's initial funder and group of advisers. However, before even developing survey questions, let alone attempted execution, it became clear that such a tack would require more people, resources and engaged leadership than we possessed. Instead, I inadvertently led the development of what I call collaboratory-action parachuting, or CAP, as a pragmatic if imperfect response-an ad hoc pivot in process that in reflection may be useful for others who value CBPR-like engagement but lack the resources to conduct it. The pivot began with an embrace of the oldest form of recording 
history that predates written history—oral history [339], the methodology akin to conversations and journalistic interview practice.

Even after the advent of written language, early historians-such as Herodotus and Thucydides in ancient Greece, West African bards known as griots (also known as jali or kevel), Zhou-dynasty scribes in China, and Bernardino de Saha, a Franciscan missionary to New Spain-utilized oral history to better understand and transmit the experiences of others [339]. In the 1800s, oral history became the subject of academic scorn, falling "into disfavor in the scientific community" [339], despite its practice by the likes of Hubert Howe Bancroft ${ }^{\mathrm{li}}$, the historian and founder of his namesake library at the University of California, Berkeley; Wisconsin-based biographer and educator Lyman Draper; a handful of biographers-including John Hay, William Herndon, Josiah Holland and John Nicolay-who, after the assassination of U.S. Pres. Abraham Lincoln, interviewed those who knew him; and oral historians employed by the Depression-era Federal Writers' Project ${ }^{\text {lii }}$ [339-341]. After the practice of oral history was revived in the 1940s by journalist-turned-historian Allan Nevins and his colleagues at Columbia University, many of today's mainstream oral historians have followed Nevins's lead and developed common practices [339,342]—arguably prioritizing structure and stricture over substance and outcome-while others strive to practice a more traditional form of oral history, a "radical" oral history rooted in conversation and utilizing oral history to collect and to transmit stories in order to address communal problems [342]. Inspired by the work of oral historians who base their work around conversation [343,344] and the oral historians who have pushed back against the Nevins-based model in order to use oral history for social change liii [340,342,345-350], I incorporated oral history as the backbone of the new community-engagement model that I was developing with our project group for our work in Puerto Rico. By conducting oral history, we were able to mitigate (although not necessarily to eliminate) eco-paternalism, knowledge extractivism, misguided allyship and what otherwise might have become a fully realized "colonized history," whose primary characteristic is in representing "the view of outsiders and not the people themselves" [351].

We chose a grasstops approach of working with leaders, as opposed to a grassroots approach of working directly with community members en masse, in order to best utilize our limited capacity and the strong communal leadership already in place. If we could support community leaders, then they would be better able to support the rest of the community-essentially enabling a few individuals to serve as a leverage point [352] for communal gain. Supporting social capital-communal social relationships and networks [353] —has proven to be an effective means of assisting communities in disaster resilience and recovery [354-360]. 
Through the RISE workshop, we also found a liaison to introduce us to community leaders [333]. Our next step was to form a multidisciplinary group, which included two engineers and two academics from the humanities and social sciences, and a multidisciplinary advisory group of an architect, an engineer and a social scientist. More research needs to be done on the effectiveness of multidisciplinary and interdisciplinary teams compared to unidisciplinary teams, but there are indications that multidisciplinary and interdisciplinary teams report higher levels of success [361,362], although such work also has a lower chance of receiving funding than unidisciplinary work [363]. We began with multidisciplinarity-in which "members carry out their analyses separately, as seen from the perspective of their individual disciplines, the final result being a series of reports pasted together, without any integrating synthesis" [364] - then moved quickly to an interdisciplinary approach-or coordinated cooperation [364]. Thus, our approach built toward transdisciplinarity- "the result of a coordination between all hierarchical levels" [364] or a collaborative approach that transcends the boundaries between disciplines as well as between academic and non-academic [365-367], including "a focus on problem-solving rather than theorizing” [367]. We chose to approach the project in this way because the majority of sustainable-development research remains conceptual [368] rather than operational, while both the field of sustainability as well as the human experience itself are inherently consilient and transdisciplinary [369-372]. It also was clear that we would need to depart from conventional structures and to draw upon a variety of skillsets in order to succeed in what would be an ambitious project. Additionally, oral history lends itself well to multidisciplinary and transdisciplinary scholarship [373] (as well as to collaborative scholarship [346,348]).

With our group in place, we held several conference calls with some of Salud's community leaders with whom we were planning to work. We developed a proposal and applied for and were fortunate to receive grants, which have been credited in detail at the end of this paper. Funding permitted our on-site work to begin in Mayagüez with a week-long trip to meet with Salud leaders and other members of the community in December 2018, followed by two more week-long trips in May and July 2019. The timing allowed us to avoid the peak of the Caribbean's hurricane season, typically from August to November, while permitting PV installation before reaching the peak of the following hurricane season. The work was frontloaded on the first two trips: The first trip was mostly for relationship building by gaining an understanding of biographies, allowing for the solar-energy component of the project to take shape during the second trip. The last visit culminated simply in observation of the PV system's installation. For our first two trips, rather than stay in hotels, we stayed in residential neighborhoods far away from tourist areas at rented homes (in one case 
a storm-damaged vacation home and in the other a local family's furnished basement), allowing us to shop for our food at local markets and to gain a better sense of day-to-day living in Puerto Rico.

We did not conduct any formal or conventional interviews in Puerto Rico. With the exception of our visit to the local Rotary Club, where we hobnobbed with local civic leaders and addressed those assembled about our project, and our visit to a local elementary school, where we taught students about solar power using a SolarSPELL liv (Solar Powered Educational Learning Library), a PV-powered computer developed by colleagues at Arizona State University, we also eschewed structured informal gatherings, such as the facilitated discussions of collaborative rationality [250] and the circle work suggested by those who promote forming collaboratories [331,374], although both of those techniques may be quite helpful in large groups. Instead, we borrowed tools from history, journalism, community organizing and CBPR to engage in a series of informal and unstructured oral-history, small-group conversations with Salud's leaders and other community stakeholders along Puerto Rico's western coast, including in Añasco, Corcovada and Hacienda Veremos. Besides our visits to the Rotary Club and the school, our conversations ranged in size from three people to no more than a dozen. The small groups ensured intimacy, which in turn helped in relationship building. Given that two-thirds of our project members who traveled to Mayagüez speak Spanish (albeit imperfectly) and the majority of the people with whom we conversed only spoke Spanish, we mostly spoke in Spanish and I translated the gist of our conversations into English for our project member who traveled to Mayagüez but does not speak Spanish.

We used chain-referral (or snowball) sampling, allowing one conversation to lead to the next. Because we were not concerned with developing a hypothesis, collecting data, analyzing data or in using what we learned to contribute to or to develop generalizable knowledge, the problems associated with chain-referral sampling [375] did not apply to our work; instead, the point of the conversations was to learn biographies and to build relationships. The conversations served just as much as a way for us to learn about the community as a way for the community to learn about us. To an outside observer, our conversations may have appeared simply to be people sitting and talking. We sat around tables at the Centro Comunal del Barrio La Salud (the community center of Salud); we walked around the neighborhood; we visited several sites with PV systems in the mountains east of Mayagüez; we explored areas badly affected by Maria; we ate meals together in restaurants and in people's homes; and we talked about any and all subjects as friends do. Although we did far more listening than talking (following the advice that listening carefully enables questions to arise organically through conversation [376]), we got to know each other as people-unique people in our own historical contexts-through conversations, shared experiences and relationship building. In so doing, we built relationships 
and mutual trust between our group and the community-a mutual trust that would be critical for the success of the project. We each needed to know that the other was committed to the project and to the partnership that we were building. We also learned that we shared the same goals and values as the community and that our skills matched their needs for the project. Had there been a mismatch of goals, values and/or skills-and this marks a significant departure from collaborative rationality-we would not have proceeded with the project. Whereas collaborative rationality is about process, with a goal of community involvement, CAP is about action, making a shared goal with the community a necessity because the method's purpose goes well beyond participation.

Our unconventional hybrid mix of CBPR and parachuting is what I call CAP, or collaboratory-action parachuting. Through three weeks of in-person conversation, we informally discussed the experience of living through Maria and how our partnership could be used to address the problems of Maria. These conversations shaped our work together. But what would happen after the project's inevitable conclusion? As discussed earlier, lack of follow up is one of the biggest shortfalls of conventional parachuting. Our final steps in conducting CAP-as described in more detail later in this paper-were to increase the community's involvement in the project over time so as to assist in the community taking ownership of the project, thereby supporting autogestión, and to plan for how problems would be solved after the completion of the project.

In summation, although we did not plan a systemic approach to our ad hoc method, in retrospect CAP consists of the following 16 steps:

1. Identify a potential community with which to work;

2. Select at least one person to serve as a liaison between your group and the community (local nonprofits and universities may be useful resources for finding liaisons);

3. Build a multidisciplinary team with shared goals, shared values and diverse skill sets and do not proceed without everyone on the team having shared goals and values because without that shared understanding the team can and probably will fail and/or dissolve;

4. Ensure that the team includes members who speak the language of the community;

5. Ask community leaders if they need support and are interested in partnership;

6. Learn about the community's holistic context;

7. Conduct pre-visit phone calls with community leaders;

8. Build from multidisciplinarity to interdisciplinarity to transdisciplinarity;

9. Parachute into the community—I suggest several weeks over a year's time span. Ideally every team member is present for every community visit in order for the team to develop a shared understanding of the 
community and to maximize the ability to build relationships with the community;

10.Utilize lodging in the community and travel around the community's geographic area;

11.Build relationships with community leaders through conversations, shared meals and shared experiences;

12. Learn what the community wants and compare that to your team's goals and skills-if there are shared goals that can be met with your team's skills, then continue, and if there is a mismatch, then either find another community, expand your team to add necessary skills, connect the community with another team, or abandon the project;

13.Partner with the community on as many aspects of the project as possible and ensure that the community invests in the project with fiscal and/or sweat equity;

14. Return to the community and continue to learn and build relationships;

15. Over time, shift greater amounts of responsibility for the project to the community, allowing for the community to take ownership of the project by its conclusion; and

16. Buy assets to be locally owned and managed and establish a mechanism for addressing problems that may arise after conclusion of the project (as we did by contracting a local business to handle maintenance, as discussed in this paper's case-study outcomes section).

Importantly, we had to be willing to walk away at step 12. The chances of having to do so can be mitigated by choosing a community wisely at step one, but I think that it is important to recognize that no matter how much advance study you do, you may not truly understand the community's needs until you develop a relationship with it. I also recognize that such a relationship may make it all the more difficult to walk away; however, there may yet be other unforeseen ways to express allyship and solidarity. One other risk in assistance being contingent on shared goals is that a community's goals may not actually align but leaders may be indifferent about the goals and say that they align in order to gain assistance.

Lastly, while CAP was not developed to conduct research in the technical sense-rather our work constitutes a form of applied scholarship [377] in that it uses transdisciplinary knowledge to address a community's problems-it is offered here in acknowledgement that our process and methods may be useful for those conducting applied scholarship, formal research or other types of work.

\section{Solar de Autogestión (SolAu)}

Our first step in designing our hurricane-resilient (and cyclone- and typhoon-resilient) PV system-which I have named Solar de Autogestión 
because it promotes self-reliance through solar energy-was to estimate the desired energy load for the community center. In our oral-history conversations, the leadership of Salud told us that they wanted to use the community center's solar power for daily activities as well as for an energy refuge available day and night for those without power during blackouts. To that end, they wanted at a minimum to be able to power the building's normal electrical load: overhead fluorescent lights; multiple cell-phone chargers; a refrigerator to keep temperature-sensitive medicine such as insulin cold; and two air conditioners (because the average high temperature for Mayagüez during hurricane season is in the 90s Fahrenheit [30s Celsius]). That the PV load and the normal load basically would be the same meant that we would not need to install a second set of wiring or configure a system for emergency use but instead could utilize the building's preexisting electrical system without major modification beyond configuration of the microgrid. We also determined that a four-kilowatt system with batteries to enable nighttime usage would produce enough energy for the demand. Such a PV system would need to survive future Marias, leading us to the idea of a PV racking system that would permit the safe removal, storage and return of its solar panels by unskilled community members without the assistance of professional PV electricians after the initial installation. Moreover, as a result of CAP, we learned that we had a willing and capable partner in the community leadership of Salud.

Beginning a month or so after our first visit to Mayagüez, we convened phone meetings with Salud leaders about twice a month. Their input was crucial in the system's design because they were knowledgeable about the installation site, were aware of local safety concerns, and most importantly, their collaboration enabled our partnership and for the community to take ownership of the project. Together, we determined the PV project's core design requirements:

- Meeting the desired energy demand (as outlined above) day and night;

- Operable and maintainable by those without a technical background; and

- Survivability for future hurricanes.

Because off-the-shelf solar panels typically weigh about 40 pounds (18 kg) per module [378], using them could make it difficult for community members to safely remove and store the panels without professional assistance. Instead, we focused on minimizing the system's weight, most of which is from the conventional glass substrate used in the modules. The solution was simple: Thin-film flexible solar panels do not require glass. The idea of flexible solar panels is not new-indeed, in the 1950s NASA developed flexible solar panels for use in space, and by the 1970s thin-film flexible panels became commonly available on small consumer electronics such as calculators-but thin-film flexible solar 
panels have yet to reach widespread usage for residential and commercial PV installations.

Until its effective closure in late 2019 [379], MiaSolé, a subsidiary of Beijing-based Hanergy, was trying to bring flexible PV to the masses by making thin-film PV using a compound of copper, indium, gallium and selenium-or CIGS-a different sunlight-absorbing material than conventional silicon. (Despite receiving millions of dollars in coronavirus-response Paycheck Protection Program forgivable loans from the U.S. government, MiaSolé remains "in a shutdown situation" and, according to media reports, used the funding for employees' back pay [380].) Nonetheless, CIGS holds great promise [381], setting efficiency records almost on par with those of silicon-based modules [382], but requires only a fraction of the thickness of the light-absorbing layer. For example, while most silicon-based modules use 200-micrometer-thick silicon wafers, CIGS modules use between one and two micrometers of sunlight-absorbing material [383,384]. Because CIGS panels are thinner, they also can be made into flexible and lightweight configurations. We chose to use MiaSolé's Flex-03W, a 500-watt module weighing only 12.3 pounds (5.6 kilograms) [385]. Despite its lack of a protective glass substrate, this module is durable and damage resilient. For example, MiaSolé found that its modules continued to function for years after sustaining damage, with multiple punctures in the panel leading to only a 5 percent to 12 percent drop in performance [386].

After multiple iterations and prototype testing of preliminary designs-each abandoned because of their complexity-Salud's leaders, in a feat of citizen science [387], helmed development of our final design, which achieved low weight and relatively easy maintenance through its simplicity. To the untrained eye, the design looks like a conventional PV system, but there are three significant differences:

- The panels are flexible, made of CIGS and installed without glass;

- The racking is composed of lightweight aluminum; and

- The design allows for the panels' safe and relatively easy removal and replacement.

The design is simple and affordable enough that community leaders themselves can build and repair the racking if/when necessary. The lightweight flexible solar panels slide into the racking and are clamped into the frame, making removal as simple as turning off the power switches on the control panel, disconnecting the panel from its wiring and unclamping the panel from its frame ${ }^{\mathrm{lv}}$, all of which can be done by a single person, thereby enabling the PV panels to be removed and stored easily without need for an electrician or other PV-trained individual. The racking design also allows the panels' tilt angle to be changed. Once removed, the panel can be rolled by hand into a cylinder almost as easily as one can roll up a laminated poster and brought down from the roof and stored out of harm's way. Additionally, thanks to a new law that 
exempts solar installations of 25 kilowatts or smaller from some bureaucratic burdens, we also would not be required to obtain a utility permit for the installation $[163,388]$.

We originally planned to develop wordless illustrated instructions so that future generations of communal leaders could learn how to remove, store and reinstall the solar panels safely. However, the group member tasked with developing the instructions disengaged from the project, and after relationship building with the community, we thought (mistakenly, I would learn later) that such instructions would be unnecessary because, by our second visit, Salud's leaders already were discussing involving younger community members and teaching them how to manage the panels.

\section{CASE-STUDY OUTCOMES}

Corresponding to the two separate but interconnected methodologies, this paper presents two outcomes-one for CAP and one for designing and implementing SolAu.

\section{Collaboratory-Action Parachuting (CAP)}

It may be impossible to find someone in Puerto Rico untouched by Hurricane Maria. Most of those with whom we spoke told us that they were living without power for extended periods of time, up to several months. Coping mechanisms for life without grid power included use of candles and diesel generators and reliance on neighbors with either generators or solar panels. Site visits provided additional context. In Corcovada, a resident with grant-writing experience was successful in securing post-Maria funding from the U.S. Federal Emergency Management Agency to install PV at the local community center. Without her proactive application, the government might not have supported PV for her community. At another PV installation in Corcovada, solar panels that survived Maria lined a hill, reducing the space for air to flow beneath them and thereby minimizing the chances of strong winds carrying them away. Solar panels at a hilltop coffee farm in rural Mayagüez, about nine miles $(14 \mathrm{~km})$ inland from downtown, fared differently. Five panels blew off the bean-roasting building during Maria. The farmers found most of the panels undamaged in the valley, but having not yet hired an electrician with PV experience to reinstall them, the panels remain unused. If the PV system had been warrantied, then it likely would have been repaired, or if the farmers had a racking system that enabled the safe removal, stowage, and replacement of panels, then their PV would be operative today. Instead, the farm is relying on a diesel generator for powering its bean-roasting building.

Conversations with stakeholders in and around Mayagüez played an invaluable role in our work. Most importantly, community leaders told us explicitly that they wanted to decolonize their energy through solar power, both to build resilience for future disasters and to build toward 
independence from energy imperialism. Indeed, a recurring theme was the desire for autogestión, to take control of electricity production as a partial means of asserting independence from the mainland, freeing themselves at least partially from dependence on both PREPA and the U.S government following the inadequate response to returning power in post-Maria Puerto Rico. The community's sentiment toward solar-reflective of the specific community at a particular historical moment in the wake of Maria and not generalizable to other populations-echoes what I found in the review, that going solar by itself has become a way of claiming self-determination in Puerto Rico. Practically speaking, addressing mistrust in PREPA and the government and supporting energy independence and energy sovereignty would mean installing solar power.

To avoid being disaster capitalists-those who seek to profit from reengineering disaster-shocked societies [124,389]—we never developed a business model, nor did we receive any financial support from the community of Salud. The only thing for which we asked in return for our services was non-fiscal partnership in the work-through which we were able to develop SolAu and CAP (see Table 1 for a comparison), charting an unconventional hybrid approach to community engagement that resulted in community self-determination.

Table 1. A comparison of community-engagement methodologies.

\begin{tabular}{|c|c|c|c|c|}
\hline & Conventional Parachuting & $\begin{array}{c}\text { Collaboratory Action } \\
\text { Parachuting (CAP) }\end{array}$ & $\begin{array}{c}\text { Collaborative } \\
\text { Rationality } \\
\end{array}$ & $\begin{array}{c}\text { Community-Based } \\
\text { Participatory Research }\end{array}$ \\
\hline Purpose & $\begin{array}{l}\text { Research, scholarship \& } \\
\text { interventions }\end{array}$ & $\begin{array}{l}\text { Research, scholarship \& } \\
\text { interventions }\end{array}$ & Governance & $\begin{array}{c}\text { Research, scholarship \& } \\
\text { interventions }\end{array}$ \\
\hline Disciplinarity & $\begin{array}{l}\text { Unidisciplinary, } \\
\text { crossdisciplinary, } \\
\text { multidisciplinary, } \\
\text { pluridisciplinary or } \\
\text { interdisciplinary }\end{array}$ & Transdisciplinary & Transdisciplinary & Transdisciplinary \\
\hline Speed & Fast & Slow & Slow & Slow \\
\hline Relative Time Investment & Low & Medium & High & High \\
\hline Relative Fiscal Cost & Low & Medium & Medium & High \\
\hline $\begin{array}{l}\text { Communal } \\
\text { Self-Determination }\end{array}$ & No & Yes & Yes & Yes \\
\hline Relative Effectiveness & Low & High & High & High \\
\hline
\end{tabular}

Through my explication of CAP, I developed the following 16 principles for its practice:

- Think collaboration rather than intervention;

- Work to embody transdisciplinarity;

- Embrace relationship building; 
- Value individuals' and communities' unique histories, cultures and contexts;

- Be willing to listen and to have preconceived notions challenged;

- The community should choose if it wants assistance (as opposed to having assistance thrust upon it);

- The goal of the work should be the betterment of the community;

- The community defines what constitutes its betterment;

- The community should be engaged as a partner in the work and ideally in every aspect of the work to the extent feasible, depending upon available skills and resources;

- Support local businesses when possible;

- Set expectations, both with the community as well as within the project group;

- Be flexible because unexpected challenges may surface and work may not proceed as expected;

- The work should not proceed if it compromises the values of participants or if there is a mismatch in expectations and/or commitment;

- Follow through on commitments-most importantly on those to the community but also to fellow members of the project group-and do so within mutually agreed-upon timeframes;

- By the conclusion of the project, the community should take ownership of the object of the collaboration-in essence, support autogestión; and

- Assume best intentions until proven otherwise.

It is important to recognize that miscommunications and misunderstandings between the group and the community and/or within the group itself may arise over the course of the project. Assuming best intentions means not rushing to a negative judgment and instead intentionally choosing to empathize with the other person, assuming that the person meant well even-or especially if-one's first reaction is offense. In essence, assuming best intentions can help to avoid negative, gut-reaction, unnecessary escalations into unproductive conflict. Assuming best intentions has its downsides-most significantly, it can exacerbate preexisting problems in relationships with power differentials between participants [390]—but it reflects positive psychology's concept of mindfulness, to "become sensitive to context and perspective" [391] and to choose to see experiences positively, thereby gaining positivity's advantages [391]. Importantly, though, it may be more difficult for people to assume best intentions if it is not done in concert with relationship building.

As a pragmatic but imperfect solution to address the problems of Maria, CAP shares both advantages and disadvantages with conventional parachuting and CBPR. This paper finds that the drawbacks include: 
- Although not as time intensive as CBPR, CAP still requires substantially more time investment than conventional parachuting;

- The longevity of CAP may make it, like CBPR, susceptible to the third-quarter phenomenon lvi [392]—in which "those undertaking deployments in challenging scenarios are likely to experience a reduction in mood, irritability, tension and decreased morale after the midpoint and into the third phase of a mission" [393].

- Because it is recommended against proceeding if the group and the community do not share the same goals, and because it can take time to get to know a community and its goals, practicing CAP may mean abandoning a project after significant time, money and other resources have been invested in it;

- Except when practiced with a community near the project group, CAP also involves travel expenses that arguably would be better spent on something tangible or simply given as cash disbursements to the community [394];

- Because CAP requires communal grasstops participation, it is not suitable for use in communities without any leadership or without leadership that wants to collaborate;

- Because the community rather than the group selects communal leadership, in patriarchies and other chauvinist societies-such as Puerto Rico and, sadly, much of the world [395] - those leaders may be disproportionately men, unless the subject of the work or the mission of the community organization is focused on womxn; in Salud we found that men held most of the top leadership positions, and we balanced their perspective by speaking with womxn in the community as well-although a more significant embrace of feminist ideology may offer practitioners more useful tools, particularly on energy issues [396,397]; and

- The grasstops approach focusing on leadership means that, unlike with collaborative rationality, a diverse set of viewpoints may not be represented.

There also are some potential downsides specifically related to CAP's emphasis on transdisciplinarity:

- It may be easy to lapse into pluridisciplinarity-“cooperation between disciplines, without coordination" [364]—or even, as seems to have been the case for some members of our group, to fall back into multidisciplinarity [398] and never achieve interdisciplinarity, let alone transdisciplinarity ${ }^{\text {lvii. }}$

- It may not be well suited for conventional unidisciplinary funding models [363,399];

- It can be difficult to determine upon which disciplines a project should draw to best benefit the project;

- For those who cannot escape the "neoliberal economic imperative of self-optimization of individuals as economic actors” [400], transdisciplinary output may not be valued by unidisciplinary 
academic departments for hiring and promotion purposes [377,401,402], may not fit neatly into the typically unidisciplinary boxes of academic journals, and may encounter further resistance because different academic fields have different expectations of what constitutes authorship and scholarship;

- Interdisciplinarity and transdisciplinarity increase the chances for disagreements and misunderstandings among project members because different disciplines have different standards, best practices, vocabulary and ethea;

- Lack of knowledge and experience correlates with relative difficulty working across disciplines and with communities [399]; and

- Interdisciplinarity and transdisciplinarity may feel uncomfortable for those accustomed to unidisciplinary approaches, although this paper would argue that it could be productive discomfort-an opportunity for personal and professional growth.

The biggest drawback, however, may be one that CAP shares with CBPR [236] and conventional parachuting-that by working within societal structures, CAP embodies the power imbalances of those structures. No matter how much we endeavored for partnership with the community, there remained an unspoken differential in power between us. After all, as academics-and therefore as perceived experts or at least as perceived members of the ruling intellectual class-we may have greater social power than our community partners. Because we acquired funding before we began working with the community, we were the ones bringing the financial resources to the table, and anytime that there is economic inequality there is power disparity. Community members had a different type of power over us-without their participation, we would have had no project-but we had better alternatives than they had. If they had chosen not to work with us, then we could have sought another community with which to work. But if we had chosen not to work with them, to whom would they have turned? It is a power imbalance inherent in transdisciplinary work, where typically "the funding body, researchers, and practitioners wield instrumental, structural, and discursive power over (i) the actors, their roles, and respective positioning; (ii) the setting of the research agenda and the definition of issues; and (iii) the setting of rules governing their interactions" [403].

To partially address this uneven power dynamic, this paper suggests building a partnership with a community first and then seeking funding together. Because many sources of funding will not permit joint applications from academics and a community, there clearly is a need for more funding agencies to support such partnerships.

\section{Solar de Autogestión (SolAu)}

Salud's community center is a single-story building with four rooms: an entrance vestibule that doubles as an office; a bathroom; a storage 
closet; and a large open-space community room that incorporates a small kitchen. Most of the roof is pitched. After a site assessment, we determined that for both safety and sunlight exposure the best location for the PV system would be on the flat concrete rectangular segment of the building's roof, measuring about 21 feet wide and about 22 feet long and only accessible by a ladder.

We hired Sun Power Energy in Aguada, about 14 miles (23 kilometers) north of Mayagüez, to install SolAu and a microgrid, which was completed in July 2019. We chose Sun Power Energy specifically because we wanted to support local labor and work with a small business, which we correctly posited would be more willing to participate in the installation of a novel racking system of the customer's design using an unconventional solar panel. During the final design stages, employees from Sun Power Energy met regularly with Salud leaders-who put the finishing touches on the design-in order to ensure successful installation. Sun Power Energy custom built the racking system using our design, featuring eight aluminum frames installed at a 10-degree angle (in order to both maximize system efficiency and to reduce the buildup of sediment on the panels) by being screwed with a drill into the concrete roof. The panels were slipped into the frames from their top sides and secured with a screwdriver by tightening clamps around the frame. Two SimpliPhi 3.5-kilowatt lithium batteries, a MidNite Solar combiner, a MidNite Solar MNE250SW E-Panel, two Schneider Electric Conext 60-amp charge controllers, a Schneider Electric Conext SW4048 power inverter, a Schneider Electric Conext control panel and a Schneider Electric Conext ComBox remote-monitoring system were installed by Sun Power Energy workers on the roof and in the storage closet, protecting the balance of systems from potential rain or wind damage. The monitoring equipment offers the opportunity for Salud's community leaders and membership to study the system's output and usage.

To avoid a solar-graveyard outcome and to provide the community of Salud with a professional party obliged to handle short-term maintenance issues, we chose to hire a professional installer because products used as part of professional installations (typically) include short-term maintenance warranties. For our installation, the batteries' warranty is 10 years; the inverters' warranty is two years; and the warranty for all other components that we bought from Sun Power Energy is five years. But the warranty for the installation itself was only valid for six months [404], an error on our part, because we should have arranged for maintenance for years, not months. We also did not plan properly for how the community would replace the batteries. While the lifespan of solar panels is 25 to 30 years, batteries typically only last five to 15 years, and although the warranty should cover a battery breakdown in the first 10 years, we neglected to develop a plan for how the community would replace the batteries should they fail or become ineffective after 10 years. 
We bought everything from the installer except for 10 flexible PV panels, which we bought directly from MiaSolé for about $\$ 9000$. We used one of the panels for initial prototype testing in Arizona; we used eight of them for the installation in Salud; and we provided an extra panel in Salud for use as a spare. The cost of the shading report (which confirmed that we had chosen the optimal location and tilt angle for the panels), the installation and its other components-including the batteries, the charge controllers, the inverter, the combiner, the E-Panel, the monitoring system and the system control panel-and taxes was about $\$ 14,000$, bringing the total cost for materials and installation of the four-kilowatt $\mathrm{PV}$ system to about $\$ 23,000$. The cost is about double what it would have been for about the same size installation with conventional silicon panels and racking from another local solar firm ${ }^{\text {lviii }}$ [405], but a conventional installation could be blown away by the next Maria.

The closest solar technology to SolAu (see Table 2 for a comparison) may be the all-in-one PV systems deployed after Maria by BoxPower, the California-based manufacturer of 20-foot-long (six-meter-long) shipping containers that double as disaster-response solar-powered microgrids and produce up to 24 kilowatts of energy. Using shipping boxes that are only six feet long, BoxPower installed miniature versions of its solar-powered microgrids at a handful of sites in Puerto Rico. The length basically triples once the panels are unpacked and attached to the top of the "MiniBox," which comes in three different 3.5-kilowatt models with varying battery sizes. Since the BoxPower system is designed for disaster response, it can be stowed in its shipping container in advance of a coming storm-although it may take hours to do so, and the panels are heavy because they include glass-whereas our system allows for relatively easy removal of solar panels in minutes. Depending upon the model, the retail price for the MiniBox ranges from about $\$ 23,000$ to about $\$ 50,000$-not including installation, which must be done by a professional [406-410]—and makes SolAu seem like a bargain by comparison.

Table 2. A comparison of PV systems.

\begin{tabular}{lcccc}
\hline & $\begin{array}{c}\text { Large-Scale } \\
\text { Conventional PV }\end{array}$ & $\begin{array}{c}\text { Small-Scale } \\
\text { Conventional PV Autogestión (SolAu) }\end{array}$ & MiniBox \\
\hline Generation Type & Centralized & Distributed & Distributed & Distributed \\
$\begin{array}{l}\text { Microgrid Compatible } \\
\text { Disaster Response }\end{array}$ & No & Sometimes & Yes & Yes \\
$\begin{array}{l}\text { Hurricane, Cyclone \& Typhoon } \\
\text { Resilient }\end{array}$ & No & Yes & Yes & Yes \\
$\begin{array}{l}\text { Easily Removed, Stowed \& } \\
\text { Restored }\end{array}$ & No & No & Yes & Yes \\
Fiscal Cost per kilowatt-hour & No & Yes & No \\
(kWh) & Low & Medium & High & Very High \\
\hline
\end{tabular}


The four-kilowatt SolAu system that we developed for the Salud community center is expected to produce an average of 6131 kilowatt-hours of electricity annually [411], lowering the community center's carbon emissions by an estimated 4.3 metric tons annually-or the equivalent of 10,756 miles (17,310 kilometers) driven by the average car [412]. The system also should save the community an estimated \$1837 annually in electricity costs [411] (based on May 2020 prices for commercial customers rather than the higher rates via debt/transition charges scheduled to have taken effect in summer 2020 [157,158], after which point the system may save even more money), and also not including savings from a reduced "demand charge" that PREPA charges commercial customers such as the community center. The demand charge-basically "an extra fee based on the period of highest usage" [156] that varies from month to month-can negate the savings from PV installations or even can result in electricity costs rising after going solar, particularly for those whose solar was installed via a power-purchase agreement, as well as for community centers and other nonprofits whose highest usage typically occurs at night [156], when solar panels are no longer generating power. Power-purchase agreements can lock in high rates; the consumer price of electricity may fall but the price of solar via a power-purchase agreement will remain fixed. However, because we gifted the PV system to the community center, no power-purchase agreement was involved, and the batteries that we installed decrease the amount that the center pulls from the grid at night, thereby lessening the demand charge. The downside of batteries is that storing the excess electricity generated from the panels means that the community center will be feeding little or no power back into the grid and therefore will not be getting compensated by PREPA for net-excess generation via net metering. Although considered effective at encouraging more than 100 megawatts of solar installations since its establishment in 2008 [68], net metering in Puerto Rico compensates relatively poorly: Customers only receive one-for-one credit for electricity they consume, so that a kilowatt-hour of electricity given to the grid is compensated by a credit for one kilowatt-hour of electricity from the grid up to a fairly high limit, beyond which PREPA pays an effective 7.5 cents per kilowatt-hourlix. With a one-for-one limit of 10 megawatt-hours for commercial customers [413], the community center likely would never receive any funds for net metering, and any such funds would not offset the higher demand charge that would apply because of a higher peak consumption without batteries. Additionally, net metering is only guaranteed in Puerto Rico for the next four years [388], and given how aggressively PREPA is adding fees for customers with solar, net metering is not necessarily viable beyond 2024 .

Distributed solar energy on customers' rooftops endangers PREPA's business model of centrally producing electricity from imported fossil fuels. Correspondingly, small-scale installations like the one at Salud's community center are often seen by utilities as a threat [156]—even 
though business models based on fossil fuels are, like the fossil fuels themselves, unsustainable. PREPA — even with a mandate from Puerto Rico's government to source its power totally from renewables by the year 2050 [163] — still seeks to punish customers who have installed solar panels. At the end of September 2019, PREPA began charging customers with solar a penalty of four cents per kilowatt-hour for electricity produced by the customers' own solar panels ${ }^{\mathrm{lx}}$-all of the power produced, regardless of whether it is used, stored or sold-but preexisting PV installations like the one we installed at Salud's community center in July 2019 are grandfathered in and exempt from the surcharge for 20 years [157,158]. Ideally, the community center's PV will cover nearly all of the building's energy demand, minimizing the negative impact of PREPA's solar surcharge when it hits the center's electric bill in 2039. Because we paid for the supplies and installation, provided the community with a panel to be used as a replacement if need be, and secured a local company to service the system, the community center has no financial obligations for the system until maintenance is required after the product warranties have expired, at which point, the community leaders assured us, they will be able to pay to maintain the system, thanks in part to the financial savings that the PV system nets the community.

Although we paid for the PV system, the installation and all the supplies, community leadership contributed sweat equity to the project. In advance of the final installation, community members invested their time and knowledge into developing, testing and installing a prototype of our PV system. They learned directly from the professional installers how to manage the panels and system so that they will be able to do so independently going forward. They also formed a relationship with the installation company that will provide ongoing support for the warranty periods. By the time of the July 2019 installation, our role had shifted to that of observers because we had allowed the community to take ownership of the project. Before the next Maria, and in just a few minutes, community members will be able both safely and relatively easily remove the solar panels from their racking and restore them after the storm passes so that the center can serve the community during the emergency.

In the time since the installation, community leaders diligently removed the panels from the roof in advance of major wind events and returned them after the storm passed. However, unbeknownst to me, they did not remove the panels before minor wind events, such as when a hurricane simply passed near Puerto Rico, bringing moderately strong but not hurricane-force winds. When Tropical Storm Isaias, before it reached hurricane strength, moved south of Puerto Rico in July 2020, its winds blew the community center's solar panels out of their racking. Fortunately, the panels were undamaged and were reinstalled. I also learned that removing and returning the panels would have been easier 
for the community if there had been graphic instructions. It is unclear if community leadership would have taken the risk of leaving the panels on the roof during minor wind events if they had invested fiscally in the project, but, lesson learned, community leadership is working to modify the PV racking to withstand minor wind events so the panels only need to be removed for major wind events-autogestión at work.

\section{DISCUSSION}

Policymakers, practitioners and academics should take notice: Clearly the conventional way that so much assistance is implemented today is not as effective as it could be, leading to wasted resources. While CAP may cost more in both time and money than conventional parachuting, CAP offers the promise of being more effective with its resources. Those at nonprofits and universities may not have much choice because their sources of funding may limit their options, but governments are in the position to change that situation by requiring grant applications to demonstrate a collaborative component for proposed interventions and by designating funds specifically for fully collaborative projects. Mandatinglxi,lxii collaboration with communities likely would increase the effectiveness of interventions and would help to support autogestión among aid recipients. Such collaborations also would serve as a good model for the corporate sector to adopt in its charitable work. Moving toward more collaborative models now also will lay groundwork for more effective assistance after a disaster. Essentially, thinking about the people first instead of the projects first can lead to more effective projects [414].

Additionally, governments could help reduce the cost of the flexible solar panels that are an integral component of the SolAu system. Eliminating tariffs that target PV would make solar energy more competitive in the marketplace, and subsidies specifically supporting flexible PV could lower prices while simultaneously encouraging private industry to produce such panels en masse, likely leading to the benefit of even lower prices through economies of scale-as has been witnessed with conventional PV [415,416], where prices fell more than 90 percent in 10 years $^{\text {lxiii }}[417,418]$. Without government assistance, corporate interest in manufacturing flexible panels may wane, particularly as other subsidies for renewable energy expire and utilities such as PREPA pursue harsh punishments against solar adopters, leading to higher prices and lower consumer demand for PV. In an American context, subsidies also may help reduce what has become a cultural bias against renewables by many who see climate change as a political issue. Governmental promotion of $\mathrm{PV}$ through public-information campaigns may help reduce cultural and social barriers to solar energy in a politically charged and divided country [419].

It is important to acknowledge that solar energy may not in itself be a panacea for the climate crisis-indeed, the production of panels 
consumes natural resources, and viable recycling methods for retired panels have not yet been developed-but on the whole, solar energy is far more sustainable than fossil fuels. Solar panels require far fewer resources than fossil-fuel power plants, do not require inputs other than sunlight, and over their 25-plus-year lifetimes, solar panels are responsible for only a small fraction of greenhouse-gas emissions when compared to fossil fuels such as coal, oil or natural gas [420]. Solar panels also lack the many negative effects associated with burning fossil fuels. For example, toxic emissions-such as nitrogen dioxide and sulfur dioxide- "generated by fossil fuels and biomass far outweigh" [420] those from solar and other renewable technologies, and among all energy processes, fossil fuels have been found to be responsible for the highest mortality risks [420], meaning that the implementation of solar energy and other renewable energies saves lives. Indeed, more than 50,000 lives could be saved annually in the United States alone if the country were to replace coal with solar energy, and taking into account the economic impact and fiscal cost of lost lives, "it is profitable to save lives" [421] by replacing fossil fuels with solar energy [421]. Although "solar modules contain some potentially dangerous materials which do not decay with time" [420], incorporating the circular economy into the lifecycle of PV by recycling their modules' precious and rare metals into new solar panels, although currently underutilized, offers great promise for the future of addressing waste in the PV lifecycle [422].

It also is worth noting that even though we developed the project together with the community, in keeping with one of community organizer Saul Alinsky's rules-to "[n]ever go outside the experience of your people" [423] —we would not have worked with the leaders of Salud if our goals and experience had not aligned with their goals. For example, if they told us that what they wanted was a diesel generator, we would not have worked with them-not just because "[h]aving empathy with someone whose values you abhor is difficult" [424], but because neither our goals nor our experience would have aligned with their goals. The corollary danger is that pursuing a positive relationship may make it difficult to notice if a difference in values emerges [424] because we may be predisposed to hearing what we want to hear. Still, developing shared goals is key [423], without which the project can fail. Taking the time to generate shared goals-and shared norms-is not only important for the relationship between group and community but also for the internal dynamics among members of the group. Our group developed shared goals and norms with the community, but we failed to do so within our group unit, and that mistake nearly doomed the project because our group never evolved into a team ${ }^{\text {lxiv }}$. This insight, of course, is not a new one. "A self-protective bias in counterfactual thinking" [425] minimizes assumption of personal responsibility for mistakes [425], eroding trust, and once trust is gone it can be exceedingly difficult to resolve conflict because problems escalate rather than deescalate. There is no shortage of 
literature on the importance of and potential paths (and obstacles) to group cohesion and teambuilding [426-431], but that our group is not the first to encounter this issue [432] is of little consolation. This paper notes that in emphasizing the relationship between the group and the community, it can be easy to neglect the relationships among members of the group. Adoption of a simple group agreement [433] may have lessened the chances for misunderstandings about responsibilities and may have laid out procedures to follow in the unforeseen but too-often inevitable event of things going awry. For example, two project-group members configured the remote-monitoring equipment but did not share the remote-access information with either the other project-group members or with the community itself-and only in October 2020, well more than a year after the initial installation, did the community finally receive access to its own remote-monitoring equipment. Nonetheless, that our group successfully developed both a novel community-interaction method and a novel PV system shows that a project can succeed even with a dysfunctional group, intermittently unengaged leadership and a lack of prioritization of the project; such a path simply makes success both less likely and, for those of us who manage it, more challenging and stressful. Essentially, our project succeeded while our group dynamic failed. Increased university support for transdisciplinary work-both in terms of assistance in managing the challenges of transdisciplinarity as well as in terms of incentivization of transdisciplinary work in academic funding and rewards systems-could help others to navigate transdisciplinary work better and to encourage more such projects [377].

Again, CAP is far from perfect, and some if not all of the concerns that this paper has with it are addressed by CBPR, which we neither had the time nor the resources to do or at least to do well. But one's choice need not be binary - either full community engagement or virtually none. This paper offers CAP as a pragmatic middle ground for those who wish to avoid many of the problems of parachuting but who do not have or cannot dedicate the capacity to properly conduct CBPR. Importantly, one need not restrict usage of CAP to the Global South; the Global North also hosts a plentitude of underserved communities where researcher and scholar engagement can be improved. For example, if you are in Washington, D.C., and you want to help people in Vicksburg, Miss., "the poorest town in the poorest state in the country" [434], work with a community group in Vicksburg. Or if you are in Washington and you want to help people in its poorest neighborhoods, in Wards 7 and 8 [435], work with community groups based there. The same actually holds true regardless of the relative wealth of the community. From the poorest to the wealthiest, if you want to work for a community, choose instead to work with a community, supporting community engagement to lead to community self-determination. 
Consistency is an important aspect of CAP. All team members should attend all trips to the host community in order to build relationships with the community and in order for all team members to have a shared understanding of the community, particularly as the project develops; once the project is complete it matters less. Not all of our group members attended every trip to Mayagüez, which resulted in uneven relationships with the community among group members-and it also may be indicative of a lack of group-member commitment to the project.

One of the reasons that our project was successful was because we hired a local company to perform the installation of our design. Installation costs accounted for the largest share of our budget, so I understand why others may choose to install PV systems themselves instead. However, in order to ensure that short-term system maintenance is covered, I suggest incorporating the cost of installation into the project's budget prior to applying for funding. Failing that approach, I suggest dedicating time to building a local team of solar-energy experts or near-experts in order to minimize the chances of a low-quality installation and system abandonment after a system failure.

Still, the main challenge to implementing SolAu is that Hanergy-owned MiaSolé-which produces the flexible solar panels upon which SolAu relies-along with a trio of other thin-film manufacturers also owned by Hanergy, effectively has been shut down, at least for now [379,380]. Hopefully Hanergy will restart MiaSolé along with its other thin-film subsidiaries-Alta, Global Solar and Solibro-and other companies will begin mass production of similarly flexible panels. The heaviest and possibly most-fragile component of a solar panel is its conventional glass substrate; because flexible panels do not require glass, they are much easier to handle and much lighter to ship. Any able-bodied adult can carry the weight of a panel, and exceptionally more flexible panels than conventional panels can fit in a shipping container or on a truck. The panels' lightweight design is key to the ability of PV modules to be removed, stored and returned to their rack easily and safely. This strength also may be a weakness, though, because it can aid potential theft.

Solar-panel theft is a growing worldwide phenomenon [436,437], and our system may be particularly vulnerable to it. In response, in Salud we installed the panels so that they cannot be seen from street level. Still, the biggest obstacle to theft may be social pressure-depending upon a community's social norms [438]. When we broached theft as a concern, community leaders in Salud were confident that no matter how desperate people may be, they would not steal from the community center. Siting the PV system within the social context of the community is possible through community engagement. However, given that PV systems that are stolen or vandalized may not be replaced [326], this paper recommends that our lightweight system be installed with locks, 
chained cables, labels identifying ownership, and/or other means to discourage theft.

Weight is not a concern for most commercial-scale and utility-scale installations. Typical PV mounting uses steel, which is heavier than aluminum, because typical silicon PV is heavier and therefore requires more support. Our use of lightweight panels enabled us to use lightweight mounting materials as well. Although to the untrained eye our design looks similar to a conventional racking design, the lightweight materials and the easy removal of panels make our system design much more appropriate for small-scale installations that can survive hurricanes.

Complete with its own microgrid and batteries, the lightweight SolAu system is befitted for shipping to and installation in off-grid remote areas. The same strengths also make it well suited for quick shipping and deployment in the aftermath of natural disasters. Of course, SolAu is designed for non-professionals to be able to remove the panels relatively easily and store them as well, making it ideal for energy resilience in areas where hurricanes and other high-wind events can be predicted. The system's capacity for disaster-response energy, hurricane-resilient (and cyclone- and typhoon-resilient) energy, energy independence and energy sovereignty gives it the capability to revolutionize how development agencies approach energy in the Global South. By design, though, what we learned about the community of Mayagüez is unique and not generalizable to other populations-even if it may mirror other populations. Although this paper is offered in the hope that its methodologies will be helpful for others to replicate elsewhere, CAP is slow work in that it requires engagement with each community even if the results may be the same. I caution that without community engagement, SolAu's potential may go unrealized.

Our work with the community of Salud already is leading to follow-up research by colleagues at Arizona State University, where the Center for Energy \& Society's Grassroots Energy Innovation Laboratory is examining the effects of our project as part of a \$1.2-million grant from the U.S. Department of Energy to study the economic and social effects of resilient PV systems in Puerto Rico, with a focus on four communities, including Salud $[439,440]$.

Other subjects for future research include:

- Incentives for the private sector to engage in CAP or collaborative interventions;

- Understanding the prevalence of the third-quarter phenomenon in long-term projects among non-isolated participants and methods to counteract or to avoid it;

- Tools to abate the inherent power imbalance of transdisciplinary work;

- Methods to reduce the cost of disaster-response, storm-resilient PV such as SolAu; 
- Mechanisms for integrating storm-resilient PV such as SolAu into larger communal microgrids, such as integrated community energy systems [441]; and

- How installation of disaster-response, storm-resilient PV affects communal attitudes to and actions on renewable energy, climate change, environmental policy and sustainability.

\section{CONCLUSIONS}

Philosopher and aphorism-producer extraordinaire George Santayana famously noted that "[t]hose who cannot remember the past are condemned to repeat it" [442] — but maybe remembering the past is insufficient to avoid repeating mistakes. Perhaps instead history repeats itself when we do not integrate its lessons into our thoughts and actions. Then, once we have changed our behavior because of past events, we can find what husband-and-wife historians Will and Ariel Durant call the adventure of the present, where "[t]here is no certainty that the future will repeat the past" [443]. In undertaking this project, I and the other members of the project group endeavored to incorporate the lessons of Puerto Rican history into our work and thereby not to repeat the mistakes of history.

This type of work is far from predetermined; at any point our partnership with the community could have dissolved, effectively ending the project. The fragility of such a project makes the relationship-building component-the mutual trust-building aspect-integral. Just talking about each others' lives and getting to know each other as people might seem superfluous to such a project, but the project likely would have failed if we had not taken the time first to build relationships and mutual trust. Still, although there is utility to relationship building, this paper does not see its purpose merely in practical and transactional terms. Rather, the focus was on relationship building in order to understand each other as people, to share knowledge and cultural understandings and to make friendships. If we do that well, then we also can work together well. Of course, befriending community members is not the only path to success, but having found it both fulfilling as well as successful, it is the path that I suggest.

The anthropocene goes by many alterative names, including the plantationocene, in recognition of the fact that "the slave plantation system was the model and motor for the carbon-greedy machine-based factory system that is often cited as an inflection point" [444] for the anthropocene. In other words, exploitation of people and exploitation of fossil fuels historically have been inextricably tied-resulting in energy imperialism and anthropogenic climate change as unsurprising byproducts that, although they did not cause Hurricane Maria, nonetheless played significant roles in making Maria's impact on Puerto Rico worse than it otherwise would have been. A full-fledged panacea for 
these issues is beyond the scope of this paper, but it has made three interdependent arguments to address the problems exposed by Maria.

Firstly, this paper has argued that the holistic context of a place and its people is important and should be considered in working with any community. History, culture, economics, politics and society affect the potential success of any project and have much to say about how a project should be executed. Failure to understand the context may doom a project to failure. Because every place and people has its own context, projects need to be tailored for their locations-whether that is an underserved community in the Global South or in the Global North.

Additionally, a project to help a community can achieve better results when conducted as a joint project with the community. Although more time may be better, this paper has offered CAP-collaboratory-action parachuting - as a pragmatic model of community engagement for those with limited time and other resources. The purpose of CAP is not to work for a community but to work with a community to achieve shared goals and lasting results. In so doing, community engagement can result in community self-determination. By working in partnership with the community of Salud, we helped to avoid the pitfalls of parachuting; we played to the strength of the autogestion ethos of Puerto Ricans; and we helped to enable the community to take ownership of the project to help ensure its future sustainability.

Lastly, instead of responding to disasters with fossil fuels, governments and others should utilize distributed microgrid PV systems, more of which are necessary to address the climate crisis. While PV—whose health impacts alone save lives [421]—can help communities to become more resilient to natural disasters, solar panels also are vulnerable to the storms themselves. Therefore, this paper argues that the SolAu PV-racking design offers great promise as both a hurricane-resilient (and cyclone- and typhoon-resilient) and disaster-response tool. A lightweight system that allows for a relatively unskilled individual to remove panels, store them and return them to the rack safely after the storm has passed, SolAu permits PV to weather storms and allows for it to be dispatched rapidly where needed.

Each argument for this project is incomplete without the other, and each leads to the next. We likely would not have developed SolAu without first developing CAP, which likely would not have been developed without first considering the three components of sustainability through the holistic context of Puerto Rico. Ideally, anyone wishing to replicate this work also will borrow all three parts, lest they fall into one of the many traps that lead to failure in parachuting research. Even the best invention can go unutilized if the recipients do not want it or do not know how to use it properly. To address the climate crisis, we need more solar power, not more solar graveyards. We also know that it is not a question of if there will be another disaster like Maria but when-and that disaster could be in Puerto Rico or anywhere else in the world. 
Hopefully this paper provides others with new tools to support autogestión by empowering energy citizens to build their own energy communities in an energy democracy, abating the cycle of slow violence and throwing off the yoke of energy imperialism-and in so doing, solving problems like the next Maria.

\section{DATA AVAILABILITY}

Data generated by the PV installation's monitoring system has not yet been collected or analyzed by the author, and therefore there have been no datasets generated for this paper.

\section{CONFLICTS OF INTEREST}

The author declares no conflict of interest.

\section{FUNDING}

The author and the project group are grateful for partial financial support from the Competitive Innovation Fund of IGERT-SUN (Solar Utilization Network), funded by the National Science Foundation (Award \#1144616); partial financial support from the Arizona Board of Regents-funded Technology and Research Initiative Fund of LightWorks at Arizona State University's Global Institute of Sustainability and Innovation; and conference-travel support from RCN-SEES-SHBE (Research Coordination Network of Science, Engineering and Education for Sustainability's Predictive Modeling Network for Sustainable Human-Building Ecosystems), funded by the National Science Foundation (Award \#1664881). The funders had no role in the design of the study; in the collection, analyses, or interpretation of data; in the writing of the manuscript, or in the decision to publish the results. The remainder of the expenses for the project and its explication in this paper was self-funded.

\section{STUDY DESIGN, IMPLEMENTATION AND OTHER ACKNOWLEDGMENTS}

The collective work this paper describes had many contributors. The following delineates contributions to this paper and the project at large, and the author apologizes in advance for any inadvertent omission. Early in the project, DK was tasked by the then-core members of the project group with leading the writing of this paper, to which he invited other members to contribute. This paper was conceptualized, outlined, compiled, edited and revised by DK. All writing and analysis were fully effectuated and completed by DK and Tara Nietzold based on their ideas for novel solutions and their experiences and observations working on the project in Puerto Rico, the unceded ancestral land of the Ortoiroid, Saladoid, Igneri (Arawak), Taíno and Kalinago (Island Carib) peoples. DK wrote this paper's introduction; the holistic context; discussion; conclusion; the energy-democracies and community-engagement sections 
of the reviews; and the collaboratory-action parachuting sections of the methods and the outcomes. DK and Nietzold jointly wrote the solar-energy sections of the reviews, the methods and the outcomes. Despite her significant contributions, Nietzold elected not to be considered a coauthor.

DK and Nietzold progenerated and developed the ideas that the project became after the project was initiated by and an unexecuted methodology was developed by Jessica Otten. DK designed and coined collaboratory-action parachuting, Nietzold improved upon it, and DK and Nietzold practiced it on site with Otten in Mayagüez, Puerto Rico, with DK and Nietzold speaking Spanish and English and Otten speaking English. Nietzold conceived of the idea for the hurricane-resilient solar-PV Solar de Autogestión racking system, which DK coined, and developed it with DK, Otten, Maxx Patterson, José Angel Ramos Caraballo and Orlando Serrano Valle. Joan I. Asencio-Yace served as the Salud community liaison. Utilizing Theo Sanderson's Up-Goer Five website ${ }^{\mathrm{lxv}}$ of the 1000 most commonly used words in the English language, DK wrote a 1000-word version of this article that won the 1000 Word Challenge organized by QESST ERC (Quantum Energy and Sustainable Solar Technologies Engineering Research Center). DK and Nietzold presented the project at Club Rotario de Mayagüez; DK presented and discussed the project on behalf of QESST ERC for students at the Barcelona Elementary School in Glendale, Ariz.; DK presented on the project at conferences; DK and Patterson postered together on the project at a conference; Nietzold and Patterson postered together on the project at a conference; Patterson presented an award-winning "fast pitch" on the project at a conference; Nietzold presented on the project at an Institute of Electrical and Electronics Engineers (IEEE) Special Interest Group on Humanitarian Technology (SIGHT) webinar; and Otten spoke to media outlets about the project. Otten spearheaded most grant writing and grant reports with support from DK, Nietzold and Patterson while serving as the main contact for the project's primary funders. DK managed RCN-SEES-SHBE conference-travel funding acquisition. In the absence of consistently engaged leadership, DK organized project meetings. Patterson worked on early system prototypes. Frankie Alemany led the installation process. Cecilio Ortiz-Garcia and Marla del Pilar Perez-Lugo suggested Salud as a community partner. Laura Hosman provided the SolarSPELL equipment. Harvey Bryan, Stephen Goodnick, Elisa Graffy and Willem Vermaas advised during the project's early stages. Vermaas served as a de facto funder for one of the project's grants and served as a fund administrator for two of the project's grants. Chien-fei Chen administered RCN-SEES-SHBE conference-travel funding. Colin K. S. Barrows, Margaret Burch, Krista Hartrick, Anna Keilty and Yong Tao processed grant disbursements.

Except for Nietzold's decision to not be considered a coauthor, DK and Nietzold jointly made all major decisions on how to proceed with this 
paper. The contributions of Alemany, Asencio-Yace, Barrows, Bryan, Burch, Caraballo, Chen, Hartrick, Hosman, Keilty, Ortiz-Garcia, Goodnick, Graffy, Otten, Patterson, Perez-Lugo, Tao, Valle and Vermaas are appreciated but unfortunately did not meet Journal of Sustainability Research's eligibility threshold for authorship, which is based on ICMJE (International Committee of Medical Journal Editors) criteria.

Additionally, the author and the project group are grateful for in-kind and technological support from SolarSPELL and from QESST ERC (a program of the National Science Foundation and the Office of Energy Efficiency and Renewable Energy of the Department of Energy under National Science Foundation Cooperative Agreement \#EEC-1041895). The author also thanks Asencio-Yace of Resilient Power Puerto Rico and leadership of the Salud community center for their partnership, friendship, openness to the process, and dedication to both their community and environmental sustainability; the people of the Salud neighborhood in Mayagüez for their persistence in the face of adversity; Alemany of Sun Power Energy in Aguada, Puerto Rico, for his willingness to try new ways of engaging a customer and installing solar PV; André Augusto of Arizona State University's Solar Power Lab and Mirele Goldsmith of the Jewish Earth Alliance for their advice; Gary Dirks for his essential support; Chen, Tao and the other participants in RCN-SEES-SHBE's Singapore workshop for sharing their thoughts and encouragement; Paul Hirt and Alon Tal for their inspiration; the editors and anonymous reviewers of Journal of Sustainability Research for their suggestions; and all others who have helped and have encouraged the project's success. Opinions expressed in this paper represent those of the author, those quoted and/or those cited and not necessarily those of other individuals or institutions.

\section{NOTES}

i Irma passed about 60 miles $(97 \mathrm{~km})$ north of Puerto Rico on Sept. 6, 2017. Maria was a category-five storm before it reached Puerto Rico but weakened to a category four before striking the island on Sept. 20 and leaving a few days later.

ii The breakdown as of this writing is about 40 percent petroleum-diesel and heavy-fuel oil, all for production of electricity, not transportation-about 40 percent natural gas, about 18 percent coal and about 2 percent renewables.

iii Although many news outlets reported that power was fully restored to Puerto Rico after 11 months, those accounts proved to be significantly premature.

iv These three terms are differentiated solely by the storm's location: Cyclones form over the South Pacific and Indian Ocean; hurricanes form over the North Atlantic, Northcentral Pacific and Northeast Pacific; and typhoons form over the Northwest Pacific. 
$\mathrm{v}$ When I write in the plural I am referring to my experiences that were shared with other project-group members and when I write in the singular I am referring to my personal experiences and thoughts exclusively. The members of the group, along with all others involved in the project, and their respective contributions, are delineated in detail in this paper's acknowledgements. Unfortunately, their contributions-with the exception of one project member who declined to be considered a coauthor-did not meet Journal of Sustainability Research's eligibility threshold for authorship, which is based on ICMJE criteria.

vi In the case of colonialism, this reverberation is called "coloniality."

vii The Jones-Shafroth Act is different from the Merchant Marine Act of 1920, which is commonly called the Jones Act and restricts maritime cabotage, meaning that only U.S.-built, U.S.-flagged, and U.S.-crewed vessels are permitted to carry goods between the U.S. mainland and Puerto Rico, effectively raising prices in Puerto Rico for mainland-produced goods for the sake of supporting the mainland's ship-manufacturing industry. Such as federal payroll tax but not federal income tax.

ix Puerto Ricans have a modicum of influence over the electoral process because both the Democratic and the Republican parties hold primaries in Puerto Rico, but residents of the island do not have the right to vote in U.S. elections for president and vice president. It is unclear if those born in Puerto Rico are eligible to run for president, as none have done so, but the precedent of John McCain-who ran for president as a Republican in 2008 even though he was born in the then-U.S.-controlled Panama Canal Zone-means that potentially someone born in Puerto Rico could run for president but not be permitted to vote for president.

x As of July 1, 2018, the most recent figure available as of this writing.

xi The estimated disenfranchised population includes U.S. citizens living in Puerto Rico, American Samoa, Guam, Northern Mariana Islands, U.S. Virgin Islands (including Saint Croix, Saint John and Saint Thomas) and the national capital, Washington, D.C. The estimate excludes other U.S. territories, such as Midway Islands, Palmyra Atoll and Wake Island, which are only inhabited by military personnel and scientists, both of which typically are permitted to vote remotely as long as their permanent residence is a U.S. state and not a territory such as Puerto Rico. Other American territories-including Johnston Atoll; Navassa Island (whose ownership is disputed by Haiti); and the Guano Islands of Baker Island, Howland Island, Jarvis Island and Kingman Reef along with two territories whose ownership is claimed by the United States but possessed by Colombia, Bajo Nuevo Bank and Serranilla Bank-are uninhabited. Denizens of former U.S. territories, such as the Marshall Islands, Micronesia and Palau-that have achieved independence but have become de facto protectorates in free association with the United States, which continues to provide wide-ranging social services, from military defense to mail delivery-do not have U.S. voting representation and are not U.S. citizens, although the United States 
grants them the right to live, study and/or work in the United States as indefinite legal residents. (Similarly, residents of former U.S. territories and administered areas-including and far from limited to Cuba, the Dominican Republic, Haiti, Nicaragua, the Philippines and the Ryukyu Islands of Japan-that are fully independent from the United States no longer have any U.S. rights.)

The 2012 referendum included two questions: The first asked if Puerto Rico should maintain its status quo, with 54 percent saying no. The second asked for preference between statehood, free association and independence, with 61 percent selecting statehood.

xiii Free association would establish Puerto Rico as its own country in an ongoing special relationship with the United States, similar to the Marshall Islands, Micronesia and Palau, all of which are sovereign nations in free association with the United States.

xiv As a basis of comparison, in the last 100 years U.S. presidents have been elected with between 43 percent of the vote-such as Richard Nixon and Bill Clinton for their first terms-and 61 percent of the vote-such as Franklin D. Roosevelt for his second term, Lyndon B. Johnson for his only elected term, and Nixon for his second term-with voter turnout ranging from 49 percent to 64 percent; and in the last 30 years only one president won with more than 52 percent of the vote: Barack Obama with 53 percent of the vote for his first election.

xv Which could happen as early as January 2021 if Democrats win both of Georgia's Senate runoff-election races scheduled for Jan. 5.

xvi The United Nations Development Programme (UNDP) does not calculate a separate Human Development Index figure for Puerto Rico, but Ricardo Fuentes-Ramírez of the Pontifical Catholic University of Puerto Rico used UNDP criteria and 2015 data to calculate a Human Development Index figure for Puerto Rico. I have placed Fuentes-Ramírez's figure for the island in the UNDP 2018 rankings to approximate Puerto Rico's standing in the index and to provide context.

xvii The racial makeup is from the U.S. Census's American Community Survey, an annual household survey based on a population sample of about 1 percent of the population. Figures from the complete U.S. Census, held every 10 years, show that between 70 percent and 80 percent of Puerto Ricans regularly self-identify solely as White, which would make Puerto Rico as White as Indiana or Utah, but the numbers are misleading for three reasons. First, the Census designates Latinx as a subcategory of White. Second, Puerto Ricans may be self-identifying as White in an attempt to seek the privileges of Whiteness in an American Herrenvolk democracy that favors Whites (due to gerrymandering, voter suppression and, in the case of territories such as Puerto Rico, outright voter disenfranchisement). Third, White may be chosen as a default because race is a largely unspoken issue for most Puerto Ricans, perhaps due to the lingering effects of José Luis Alberto Muñoz Marín-the journalist who became the first elected governor of Puerto Rico 
and the "Architect of the Puerto Rico Commonwealth"-who preached that both racism and the idea of race itself would need to be discarded in order to enable social progress.

xviii It is unknown who Trump envisioned would buy Puerto Rico, but the notion that the U.S. president sees the island-and its people-as an asset that could be bought or sold shows yet one more way how Puerto Rico and its people are treated differently than other parts of the United States.

xix Perhaps best crystalized by the imagery of Trump tossing paper towels-like they were promotional T-shirts at a sporting event-to Puerto Ricans at a hurricane-relief center inside a San Juan church about two weeks after Maria struck the island.

xx It is worth noting that Trump-who was born into a wealthy family and has spent his life surrounded by those who do everything for him-displays a tendency of projecting his own behavior and preferences onto others.

xxi Although the notion of comparing marginalized people to non-human animals may not be regarded as an effective insult by those who see little differentiation in worth between humans and non-human animals, Trump's derisive intent remains clear regardless of how one views comparisons to non-human animals.

xxii Trump later backtracked, claiming that he only was referring to immigrants who are members of MS-13, the common moniker for Mara Salvatrucha, an international criminal street gang launched in the 1970s by immigrants from El Salvador in Los Angeles. Racist epithets that, after a backlash-initiated denial, could be construed as benign, along with gaslighting, have been hallmarks of the racism for which Trump and his administration have become known.

xxiii Deriding Jews as lowly animals has a long history and was far from limited to the Nazis, as reflected in the Spanish Empire's referral reference to Jews as pigs; in Shylock, the Jewish character in William Shakespeare's "Merchant of Venice,” complaining that his Christian customers call him a dog (Act 1, Scene 3); and in many other examples too numerous to list here.

xxiv It is unclear whether or not Rhoads actually killed eight of his Puerto Rican patients or simply exaggerated, but either way his sentiment reflects hatred for Puerto Ricans. Rhoads eluded punishment, and subsequent anger fueled the Puerto Rican independence movement, eventually leading as far as a failed assassination attempt of U.S. Pres. Harry Truman and a mass shooting that injured five congressmen inside the chamber of the U.S. House of Representatives.

xxv In 1499, before their eventual expulsion between 1609 and 1614 as part of the Inquisition, Spain began forcibly converting to Christianity resident Muslims, mostly descendants of Moors from the Maghreb region of Northern Africa. Many continued to practice Islam secretly and became Crypto-Muslims, or New Christians, although more commonly referred to by the diminutive term Moriscos (meaning Moorish or little Moors) and as the derogatory term Saracens (associated with thievery). In an attempt to avoid 
further persecution, some Crypto-Muslims fled to Spanish colonies such as Puerto Rico, which Christopher Columbus claimed for Spain in 1493-however limpieza de sangre (blood purity) laws mostly restricted movement of New Christians, limiting the number of Crypto-Muslims who were able to escape Spain for the Americas.

xxvi Mostly enslaved people from West Africa.

xxvii Following the Massacre of 1391, in which thousands of Jews were murdered by Spanish Christians and thousands more were forcibly converted and became known as Conversos, many of the latter continued to practice Judaism secretly. These Crypto-Jews are less commonly known as Judaizantes (and included with Crypto-Muslims as New Christians) and more commonly known today by the pejorative term Marranos (and as Xuetes/Chuetas on the Spanish island of Mallorca/Majorca), usually understood to mean swine. Frustrated by the existence of Jews who were forced to convert but who did not fully leave Judaism, Spain's King Ferdinand II and Queen Isabella I initiated the Inquisition in 1478. After the Alhambra Decree in 1492 dictated that Jews convert, leave Spain or be murdered, some Crypto-Jews fled to Spanish colonies such as Puerto Rico, which Christopher Columbus claimed for Spain in 1493. Limpieza de sangre (blood purity) laws mostly restricted movement of New Christians, however, limiting the number of Crypto-Jews who were able to escape Spain for the Americas.

xxviii Including non-Moorish, non-enslaved Afro-Puerto Ricans (also known as Afro-Boricuas or Afro-Borincanos) called libertos who came to Puerto Rico with the conquistadors, and people of African descent who escaped slavery in British and French colonies in the Caribbean for freedom in Puerto Rico.

xxix Consisting of the widely reported $\$ 75$ billion in ordinary debt and about $\$ 55$ billion in unfunded pensions.

xxx Also boding poorly for Puerto Rico's ability to handle a pandemic, such as COVID-19 and multisystem inflammatory syndrome, or MIS-C- the disease and the syndrome caused by the novel coronavirus, SARS-CoV-2.

xxxi Whether or not greater public participation in energy decisions could have averted the climate crisis and the torrent of air pollution is an open question.

xxxii Market systems that limit carbon emissions, allow trading of carbon credits and provide rebates and/or tax credits to energy consumers.

xxxiii An alternative to the terms "woman" and "women," the plurale tantum term "womxn" is not built on the word "man" or "men." Unlike the older alternative of "womyn," womxn is considered by some to be more inclusive of nonbinary and trans women.

xxxiv This type of "aid" is akin to being compensated with scrip valid for merchandise at the company store, common in industries that control workers' labor, housing, and access to supplies.

xxxv Booher and Innes do not specify who exactly should perform the selection, just that it should not be done by government officials, who may be inclined to exclude those with inconvenient opinions. 
xxxvi Or, as Winston Churchill famously paraphrased an anonymous aphorism, "it has been said that democracy is the worst form of government except for all those other forms that have been tried.”

xxxvii Some refer to microgrids that only cover a single building as nanogrids.

xxxviii Some refer to microgrids that are never connected to the main grid as mini-grids.

xxxix In its Nov 2019 iteration hosted at the University of Albany, the RISE abbreviation was redefined as standing for "Resilience In Sustainable rEconstruction.”

$\mathrm{xl}$ They have done so independently of downtown Phoenix's abandoned Solar Oasis project that in the early 1990s was to showcase downdraft evaporative-cooling towers designed by the University of Arizona's Environmental Research Laboratory for the lot north of the Phoenix Symphony Hall, where the Phoenix Convention Center subsequently was built.

xli If you are motivated to make your own PV system, the site is: reddit.com/r/SolarDIY

xlii In this particular example, most milk consumed in the former French colony of Senegal was powdered and imported from Europe; demand for fresh milk and dairy products grew with support from international nonprofits and European dairy companies such as Danone.

xliii The latest figure available as of this writing.

xliv Although Katrin Muff, cited here, does not cite Wulf in her work, indicating that she and her group developed their concept of a collaboratory independently of Wulf's thought influence, their ideas for a collaboratory nonetheless serve as a natural evolution of Wulf's.

xlv Candlemas is a Christian holiday that commemorates baby Jesus being taken to the Temple in Jerusalem.

xlvi Mayagüez also has numerous nicknames, including, alternatively, La Ciudad del Mangó and El Pueblo del Mangó (meaning “The City of the Mango” and "The Town of the Mango"), because of the area's plentiful mango trees, which are grown for agricultural purposes and also line streets. During my visits, I found that the edges of many roads in the region were littered with fruit.

xlvii According to the U.S. Census Bureau's 2017 American Community Survey Five-Year Estimates.

xlviii I am using employment rates as opposed to unemployment rates since the latter excludes those who are not seeking employment, such as students or those who have given up on finding a position.

xlix Salud is frequently called Barrio Salud, although technically it is Sub-barrio Salud.

$1 \quad$ After the territorial autogestión office identified 686 initial neighborhoods and sub-neighborhoods in 2003, it later added another 172 communities to the list. 
Some would add Joseph "Joe” Gould, also known as "Professor Sea Gull," the famously eccentric New York-based writer who claimed to have written "An Oral History of the Contemporary World," and subject of the book "Joe Gould's Secret” by Joseph Mitchell and its film adaptation starring Ian Holm, Stanley Tucci and Susan Sarandon. Because Gould never actually wrote the book, however-and he was at best a professional embellisher and at worst an outright fabricator-I exclude him from my list of significant early-modern oral historians, but include this endnote for those curious about his absence.

lii Although playing an important role in the history of oral history, the Federal Writers' Project-part of the Works Progress Administration, more commonly known as the WPA—sadly included oral historians who displayed bias against African Americans.

Such as members of Groundswell: Oral History for Social Change (oralhistoryforsocialchange.org).

liv Which we gifted to the classroom afterward.

lv Still, even if one disconnects the panel from the battery system, if it is in sunlight and one simultaneously touches both of its wire leads there is a high chance of electrocution, so it is recommended that amateurs either wear protective gloves and/or remove the panels at night.

lvi Originally observed among participants in isolated conditions, such as submarines and Antarctic research bases, the third-quarter phenomenon may play a role in other long, intense projects as well, and I observed it affecting our project group.

lvii Disciplanarity type is not a constant; individuals can operate at different disciplinary levels than their peers can, and their type of engagement can change over time.

lviii A 3.9-kilowatt PV system with 15 silicon-based 260-watt panels, batteries, off-the-shelf racking and installation would cost $\$ 12,850$ from a competing solar firm in Mayagüez.

lix Technically, PREPA pays 10 cents per kilowatt-hour for 75 percent of the kilowatt-hours fed into the grid that exceed the one-for-one credit limit, with the remaining 25 percent collected by PREPA and rededicated to support the energy bills of public schools.

Ix PREPA is the first utility in the United States to institute such a charge.

lxi Exemptions, of course, would need to be made for projects with insufficient budgets and those with an urgency that collaboration cannot accommodate, although long-term collaborations with communities could help to build relationships and social capital that would enable collaborative projects with quick timelines.

Ixii Collaboration already is required for some governmental work-hence the opportunities for public input through government-run forums-but requiring a collaborative component to receive government funding would move universities and other grant recipients into collaborative work with communities as well. 
lxiii For example, the price of European crystalline PV fell from \$3.331 per watt in 2018-equivalent U.S. dollars in January 2010 to $\$ 0.508$ per watt in 2018-equivalent U.S. dollars in May 2017, a drop of about 85 percent in about seven and a half years.

lxiv Unfortunately, merely using the word team does not itself make a group an actual team.

lxv Inspired by an xkcd comic (by cartoonist, engineer and former NASA roboticist Randall Munroe) that presents a simplification of NASA's Saturn V rocket (xkcd.com/1133), the Up-Goer 5 engine allows you to enter any text and to be alerted to words that you used that are not among the thousand most commonly used in English-or, really, among the ten-hundred most commonly used words, because "thousand" is not among them. If you want to try making your own work more accessible, the site is: splasho.com/upgoer5.

\section{REFERENCES}

1. Meyer R. What's Happening With the Relief Effort in Puerto Rico? The Atlantic. 2017 Oct 4.

2. Houser T, Marsters P. The World's Second Largest Blackout. Rhodium Group. 2018. Available from: rhg.com/research/puerto-rico-hurricane-maria-worldssecond-largest-blackout/. Accessed 2019 Jul 10.

3. U.S. Energy Information Administration. Puerto Rico Territory Energy Profile. 2020. Available from: eia.gov/state/print.php?sid=RQ. Accessed 2020 May 8.

4. Smith-Nonini S. The Debt/Energy Nexus behind Puerto Rico's Long Blackout: From Fossil Colonialism to New Energy Poverty. Lat Am Perspect. 2020;47(3):64-86.

5. de Onís CM. Energy Colonialism Powers the Ongoing Unnatural Disaster in Puerto Rico. Front Commun. 2018;3:1-5.

6. The Associated Press. Puerto Rico Power Fully Restored 18 Months After Hurricane Maria Wiped Out the Grid: The Weather Channel. 2019. Available from: $\quad$ weather.com/news/news/2019-03-21-puerto-rico-power-restoredhurricane-maria. Accessed 2019 Jul 10.

7. Popke J, Harrison C. Energy, Resilience, and Responsibility in Post-Hurricane Maria Dominica: Ethical and Historical Perspectives on 'Building Back Better'. J Extreme Events. 2018;5(04):184000.

8. Knutson TR, McBride JL, Chan J, Emanuel K, Holland G, Landsea C, et al. Tropical Cyclones and Climate Change. Nat Geosci. 2010;3(3):157-63.

9. Elsner JB, Kossin JP, Jagger TH. The Increasing Intensity of the Strongest Tropical Cyclones. Nature. 2008;455(7209):92-5.

10. Trenberth KE. Warmer Oceans, Stronger Hurricanes. Sci Am. 2007;297(1):44-51.

11. Elsner JB. Continued Increases in the Intensity of Strong Tropical Cyclones. Bull Am Meteorol Soc. 2020(2020):1-8. 
12. Kossin JP, Knapp KR, Olander TL, Velden CS. Global Increase in Major Tropical Cyclone Exceedance Probability Over the Past Four Decades. Proc Natl Acad Sci U S A. 2020;117(21):1-6.

13. Gore A. An Inconvenient Truth: The Planetary Emergency of Global Warming and What We Can Do About It. New York (NY, US): Rodale; 2006.

14. Ripple WJ, Wolf C, Newsome TM, Galetti M, Alamgir M, Crist E, et al. World Scientists' Warning to Humanity: A Second Notice. BioScience. 2017;67(12):1026-8.

15. Intergovernmental Panel on Climate Change. Global Warming of $1.5^{\circ} \mathrm{C}$ : First Joint Session of Working Groups I, II and III of the IPCC and Accepted by the 48th Session of the IPCC. Geneva (Switzerland): United Nations; 2018.

16. Ripple WJ, Wolf C, Newsome TM, Barnard P, Moomaw WR. World Scientists' Warning of a Climate Emergency. BioScience. 2020;70(1):8-12.

17. Lloréns H, Santiago R, Garcia-Quijano CG, de Onís CM. Hurricane Maria: Puerto Rico's Unnatural Disaster. Social Justice: A Journal of Crime, Conflict \& World $\quad$ Order. 2018. Available from: socialjusticejournal.org/hurricane-maria-puerto-ricos-unnatural-disaster/. Accessed 2020 Nov 1.

18. Taleb NN. The Black Swan: The Impact of the Highly Improbable. New York (NY, US): Random House; 2007.

19. Peñaloza M. 'I Don't Feel Safe': Puerto Rico Preps for Next Storm Without Enough Government Help. National Public Radio. 2019. Morning ed. Available from: npr.org/2019/07/03/737001701/i-don-t-feel-safe-puerto-ricopreps-for-another-maria-without-enough-government. Accessed 2019 Sep 25.

20. Schmidt S, Hernández AR. A Year After Hurricane Maria, a Puerto Rican Town is Still in Upheaval. The Washington Post. 2018 Sep 13.

21. Newkirk II VR. Can Puerto Rico Recover from Maria Before the Next Storm Hits? The Atlantic. 2018.

22. Cloutier G, Papin M, Bizier C. Do-It-Yourself (DIY) Adaptation: Civic Initiatives as Drivers to Address Climate Change at the Urban Scale. Cities. 2018;74:284-91.

23. Iveson K. Cities Within the City: Do-It-Yourself Urbanism and the Right to the City. Int J Urban Region Res. 2013;37(3):941-56.

24. Finn D. DIY Urbanism: implications for Cities. J Urban Int Res Placemaking Urban Sustain. 2014;7(4):381-98.

25. Pagano C. DIY Urbanism: Property and Process in Grassroots City Building. Marquette Law Rev. 2013;97:335-89.

26. Talen E. Do-It-Yourself Urbanism: A History. J Plan History. 2015;14(2):135-48.

27. Hou J, editor. Insurgent Public Space: Guerrilla Urbanism and the Remaking of Contemporary Cities. London (UK): Routledge; 2010.

28. Dovey K. Informal Urbanism and Complex Adaptive Assemblage. Int Dev Plan Rev. 2012;34(4):349-68.

29. Wortham-Galvin BD. An Anthropology of Urbanism: How People Make Places (and What Designers and Planners Might Learn from It). Footprint. 2013;21-40. 
30. Silva P. Tactical Urbanism: Towards an Evolutionary Cities' Approach? Environ Plan B Plan Des. 2016;43(6):1040-51.

31. Lydon M, Garcia A. Tactical Urbanism: Short-Term Action for Long-term Change. Washington (DC, US): Island Press; 2015.

32. Mould O. Tactical Urbanism: The New Vernacular of the Creative City. Geogr Compass. 2014;8(8):529-39.

33. Crabapple M. Puerto Rico's DIY Disa ster Relief. The New York Review of Books. 2017 Nov 17.

34. Bonilla Y. Trump Hasn't Treated Puerto Rico Well. But That's a Long U.S. Tradition. The Washington Post. 2019 Apr 1.

35. Coto D. Puerto Ricans Grab Machetes, Shovels to Help Restore Power. The Associated $\quad$ Press. 2018. Available from: apnews.com/394fe201adf64649a92fe8e9b82000e1/Puerto-Ricans-grab-mache tes,-shovels-to-help-restore-power. Accessed 2020 May 22.

36. Florido A. After Months Without Power, a Puerto Rico Town Strings its Own Lines. All Things Considered. 2018. Available from: npr.org/2018/01/19/579196353/after-four-months-without-power-a-puerto-ric o-town-strings-its-own-lines. Accessed 2020 May 23.

37. Feliciano-Arroyo S. Autogestión: Reconfiguring the Spaces of Cultural Production in Latin America [dissertation]. Philadelphia (PA, US): University of Pennsylvania; 2011.

38. Vieta M. The Stream of Self-Determination and Autogestión: Prefiguring Alternative Economic Realities. Ephemera. 2014;14(4):781.

39. Wulf WA. The Collaboratory Opportunity. Science. 1993;261(5123):854-6.

40. Nightingale AJ, Eriksen S, Taylor M, Forsyth T, Pelling M, Newsham A, et al. Beyond Technical Fixes: Climate Solutions and the Great Derangement. Clim Dev. 2020;12(4):343-52.

41. Orwell G. Politics and the English Language. In: Packer G, editor. All Art is Propaganda: Critical Essays. Boston (MA, US): Mariner Books; 2009. p. 270-86.

42. Sorman AH, Turhan E, Rosas Casals M. Democratizing Energy, Energizing Democracy: Central Dimensions Surfacing in the Debate. Front Energy Res. 2020;8:1-7.

43. Purvis B, Mao Y, Robinson D. Three Pillars of Sustainability: In Search of Conceptual Origins. Sustain Sci. 2019;14:681-95.

44. Kuhlman T, Farrington J. What is Sustainability? Sustainability. 2010;2(11):3436-48.

45. Basiago AD. Economic, Social, and Environmental Sustainability in Development Theory and Urban Planning Practice. Environmentalist. 1999;19(2):145-61.

46. Pope J, Annandale D, Morrison-Saunders A. Conceptualising Sustainability Assessment. Environ Impact Assess Rev. 2004;24(6):595-616.

47. Gibson RB. Beyond the Pillars: Sustainability Assessment as a Framework for Effective Integration of Social, Economic and Ecological Considerations in Significant Decision-Making. J Environ Assess Policy Manag. 2006;8(3):259-80. 
48. Waas T, Hugé J, Verbruggen A, Wright T. Sustainable Development: A Bird's Eye View. Sustainability. 2011;3(10):1637-61.

49. Moldan B, Janoušková S, Hák T. How to Understand and Measure Environmental Sustainability: Indicators and Targets. Ecol Indic. 2012;17:4-13.

50. Schoolman ED, Guest JS, Bush KF, Bell AR. How Interdisciplinary is Sustainability Research? Analyzing the Structure of an Emerging Scientific Field. Sustain Sci. 2012;7(1):67-80.

51. Boyer RHW, Peterson ND, Arora P, Caldwell K. Five Approaches to Social Sustainability and an Integrated Way Forward. Sustainability. 2016;8(9):1-18.

52. Goodland R. The Concept of Environmental Sustainability. Ann Rev Ecol Syst. 1995;26(1):1-24.

53. Lozano R. Envisioning Sustainability Three-Dimensionally. J Clean Prod. 2008;16(17):1838-46.

54. Tanguay GA, Rajaonson J, Lefebvre J-F, Lanoie P. Measuring the Sustainability of Cities: An Analysis of the Use of Local Indicators. Ecol Indic. 2010;10(2):407-18.

55. Heinberg R. What Is Sustainability? In: Heinberg R, Lerch D, editors. The Post Carbon Reader. Healdsburg (CA, US): Watershed Media; 2010. p. 11-9.

56. Du Pisani JA. Sustainable Development-Historical Roots of the Concept. Environ Sci. 2006;3(2):83-96.

57. Zijp MC, Heijungs R, Van der Voet E, Van de Meent D, Huijbregts MAJ, Hollander A, et al. An Identification Key for Selecting Methods for Sustainability Assessments. Sustainability. 2015;7(3):2490-512.

58. Lehtonen M. The Environmental-Social Interface of Sustainable Development: Capabilities, Social Capital, Institutions. Ecol Econ. 2004;49(2):199-214.

59. Moir S, Carter K. Diagrammatic Representations of Sustainability-A Review and Synthesis. In: Smith SD, editor. Proceedings of the 28th Annual ARCOM Conference; 2012 Sep 3-5; Edinburgh, UK. Edinburgh (UK): ARCOM (Association of Researchers in Construction Management); 2012. p. 1479-89.

60. Mori K, Christodoulou A. Review of Sustainability Indices and Indicators: Towards a New City Sustainability Index (CSI). Environ Impact Assess Rev. 2012;32(1):94-106.

61. Stirling A. The Appraisal of Sustainability: Some Problems and Possible Responses. Local Environ. 1999;4(2):111-35.

62. Vos RO. Defining Sustainability: A Conceptual Orientation. J Chem Technol Biotechnol. 2007;82(4):334-9.

63. Arushanyan Y, Ekener E, Moberg Å. Sustainability Assessment Framework for Scenarios-SAFS. Environ Impact Assess Rev. 2017;63:23-34.

64. Brown BJ, Hanson ME, Liverman DM, Merideth RW Jr. Global Sustainability: Toward Definition. Environ Manag. 1987;11(6):713-9.

65. Elkington J. Towards the Sustainable Corporation: Win-Win-Win Business Strategies for Sustainable Development. Calif Manag Rev. 1994;36(2):90-100. 
66. Miller CA, Altamirano-Allende C, Johnson N, Agyemang M. The Social Value of Mid-Scale Energy in Africa: Redefining Value and Redesigning Energy to Reduce Poverty. Energy Res Soc Sci. 2015;5:67-9.

67. Walker A. One Child of One's Own. Ms. 1979 August;50.

68. O'Neill-Carrillo E, Rivera-Quinones MA. Energy Policies in Puerto Rico and their Impact on the Likelihood of a Resilient and Sustainable Electric Power Infrastructure. Centro J. 2018;30(3):147-71.

69. Immerwahr D. How to Hide an Empire: A History of the Greater United States. New York (NY, US): Farrar, Straus and Giroux; 2019.

70. Grandin G. What was the Confederate Flag Doing in Cuba, Vietnam, and Iraq? The Nation. 2015 Jul 7.

71. Simkins FB. The South, Old and New: A History, 1820-1947. New York (NY, US): A.A. Knopf; 1947.

72. McGill R. Look Away, Look Away. Proc Massachusetts Hist Soc. 1966;78:50-62.

73. Cobb JC. Away Down South: A History of Southern Identity. Oxford (UK): Oxford University Press; 2005.

74. Andrade E, Barrett N, Colon-Ramos U, Edberg M, Garcia-Meza A, Goldman A, et al. Ascertainment of the Estimated Excess Mortality from Hurricane María in Puerto Rico. Washington, DC (US): Milken Institute of Public Health at The George Washington University; 2018. p. 1-69.

75. U.S. Census Bureau. Table 1. Annual Estimates of the Resident Population for the United States, Regions, States, and Puerto Rico: April 1, 2010 to July 1, 2018. Suitland (MD, US): U.S. Census Bureau; 2018.

76. Steckelberg A, Esteban C. Over 4 Million Americans Don’t Have Anyone to Vote for Them in Congress. The Washington Post. 2017 Sep 28.

77. Greenblatt A. The US Almost Tore Itself Apart to Get to 50 States. Can DC Make It 51? Vox. 2020. Available from: vox.com/the-highlight/2019/9/18/20863026/dc-statehood-george-floyd-puertorico-statehood. Accessed 2020 Sep 29.

78. Robles F. 23\% of Puerto Ricans Vote in Referendum, 97\% of Them for Statehood. The New York Times. 2017 Jun 12.

79. Fernández A. Puerto Rico’s Push for Statehood, Explained: Puerto Rico is Asking to Become the 51st U.S. State. Trump Just Said No. Vox. 2018. Available from: vox.com/policy-and-politics/2018/1/11/15782544/puerto-ricopushes-for-statehood-explained. Accessed 2019 Apr 3.

80. Kasperowicz P. Congress Expected to Ignore Puerto Rico's Vote for Statehood. The Hill. 2012. Available from: thehill.com/blogs/floor-action/house/ 266799-congress-expected-to-ignore-puerto-ricos-statehood-vote. Accessed 2020 Nov 2.

81. Johnson M, Bernal R. Hopes for DC, Puerto Rico Statehood Rise. The Hill. 2020 Sep 24.

82. Sanchez R, Stracqualursi V. A 122-Year Love-Hate Relationship: Puerto Rico-Once Again-Will Vote on Statehood. CNN. 2020. Available from: cnn.com/2020/10/31/politics/puerto-rico-2020-statehood-vote/index.html. Accessed 2020 Nov 1. 
83. Gutiérrez L. Puerto Rico's Referendum No Substitute for a Self-Determination Process. The Hill. 2020. Available from: thehill.com/opinion/campaign/523996-puerto-ricos-referendum-no-substitut e-for-a-self-determination-process. Accessed 2020 Nov 2.

84. Comisión Estatal de Elecciones. Plebiscito: Resultados Isla. 2020. Available from: $\quad$ elecciones2020.ceepur.org/Noche del Evento 92/index.html\#es/ default/PLEBISCITO Resumen.xml. Accessed 2020 Nov 6.

85. Briggs L. Reproducing Empire: Race, Sex, Science, and U.S. imperialism in Puerto Rico. Berkeley (CA, US): University of California Press; 2002.

86. Cabán PA. Constructing a Colonial People: Puerto Rico and the United States, 1898-1932. Boulder (CO, US): Westview Press; 1999.

87. Malavet PA. America's Colony: The Political and Cultural Conflict Between the United States and Puerto Rico. New York (NY, US): NYU Press; 2004.

88. Malavet PA. Puerto Rico: Cultural Nation, American Colony. Mich J Race Law. 2000;6(1):1-106.

89. Monge JT. Puerto Rico: The Trials of the Oldest Colony in the World. New Haven (CT, US): Yale University Press; 1999.

90. Vélez JA, Schweers CW. A U.S. Colony at a Linguistic Crossroads: The Decision to Make Spanish the Official Language of Puerto Rico. Lang Probl Lang Plann. 1993;17(2):117-39.

91. Atiles-Osoria JM. Environmental Colonialism, Criminalization and Resistance: Puerto Rican Mobilizations for Environmental Justice in the 21st Century. RCCS Ann Rev. 2014;6:3-21.

92. de Onís CM. Fueling and Delinking from Energy Coloniality in Puerto Rico. J Appl Commun Res. 2018;46(5):535-60.

93. Cabán P. Hurricane Maria's Aftermath: Redefining Puerto Rico's Colonial Status. Curr History. 2019;118(805):43-9.

94. Denis N. War Against All Puerto Ricans: Revolution and Terror in America's Colony. New York (NY, US): Bold Type Books; 2015.

95. Rodríguez-Díaz CE. Maria in Puerto Rico: Natural Disaster in a Colonial Archipelago. Am J Pub Health. 2018;108(1):30-2.

96. Bonilla Y. The Coloniality of Disaster: Race, Empire, and the Temporal Logics of Emergency in Puerto Rico, USA. Politic Geogr. 2020;78:102181.

97. Roman E. Empire Forgotten: The United States' Colonization of Puerto Rico. Villanova Law Rev. 1997;42:1119-211.

98. Collado-Schwarz A. Decolonization Models for America’s Last Colony: Puerto Rico. Syracuse (NY, US): Syracuse University Press; 2012.

99. Central Intelligence Agency. Country Comparison: GDP-Per Capita (PPP). The World Factbook. Langley (VA, US): Central Intelligence Agency; 2020.

100. United Nations Development Programme. Human Development Indices and Indicators: 2018 Statistical Update. New York (NY, US): United Nations Development Programme; 2018. p. 1-123.

101. Fuentes-Ramírez RR. An Approximation of Puerto Rico's Human Development Index. Caribbean Stud. 2014;42(1):253-8.

102. Fuentes-Ramírez RR. Human Development Index Trends and Inequality in Puerto Rico 2010-2015. Ceteris Paribus. 2017;7:1-9. 
103. U.S. Census Bureau. QuickFacts: Puerto Rico: U.S. Census Bureau; 2018. Available from: census.gov/quickfacts/PR. Accessed 2019 Jul 11.

104. Dropp K, Nyhan B. Nearly Half of Americans Don’t Know Puerto Ricans are Fellow Citizens. The New York Times. 2017 Sep 26; Sect. The Upshot.

105. Karni A, Mazzei P. As He Derides Puerto Rico's Leaders, Trump Overstates Aid Figures. The New York Times. 2019 Apr 3; Sect. 2 April.

106. Shear MD. Ex-Cabinet Official Details Chaos of the Trump Circle. The New York Times. 2020 Jul 11.

107. Trump DJ (@realDonaldTrump). “So interesting to see "Progressive” Democrat Congresswomen, who originally came from countries whose governments are a complete and total catastrophe, the worst, most corrupt and inept anywhere in the world (if they even have a functioning government at all), now loudly...........and viciously telling the people of the United States, the greatest and most powerful Nation on earth, how our government is to be run. Why don't they go back and help fix the totally broken and crime infested places from which they came. Then come back and show us how........it is done. These places need your help badly, you can’t leave fast enough. I'm sure that Nancy Pelosi would be very happy to quickly work out free travel arrangements!”: Twitter; 2019 [updated 5:27 AM, 2019 Jul 14]. Available from: twitter.com/realDonaldTrump/status/1150381394234941448. Accessed 2019 Sep 25.

108. Allyn B. Congresswomen Denounce Trump Tweets Telling Them To 'Go Back' To Their Home Countries. NPR. 2019. Available from: npr.org/2019/07/14/741630889/congresswomen-denounce-trump-tweets-telli ng-them-to-go-back-to-their-home-countr. Accessed 2019 Sep 25.

109. Trump DJ (@realDonaldTrump). “...Such poor leadership ability by the Mayor of San Juan, and others in Puerto Rico, who are not able to get their workers to help. They....”: Twitter; 2017 [updated 4:26 AM, 2017 Sep 30]. Available from: twitter.com/realDonaldTrump/status/914089003745468417. Accessed 2019 Sep 25.

110. Trump DJ (@realDonaldTrump). “...want everything to be done for them when it should be a community effort. 10,000 Federal workers now on Island doing a fantastic job.”: Twitter; 2017 [updated 4:29 AM, 2017 Sep 30]. Available from: twitter.com/realDonaldTrump/status/914089888596754434. Accessed 2019 Sep 25.

111. Giroux HA. White Nationalism, Armed Culture and State Violence in the Age of Donald Trump. Philos Soc Critic. 2017;43(9):887-910.

112. Heidt SJ. Scapegoater-in-Chief: Racist Undertones of Donald Trump's Rhetorical Repertoire. In: Gutsche Jr. RE, editor. The Trump Presidency, Journalism, and Democracy. New York (NY, US): Routledge; 2018. p. 206-28.

113. Huber LP. Make America Great Again: Donald Trump, Racist Nativism and the Virulent Adherence to White Supremecy Amid US Demographic Change. Charleston L Rev. 2016;10:215-48.

114. Konrad AM. Denial of Racism and the Trump Presidency. Equal Diver Inclus. 2018;37(1):14-30. 
115. Pulido L, Bruno T, Faiver-Serna C, Galentine C. Environmental Deregulation, Spectacular Racism, and White Nationalism in the Trump Era. Ann Am Assoc Geogr. 2019;109(2):520-32.

116. Lind D. Trump on Deported Immigrants: “They're Not People. They're Animals.” Vox. 2019. Available from: vox.com/2018/5/16/17362870/trumpimmigrants-animals-ms-13-illegal. Accessed 2019 Sep 25.

117. Graham DA. Trump Says Democrats Want Immigrants to 'Infest' the U.S. The Atlantic. 2018 Jun 19.

118. Trump DJ (@realDonaldTrump). “Democrats are the problem. They don't care about crime and want illegal immigrants, no matter how bad they may be, to pour into and infest our Country, like MS-13. They can't win on their terrible policies, so they view them as potential voters!”: Twitter; 2018 [updated 6:52 AM, 2018 Jun 19]. Available from: twitter.com/realDonaldTrump/status/1009071403918864385. Accessed 2019 Sep 25.

119. Bytwerk RL. The Argument for Genocide in Nazi Propaganda. Q J Speech. 2005;91(1):37-62.

120. Dawidowicz LS. The War Against the Jews: 1933-1945. New York (NY, US): Bantam Books; 1986.

121. Goebbels J, Fred Taylor (Translator). The Goebbels Diaries: 1939-1941. London (UK): Hamish Hamilton; 1982.

122. Hitler A. Mein Kampf. Munich (Germany): Franz Eher Nachfolger GmbH; 1925.

123. Clark TR. Puerto Rico and the United States, 1917-1933. Pittsburgh (PA, US): University of Pittsburgh Press; 1975.

124. Klein N. The Battle for Paradise: Puerto Rico Takes on the Disaster Capitalists. Chicago (IL, US): Haymarket Books; 2018.

125. Garcia-Lopez GA. The Multiple Layers of Environmental Injustice in Contexts of (Un)natural Disasters: The Case of Puerto Rico Post-Hurricane Maria. Environ Just. 2018;11(3):101-8.

126. Ocasio-Cortez A (@AOC). “Before everyone jumps one me - yes, culture isn’t DNA. But to be Puerto Rican is to be the descendant of: African Moors + slaves, Taino Indians, Spanish colonizers, Jewish refugees, and likely others. We are all of these things and something else all at once - we are Boricua.”: Twitter; 2018 [updated 6:01 AM, 2018 Dec 10]. Available from: twitter.com/aoc/status/1072129158745112576. Accessed 2019 Sep 25.

127. Hackett C, Connor P, Stonawski M, Skirbekk V, Potancoková M, Abel G, et al. The Future of World Religions: Population Growth Projections, 2010-2050. Washington DC (US): Pew Research Center, 2015.

128. Murray A. The Later Middle Ages. In: Harries R, Mayr-Harting H, editors. Christianity: Two Thousand Years. Oxford (UK): Oxford University Press; 2001. p. 107.

129. Martinez G. Why This Disaster Relief Bill is Stuck on a Debate Over Puerto Rico Food Stamps. PBS News Hour. 2019. Available from: pbs.org/newshour/politics/why-this-disaster-relief-bill-is-stuck-on-a-debate-o ver-puerto-rico-food-stamps. Accessed 2019 Apr 3. 
130. Rivera Y, Levin J. Over a Year Later, the U.S. and Puerto Rico Fight Over Every Dollar of Hurricane Aid: The Recovery from Maria is Playing Out in This Remote Hospital. Bloomberg. 2019. Available from: bloomberg.com/news/features/2019-03-08/over-a-year-later-the-u-s-and-puer to-rico-fight-over-every-dollar-of-hurricane-aid. Accessed 2019 Apr 3.

131. Rogers D. Trump White House Stonewalls as Puerto Rico Aid Runs Dry: The President's Theories About How the Storm-Wracked Island is Using Disaster Relief Money Could Have Dire Consequences for its Residents. Politico. 2019. Available from: politico.com/story/2019/01/26/puerto-rico-hurricane-aid1125530. Accessed 2019 Apr 3.

132. Straub AM. "Natural Disasters Don’t Kill People, Governments Kill People”: Hurricane Maria, Puerto Rico-recreancy, and "Risk Society”. Nat Hazards. 2020;104(2):1-19.

133. The Associated Press. Length of Outage After Sandy Not Unusual: San Francisco Chronicle. 2012. Available from: sfgate.com/nation/article/Length-of-outage-after-Sandy-not-unusual-4045567. php. Accessed 2019 Jul 10.

134. Waugh WL Jr. The Political Costs of Failure in the Katrina and Rita Disasters. Ann Am Acad Polit Soc Sci. 2006;604(1):10-25.

135. Bier V. Hurricane Katrina as a Bureaucratic Nightmare. In: Kettl DJ, editor. On Risk and Disaster: Lessons from Hurricane Katrina. Philadelphia (PA, US): University of Pennsylvania Press; 2006. p. 243-54.

136. Brasch WM. Unacceptable: The Federal Government's Response to Hurricane Katrina. Karachi (Pakistan): Spectrum Publishers; 2005.

137. Berube A, Holmes N. Concentrated Poverty in New Orleans 10 Years After Katrina. The Brookings Institution. 2015. Available from: brookings.edu/blog/the-avenue/2015/08/27/concentrated-poverty-in-new-orle ans-10-years-after-katrina/. Accessed 2019 Jul 10.

138. Plyer A, Gardere L. The New Orleans Prosperity Index: Tricentennial Edition. New Orleans (LA, US): The Data Center (Nonprofit Knowledge Works); 2018. p. 1-72.

139. Walton R. 10 Years After: Remembering How Entergy New Orleans Survived Hurricane Katrina. Electric Light \& Power. 2015. Available from: elp.com/articles/powergrid international/print/volume-20/issue-9/features/1 0-years-after-remembering-how-entergy-new-orleans-survived-hurricane-ka trina.html. Accessed 2019 Jul 11.

140. U.S. House of Representatives Committee on Natural Resources. The Status of Puerto Rico Oversight, Management, and Economic Stability Act (PROMESA): Lessons Learned Three Years Later: Oversight Hearing Before the Committee on Natural Resources, U.S. House of Representatives, One Hundred Sixteenth Congress, First Session, Thursday, May 2, 2019. Washington DC (US): U.S. Government Publishing Office; 2019. p. 1-135.

141. Mufson S. Hurricane Maria has Dealt a Heavy Blow to Puerto Rico's Bankrupt Utility and Fragile Electric Grid. The Washington Post. 2017 Sep 20. 
142. Newkirk II VR. A Commonwealth in Crisis: As Puerto Rico Reaches Another Debt Cliff, Political Dysfunction on the Mainland Spells Disaster. The Atlantic. 2016 Apr 27.

143. Meléndez E. The Economics of PROMESA. CENTRO. 2018;30(3):72-103.

144. González J. Puerto Rico's $\$ 123$ Billion Bankruptcy Is the Cost of U.S. Colonialism. The Intercept. 2017. Available from: theintercept.com/2017/05/09/puerto-ricos-123-billion-bankruptcy-is-the-costof-u-s-colonialism/. Accessed 2020 May 1.

145. Abel JR, Deitz R. The Causes and Consequences of Puerto Rico's Declining Population. Curr Iss Econ Finance. 2014;20(4):1-8.

146. U.S. Department of Health \& Human Services Office of the Assistant Secretary for Planning and Evaluation. Evidence Indicates a Range of Challenges for Puerto Rico Health Care System. Washington DC (US): Office of the Assistant Secretary for Planning and Evaluation ;2017. p. 1-26.

147. Allen G. SOS: Puerto Rico Is Losing Doctors, Leaving Patients Stranded: National Public Radio. 2016. Available from: npr.org/sections/health-shots/2016/03/12/469974138/sos-puerto-rico-is-losingdoctors-leaving-patients-stranded. Accessed 2019 Apr 26.

148. Vives R, Hennessy-Fiske M. Puerto Rico’s Debt-Plagued Power Grid was on Life Support Long Before Hurricanes Wiped It Out. Los Angeles Times 2017 Sep 28.

149. Mookerjea S. Renewable Energy Transition Under Multiple Colonialisms: Passive Revolution, Fascism Redux and Utopian Praxes. Cult Stud. 2019;33(3):570-93.

150. Nixon R. Slow Violence and the Environmentalism of the Poor. Cambridge (MA, US): Harvard University Press; 2011.

151. Perera FP. Children are Likely to Suffer Most from Our Fossil Fuel Addiction. Environ Health Perspect. 2008;116(8):987-90.

152. Healy N, Stephens JC, Malin SA. Embodied Energy Injustices: Unveiling and Politicizing the Transboundary Harms of Fossil Fuel Extractivism and Fossil Fuel Supply Chains. Energy Res Soc Sci. 2019;48:219-34.

153. Hill BE. Bad Policy, Disastrous Consequences: Coal-Fired Power in Puerto Rico. Environ Law Report. 2020;50:1-14.

154. Lloréns H. In Puerto Rico, Environmental Injustice and Racism Inflame Protests Over Coal Ash. The Conversation. 2016. Available from: theconversation.com/in-puerto-rico-environmental-injustice-and-racism-infl ame-protests-over-coal-ash-69763. Accessed 2019 Dec 18.

155. Lerner S. Sacrifice Zones: The Front Lines of Toxic Chemical Exposure in the United States. Cambridge (MA, US): MIT Press; 2010.

156. Krantz D. Solar Sacrifice: How an Arizona Church Lost Money by Going Solar-and Solutions for When Energy Incentives Fail to Serve the Needs of Nonprofits. Case Stud Environ. 2018;2(1):1-8.

157. Kunkel C, Sanzillo T. Under PREPA’s New Debt Deal, Electricity Prices will Rise $13 \%$ by Next Summer in Puerto Rico Institute for Energy Economics and Financial Analysis. 2019. Available from: 
ieefa.org/ieefa-update-under-prepas-new-debt-deal-electricity-prices-will-ris e-13-by-next-summer-in-puerto-rico/. Accessed 2020 May 10.

158. Aronoff K. To Help Pay Off Bondholders, Solar Panel Owners will be Hit Hard in Puerto Rico. The Intercept. 2019. Available from: theintercept.com/2019/05/22/puerto-rico-debt-solar-panels-electricity/. Accessed 2020 May 10.

159. Żuk P, Szulecki K. Unpacking the Right-Populist Threat to Climate Action: Poland's Pro-Governmental Media on Energy Transition and Climate Change. Energy Res Soc Sci. 2020;66:1-12.

160. Ćetković S, Hagemann C. Changing Climate for Populists? Examining the Influence of Radical-Right Political Parties on Low-Carbon Energy transitions in Western Europe. Energy Res Soc Sci. 2020;66:1-9.

161. Schneider J, Peeples J. The Energy Covenant: Energy Dominance and the Rhetoric of the Aggrieved. Front Commun. 2018;3:1-12.

162. de Onís CM. For Many in Puerto Rico, 'Energy Dominance' is Just a New Name for US Colonialism. The Conversation. 2017. Available from: theconversation.com/for-many-in-puerto-rico-energy-dominance-is-just-a-ne w-name-for-us-colonialism-80243. Accessed 2020 Nov 1.

163. Irfan U. Puerto Rico is Targeting 100\% Renewable Energy. The Trump Administration has Other Ideas. Vox. 2019. Available from: vox.com/2019/4/17/18306417/puerto-rico-renewable-energy-natural-gas. Accessed 2020 May 20.

164. Brown A. Energy Insurrection: Puerto Rico's Power Failures Inspired a Rooftop Solar Movement. But Officials are Undermining It-in Favor of Natural Gas. The Intercept. 2020. Available from: theintercept.com/2020/02/09/puerto-rico-energy-electricity-solar-natural-gas/. Accessed 2020 May 20.

165. Santiago R, de Onís CM, Lloréns H. Powering Life in Puerto Rico: The Struggle to Transform Puerto Rico's Flawed Energy Grid with Locally Controlled Alternatives is a Matter of Life and Death. NACLA Report on the Americas. 2020;52(2):178-85.

166. de Onís C. Puerto Rican Energy Researchers Excluded From Island's Energy Transition Deliberations. Latino Rebels. 2017. Available from: latinorebels.com/2017/10/16/puerto-rican-energy-researchers-excluded-from -islands-energy-transition-deliberations/. Accessed 2020 Nov 1.

167. Callaghan G, Williams D. Teddy Bears and Tigers: How Renewable Energy Can Revitalise Local Communities. Local Economy. 2014;29(6-7):657-74.

168. Brummer V. Community Energy-Benefits and Barriers: A Comparative Literature Review of Community Energy in the UK, Germany and the USA, the Benefits it Provides for Society and the Barriers it Faces. Renew Sustain Energy Rev. 2018;94:187-96.

169. Lamb WF, Antal M, Bohnenberger K, Brand-Correa LI, Müller-Hansen F, Jakob M, et al. What are the Social Outcomes of Climate Policies? A Systematic Map and Review of the Ex-Post Literature. Environ Res Lett. 2020;15(11):113006. 
170. Ishii J, Yan J. Does Divestiture Crowd Out New Investment? The "Make or Buy” Decision in the U.S. Electricity Generation Industry. RAND J Econ. 2007;38(1):185-213.

171. Joskow PL. Markets for Power in the United States: An Interim Assessment. Energy J. 2006;27(1):1-36.

172. Gultom YML. Governance Structures and Efficiency in the U.S. Electricity Sector After the Market Restructuring and Deregulation. Energy Policy. 2019;129:1008-19.

173. Pitt D, Michaud G, Duggan A. Analyzing the Costs and Benefits of Distributed Solar Energy in Virginia (USA): A Case Study of Collaborative Energy Planning. J Environ Plan Manag. 2018;61(11):2032-49.

174. Ambrose A. Walking with Energy: Challenging Energy Invisibility and Connecting Citizens with Energy Futures Through Participatory Research. Futures. 2020;117:1-11.

175. Lelieveld J, Evans JS, Fnais M, Giannadaki D, Pozzer A. The Contribution of Outdoor Air Pollution Sources to Premature Mortality on a Global Scale. Nature. 2015;525(7569):367-71.

176. Martinez DE. The Right to Be Free of Fear: Indigeneity and the United Nations. Wicazo Sa Rev. 2014;29(2):63-87.

177. Becker S, Naumann M. Energy Democracy: Mapping the Debate on Energy Alternatives. Geogr Compass. 2017;11(8):1-13.

178. Szulecki K. Conceptualizing Energy Democracy. Environ Polit. 2018;27(1):21-41.

179. Fairchild D, Weinrub A. Energy Democracy. In: Lerch D, editor. The Community Resilience Reader: Essential Resources for an Era of Upheaval. Washington DC (US): Island Press/Center for Resource Economics; 2017. p. 195-206.

180. Feldpausch-Parker AM, Endres DE, Peterson T. A Research Agenda for Energy Democracy. Front Commun. 2019;4:1-8.

181. Kunze C, Becker S. Energy Democracy in Europe: A Survey and Outlook. Brussels (Belgium): Rosa-Luxemburg-Stiftung; 2014.

182. Demaria F, Schneider F, Sekulova F, Martinez-Alier J. What is Degrowth? From an Activist Slogan to a Social Movement. Environ Values. 2013;22(2):191-215.

183. Schneider F, Kallis G, Martinez-Alier J. Crisis or Opportunity? Economic Degrowth for Social Equity and Ecological Sustainability. Introduction to This Special Issue. J Clean Prod. 2010;18(6):511-8.

184. Sekulova F, Kallis G, Rodríguez-Labajos B, Schneider F. Degrowth: From Theory to Practice. J Clean Prod. 2013;38:1-6.

185. Alier JM. Socially Sustainable Economic De-Growth. Dev Change. 2009;40(6):1099-119.

186. Van Veelen B, van der Horst D. What is Energy Democracy? Connecting Social Science Energy Research and Political Theory. Energy Res Soc Sci. 2018;46:19-28.

187. Burke MJ, Stephens JC. Energy Democracy: Goals and Policy Instruments for Sociotechnical Transitions. Energy Res Soc Sci. 2017;33:35-48. 
188. Pitt D, Congreve A. Collaborative Approaches to Local Climate Change and Clean Energy Initiatives in the USA and England. Local Environ. 2017;22(9):1124-41.

189. McIntyre S, Duane TP. Water, Work, Wildlife, and Wilderness: The Collaborative Federal Public Lands Planning Framework for Utility-Scale Solar Energy Development in the Desert Southwest. Environ Law. 2011;41(4):1093-190.

190. U.S. Department of Energy Office of Energy Efficiency \& Renewable Energy. Community and Shared Solar u.d. Available from: energy.gov/eere/solar/community-and-shared-solar. Accessed 2020 May 22.

191. Prehoda E, Winkler R, Schelly C. Putting Research to Action: Integrating Collaborative Governance and Community-Engaged Research for Community Solar. Soc Sci. 2019;8(1):1-24.

192. Aklin M, Urpelainen J. Renewables: The Politics of a Global Energy Transition. Cambridge (MA, US): MIT Press; 2018.

193. Sweeney S. Resist, Reclaim, Restructure: Unions and the Struggle for Energy Democracy. New York (NY, US): Trade Unions for Energy Democracy; 2012.

194. Stephens JC, Burke MJ, Gibian B, Jordi E, Watts R. Operationalizing Energy Democracy: Challenges and Opportunities in Vermont's Renewable Energy Transformation. Front Commun. 2018;3:1-12.

195. Angel J. Strategies of Energy Democracy. Brussels (Belgium): Rosa-Luxemburg-Stiftung; 2016.

196. Costello A, Zumla A. Moving to Research Partnerships in Developing Countries. BMJ. 2000;321(7264):827-9.

197. Mukenge-Tshibaka L, Alary M, Geraldo N, Lowndes CM. Incorrect Condom Use and Frequent Breakage Among Female Sex Workers and Their Clients. Int J STD AIDS. 2005;16(5):345-7.

198. Foster T. Predictors of Sustainability for Community-Managed Handpumps in Sub-Saharan Africa: Evidence from Liberia, Sierra Leone, and Uganda. Environ Sci Technol. 2013;47(21):12037-46.

199. Mottram V. A Community Forgotten: Deaf People in Health Care. BMJ. 1999;319.

200. Hanna R, Duflo E, Greenstone M. Up in Smoke: The Influence of Household Behavior on the Long-Run Impact of Improved Cooking Stoves. Am Econ J Econ Policy. 2016;8(1):80-114.

201. Simmet HR. "Lighting a Dark Continent”: Imaginaries of Energy Transition in Senegal. Energy Res Soc Sci. 2018;40:71-81.

202. Simon S. Best Intentions: When Disaster Relief Brings Anything But Relief: CBS News. 2017. Available from: cbsnews.com/news/best-intentions-when-disaster-relief-brings-anything-butrelief/. Accessed 2019 Sep 25.

203. Kenny C. Haiti Doesn’t Need Your Old T-Shirt. Foreign Policy. 2011 Oct 11.

204. Harris E. Building Scientific Capacity in Developing Countries. EMBO reports. 2004;5(1):7-11.

205. Murphy B. Expect the Unexpected: Unanticipated Consequences and Development Programming: Itad; 2017. Available from: 
itad.com/expect-the-unexpected-unanticipated-consequences-and-developm ent-programming/. Accessed 2019 Sep 25.

206. Nunn N, Qian N. Aiding Conflict: The Impact of U.S. Food Aid on Civil War. Cambridge (MA, US): National Bureau of Economic Research; 2012.

207. Watkins K, Von Braun J. Time to Stop Dumping on the World's Poor. IFPRI Annual Report: 2002-2003. Washington DC (US): International Food Policy Research Institute; 2003.

208. Davidson A, Kenney C. \#186: Haiti's Rice Market is a Mess: National Public Radio. 2010. Available from: npr.org/player/embed/127868399/380331160. Accessed 2020 Jan 18.

209. Eberhard A, Rosnes O, Shkaratan M, Vennemo H. Africa's Power Infrastructure: Investment, Integration, Efficiency. The World Bank. 2011;0821384554.

210. Short R, Gurung R, Rowcliffe M, Hill N, Milner-Gulland EJ. The Use of Mosquito Nets in Fisheries: A Global Perspective. PLoS One. 2018;13(1):1-14.

211. Areán PA, Gallagher-Thompson D. Issues and Recommendations for the Recruitment and Retention of Older Ethnic Minority Adults into Clinical Research. J Consult Clin Psychol. 1996;64(5):875-80.

212. Jacklin K, Kinoshameg P. Developing a Participatory Aboriginal Health Research Project: “Only If It's Going to Mean Something”. J Empir Res Hum Res Ethics. 2008;3(2):53-67.

213. Clapp J. Corporate Interests in US Food Aid Policy: Global Implications of Resistance to Reform. In: Clapp J, Fuchs D, editors. Corporate Power in Global Agrifood Governance. Cambridge (MA, US): The MIT Press; 2009. p. 125-52.

214. Zerbe N. Feeding the Famine? American Food Aid and the GMO Debate in Southern Africa. Food Policy. 2004;29(6):593-608.

215. Office of the Federal Register. Electronic Code of Federal Regulations (§46.102). Washington DC (US): Government Publishing Office; 2018.

216. Brainard J. Federal Agency Says Oral History is Not Subject to Rules on Human Research Volunteers. Chronicle of Higher Education. 2003 Oct 21.

217. Malone RE, Yerger VB, McGruder C, Froelicher E. "It's Like Tuskegee in Reverse”: A Case Study of Ethical Tensions in Institutional Review Board Review of Community-Based Participatory Research. Am J Pub Health. 2006;96(11):1914-9.

218. Chapman S. When Outcomes Threaten Incomes: A Case Study of the Obstruction of Research to Reduce Teenage Smoking. Health Policy. 1997;39(1):55-68.

219. Brown P, Morello-Frosch R, Brody JG, Altman RG, Rudel RA, Senier L, et al. Institutional Review Board Challenges Related to Community-Based Participatory Research on Human Exposure to Environmental Toxins: A Case Study. Environ Health. 2010;9(1):39.

220. Schneider C. Case Study: Voices. The Censor's Hand: The Misregulation of Human-Subject Research. Cambridge (MA, US): MIT Press; 2015. p. 168-9.

221. Barber TX. Pitfalls in Human Research: Ten Pivotal Points. 3rd ed. New York (NY, US): Pergamon Press; 1985. 
222. Bell GH. Using Action Inquiry. J Serv Educ. 1987;14(1):34-42.

223. Argryis C, Putnam R, Smith D. Action Science: Concepts, Methods, and Skills for Research and Intervention. San Francisco (CA, US): Jossey-Bass; 1985.

224. Pine GJ. Collaborative Action Research in School Counseling: The Integration of Research and Practice. Person Guid J. 1981;59(8):495-501.

225. Kemmis S, McTaggart R. Participatory Action Research. In: Denzin NK, Lincoln YS, editors. Handbook of Qualitative Research. 2nd ed. Thousand Oaks (CA, US): Sage Publications; 2000. p. 567-605.

226. Miedema S. The Theory-Practice Relation in Critical Pedagogy. Phenomenol Pedag. 1987;5(3):221-9.

227. Tripp DH. Socially Critical Action Research. Theory Pract. 1990;29(3):158-66.

228. Gitlin A, Siegel M, Boru K. The Politics of Method: From Leftist Ethnography to Educative Research. Int J Qual Stud Educ. 1989;2(3):237-53.

229. Hall B. Participatory Research: An Approach for Change. Convergence. 1975;8(2):24-33.

230. Wallerstein N, Duran B. The Theoretical, Historical and Practice Roots of CBPR. In: Minkler M, Wallerstein N, editors. Community-Based Participatory Research for Health: Advancing Social and Health Equity. 2nd ed. San Francisco (CA, US): Jossey-Bass; 2008. p. 25-46.

231. Adelman C. Kurt Lewin and the Origins of Action Research. Educ Action Res. 1993;1(1):7-24.

232. Lewin K. Action Research and Minority Problems. Journal of Social Issues. 1946;2(4):34-46.

233. Lewin K. Frontiers in Group Dynamics: II. Channels of Group Life; Social Planning and Action Research. Human Relations. 1947;1(2):143-53.

234. McTaggart R. Participatory Action Research: Issues in Theory and Practice. Educ Action Res. 1994;2(3):313-37.

235. Macaulay AC. Participatory Research: What is the History? Has the Purpose Changed? Family Pract. 2017;34(3):256-8.

236. Janes JE. Democratic Encounters? Epistemic Privilege, Power, and Community-Based Participatory Action Research. Action Res. 2016;14(1):72-87.

237. Kim S, Flaskerud JH, Koniak-Griffin D, Dixon EL. Using Community-Partnered Participatory Research to Address Health Disparities in a Latino Community. J Prof Nurs. 2005;21(4):199-209.

238. W.K. Kellogg Foundation. Overview of the Community-Based Public Health Initiative u.d. Available from: wkkf.org/resource-directory/resource/2001/12/ overview-of-the-community-based-public-health-initiative. Accessed 2019 Sep 15.

239. Israel BA, Schulz AJ, Parker EA, Becker AB. Review of Community-Based Research: Assessing Partnership Approaches to Improve Public Health. Ann Rev Public Heal. 1998;19(1):173-202.

240. Katz DL. Representing Your Community in Community-Based Participatory Research: Differences Made and Measured. PPrevent Chronic Dis. 2004;1(1):1-4. 
241. Viswanathan M, Ammerman A, Eng E, Garlehner G, Lohr KN, Griffith D, et al. Community-Based Participatory Research: Assessing the Evidence: Summary. AHRQ Evidence Report Summaries. Rockville (MD, US): U.S. Departmemt of Health \& Human Services Agency for Healthcare Research and Quality; 2004.

242. Bastida EM, Tseng T-S, McKeever C, Jack L Jr. Ethics and Community-Based Participatory Research: Perspectives from the Field. Health Promot Pract. 2010;11(1):16-20.

243. Vostal F. Accelerating Academia: The Changing Structure of Academic Time. London (UK): Palgrave Macmillan; 2016.

244. Ylijoki O-H. Entangled in Academic Capitalism? A Case-Study on Changing Ideals and Practices of University Research. High Educ. 2003;45(3):307-35.

245. Lyon A, Bell M, Croll NS, Jackson R, Gratton C. Maculate Conceptions: Power, Process, and Creativity in Participatory Research. Rural Sociol. 2010;75(4):538-59.

246. Julsrud TE, Hjorthol R, Denstadli JM. Business Meetings: Do New Videoconferencing Technologies Change Communication Patterns? J Transp Geogr. 2012;24:396-403.

247. Denstadli JM, Julsrud TE, Hjorthol RJ. Videoconferencing as a Mode of Communication: A Comparative Study of the Use of Videoconferencing and Face-to-Face Meetings. J Bus Tech Commun. 2012;26(1):65-91.

248. Habermas J, McCarthy T. (Translator). The Theory of Communicative Action: Reason and the Rationalization of Society. Boston (MA, US): Beacon Press; 1987.

249. Innes JE, Booher DE. Collaborative Rationality as a Strategy for Working with Wicked Problems. Landscape Urban Plan. 2016;154:8-10.

250. Innes JE, Booher DE. Planning with Complexity: An Introduction to Collaborative Rationality for Public Policy. Second ed. New York (NY, US): Routledge; 2018.

251. Elster J, editor. Deliberative Democracy. Cambridge (UK): Cambridge University Press; 1998.

252. Dryzek JS. Deliberative Democracy and Beyond: Liberals, Critics, Contestations. Oxford (UK): Oxford University Press; 2002.

253. Dryzek JS. Deliberative Global Politics: Discourse and Democracy in a Divided World. Cambridge (UK): Polity; 2006.

254. Gutmann A, Thompson DF. Why Deliberative Democracy? Princeton (NJ, US): Princeton University Press; 2009.

255. Backstrand K, Khan J, Kronsell A, Löbrand E, editors. Environmental Politics and Deliberative Democracy: Examining the Promise of New Modes of Governance. Cheltenham (UK): Edward Elgar Publishing; 2010.

256. Fishkin JS. When the People Speak: Deliberative Democracy and Public Consultation. Oxford (UK): Oxford University Press; 2011.

257. Steiner J. The Foundations of Deliberative Democracy: Empirical Research and Normative Implications. Cambridge (UK): Cambridge University Press; 2012. 
258. Bächtiger A, Dryzek JS, Mansbridge J, Warren ME, editors. The Oxford Handbook of Deliberative Democracy. Oxford (UK): Oxford University Press; 2018.

259. Bohman J, Rehg W, editors. Deliberative Democracy: Essays on Reason and Politics. Cambridge (MA, US): MIT Press; 1997.

260. Booher DE, Innes JE. Governance for Resilience: CALFED as a Complex Adaptive Network for Resource Management. Ecol Soc. 2010;15(3):1-16.

261. Innes JE, Booher DE. Collaborative Policymaking: Governance Through Dialogue. In: Hajer MA, Wagenaar H, editors. Deliberative Policy Analysis: Understanding Governance in the Network Society. Cambridge (MA, US): Cambridge University Press; 2003. p. 33-59.

262. Papadopoulos Y, Warin P. Are Innovative, Participatory and Deliberative Procedures in Policy Making Democratic and Effective? Eur J Polit Res. 2007;46(4):445-72.

263. Fung A, Wright EO. Countervailing Power in Empowered Participatory Governance. In: Fung A, Wright EO, editors. Deepening Democracy: Institutional innovations in Empowered Participatory Governance. Real Utopias Project. London (UK): Verso; 2003. p. 259-89.

264. Innes JE, Booher DE. Consensus Building and Complex Adaptive Systems: A Framework for Evaluating Collaborative Planning. J Am Plan Assoc. 1999;65(4):412-23.

265. Mouffe C. The Democratic Paradox. London and New York: Verso; 2000.

266. Laclau E, Mouffe C. Hegemony and Socialist Strategy: Towards a Radical Democratic Politics. 2nd ed. London (UK): Verso; 2001.

267. Jeffers RF, Staid A, Baca MJ, Currie FM, Fogleman WE, DeRosa S, et al. Analysis of Microgrid Locations Benefitting Community Resilience for Puerto Rico. Albuquerque (NM, US): Sandia National Laboratories; 2018.

268. Dal Maso M, Olsen KH, Dong Y, Pedersen MB, Hauschild MZ. Sustainable Development Impacts of Nationally Determined Contributions: Assessing the Case of Mini-Grids in Kenya. Climate Policy. 2020;20(7):815-31.

269. Wang S, Kim AA, Reed DA. Embedded Distribution Systems for Enhanced Energy Resilience. J Sol Energy Eng. 2017;139(011005):1-9.

270. Pagliaro M. Renewable Energy Systems: Enhanced Eesilience, Lower Costs. Energy Technol. 2019;7(11):1-6.

271. Qazi S, Young W. Disaster Relief Management and Resilience Using Photovoltaic Energy. 2014 International Conference on Collaboration Technologies and Systems (CTS); 2014 May 19-23. Minneapolis (MN, US): IEEE; 2014. p. 628-32.

272. Irizarry-Rivera A, Montano-Martinez K, Alzate-Drada SI, Andrade F. A Case Study of Residential Electric Service Resiliency Through Renewable Energy Following Hurricane Maria. Mediterranean Conference on Power Generation, Transmission, Distribution and Energy Conversion (MEDPOWER 2018); 2018 Nov 12-15; Dubrovnik, Croatia. p. 1-6.

273. Belding S, Walker HA, Watson AC. Will Solar Panels Help When the Power Goes Out? Planning for PV Resilience. Golden (CO, US): National Renewable Energy Laboratory; 2020. 
274. Delina LL, Ocon J, Esparcia E Jr.. What Makes Energy Systems in Climate-Vulnerable Islands Resilient? Insights from the Philippines and Thailand. Energy Res Soc Sci. 2020;69:1-8.

275. O'Neill-Carrillo E, Irizarry-Rivera A. How to Harden Puerto Rico's Grid Against Hurricanes. IEEE Spectrum. 2019;56(11):42-8.

276. Fthenakis V. The Resilience of PV During Natural Disasters: The Hurricane Sandy Case. In: 2013 IEEE 39th Photovoltaic Specialists Conference (PVSC); 2013 Jun 16-21; Tampa, FL, US. New York (NY, US): IEEE; 2013. p. 2364-7.

277. Kwasinski A, Andrade F, Castro-Sitiriche MJ, O’Neill-Carrillo E. Hurricane Maria Effects on Puerto Rico Electric Power Infrastructure. IEEE Power Energy Tech Syst J. 2019;6(1):85-94.

278. McAtee R. Solar Photovoltaic: Reliability after Hurricanes. Military Engineer. 2018;110(713):64-6.

279. Kwasinski A. Effects of Hurricane Maria on Renewable Energy Systems in Puerto Rico. In: 7th International Conference on Renewable Energy Research and Applications (ICRERA). Paris (France): IEEE; 2018. p. 383-90.

280. Keerthisinghe C, Ahumada-Paras M, Pozzo LD, Kirschen DS, Pontes H, Tatum WK, et al. PV-Battery Systems for Critical Loads During Emergencies: A Case Study from Puerto Rico After Hurricane Maria. IEEE Power Energy Magaz. 2019;17(1):82-92.

281. Lopez-Cardalda G, Lugo-Alvarez M, Mendez-Santacruz S, Rivera EO, Bezares EA. Learnings of the Complete Power Grid Destruction in Puerto Rico by Hurricane Maria. In: 2018 IEEE International Symposium on Technologies for Homeland Security (HST); 2018 Oct 23-24; Woburn (MA, US): IEEE; 2018. p. 1-6.

282. Burgess C, Goodman J. Solar Under Storm: Select Best Practices for Resilient Ground-Mount PV Systems with Hurricane Exposure. Basalt (CO, US): Rocky Mountain Institute; 2018.

283. Levitan D. Rooftop Solar Stood Up to Sandy IEEE Spectrum. 2012. Available from: spectrum.ieee.org/green-tech/solar/rooftop-solar-stood-up-to-sandy. Accessed 2019 Dec 9.

284. Gallucci M. Rebuilding Puerto Rico's Grid. IEEE Spectrum. 2018;55(5):30-8.

285. López GG. Recuperar los Comunes para un País Vivo: Perspectivas Desde la Lucha Contra el Despojo y por la Autogestión Comunitaria en Casa Pueblo, Puerto Rico. Ecología Política. 2015(49):51-60. Spanish.

286. Massol-Deyá A. The Energy Uprising: A Community-Driven Search for Sustainabiliy and Sovereignty in Puerto Rico. In: Bonilla Y, LeBrón M, editors. Aftershocks of Disaster: Puerto Rico Before and After the Storm. Chicago (IL, US): Haymarket Books; 2019.

287. Honnold Foundation. About: Honnold Foundation. Available from: honnoldfoundation.org/about. Accessed 2019 Dec 12.

288. Sánchez Molina P. Adjuntas Será el Primer Pueblo Solar de Puerto Rico. 2019. Available from: pv-magazine-latam.com/2019/04/25/adjuntas-sera-el-primerpueblo-solar-de-puerto-rico/. Accessed 2019 Dec 12.

289. Korosec K. Rivian and 'Free Solo' Star Alex Honnold Team Up to Build Solar Microgrid with Used EV Batteries. TechCrunch. 2019. Available from: 
techcrunch.com/2019/06/14/rivian-and-free-solo-star-alex-honnold-team-up-t o-build-solar-microgrid-with-used-ev-batteries/. Accessed 2019 Dec 12.

290. Footprint Project. Project de Popo Mutuo de Mariana: Footprint Project. 2018. Available from: footprintproject.org/mariana. Accessed 2019 Dec 12.

291. Dilawar A. Puerto Rican 'Anarchistic Organizers' Took Power into Their Own Hands After Hurricane Maria. Newsweek. 2018 Sep 11.

292. Footprint Project. Centro de Apoyo Mutuo-Community Kitchen: Footprint Project. 2018. Available from: footprintproject.org/caguas. Accessed 2019 Dec 12.

293. University of Michigan. Puerto Rico: Networking to Power a Grid: University of Michigan; u.d. Available from: global.umich.edu/newsroom/puerto-rico/. Accessed 2019 Dec 12.

294. Graham Sustainability Institute. Reimagining Puerto Rico's Energy and Food Systems Through Community Engagement and Industrial Symbiosis: University of Michigan; u.d. Available from: graham.umich.edu/activity/42908. Accessed 2019 Dec 12.

295. Narigon A. School of Architecture Partners with University of Puerto Rico. University of Minnesota College of Design. 2018. Available from: designatmnblog.com/2018/06/school-of-architecture-partners-with-universit y-of-puerto-rico/. Accessed 2019 Dec 16.

296. Stager A. University Architects Work with Other Schools to Provide Aid to Puerto Rico. Minnesota Daily. 2018 Jul 6.

297. Ojeda-Cana O, Santiago-Robles H. Vieques Community Workshop on Social Recovery. Resiliency through Innovation in Sustainable Energy. 2019. Available from: umnconvergencepuertorico.org/blog/2019/1/16/viequescommunity-workshop-on-social-recovery. Accessed 2020 May 22.

298. Narigon A. Catalyst 2019: Extended Communities of Practice. University of Minnesota College of Design. 2019. Available from: designatmnblog.com/2019/03/catalyst-2019-extended-communities-of-practic el. Accessed 2020 May 22.

299. GuideStar. Coastal Marine Resource Center of New York Inc.: GuideStar; u.d. Available from: guidestar.org/profile/20-2669808. Accessed 2019 Dec 12.

300. Coastal Marine Resource Center. Power Rockaways Resilience: Coastal Marine Resource Center; u.d. Available from: coastalmarine.org/our-work. Accessed 2019 Dec 12.

301. Coastal Marine Resource Center. Protecting and Conserving the New York New Jersey Harbor Estuary and Bight: Coastal Marine Resource Center. Available from: thecmrc.org. Accessed 2019 Dec 12.

302. Coastal Marine Resource Center. Community Solar Energy Initiative: Resilient Power Puerto Rico; u.d. Available from: resilientpowerpr.org/csei. Accessed 2019 Dec 12.

303. Coastal Marine Resource Center. The Renewable Energy Microgrid Program: Resilient Power Puerto Rico; u.d. Available from: resilientpowerpr.org/renewable-energy-microgrids-program/. Accessed 2019 Dec 12. 
304. Coastal Marine Resource Center. About Us: Resilient Power Puerto Rico; u.d. Available from: resilientpowerpr.org/about-us. Accessed 2019 Dec 12.

305. Blander A. How Resilient Power Puerto Rico is Building Sustainable Communities. $2019 . \quad$ Metropolis. Available from: metropolismag.com/architecture/jonathan-marvel-resilient-power-puerto-ri co/. Accessed 2019 Dec 12.

306. Hoyos J. How Being Prepared for Hurricane Season Starts with Solar Power in One Puerto Rico Town. ABC News. 2018. Available from: abcnews.go.com/US/prepared-hurricane-season-starts-solar-power-puerto-ri co/story?id=55522507. Accessed 2019 Dec 12.

307. Rollings J. After Maria, Architects Work to Supply Puerto Rico with Solar Solutions. The Architect's Newspaper. 2017. Available from: archpaper.com/2017/10/architects-supply-puerto-rico-solar-energy/. Accessed 2019 Dec 12.

308. Rollings J. Puerto Rico's Energy Crisis Calls for Sustainable Solutions, Not More of the Same. The Architect's Newspaper. 2017. Available from: archpaper.com/2017/09/puerto-rico-energy-emergency-solar/. Accessed 2017 Sep 29.

309. Calma J. Solar to the People. Grist. 2018. Available from: grist.org/article/monxo-lopez-diy-solar-power-puerto-rico/. Accessed 2019 Dec 12.

310. Morales AR. In Puerto Rico’s Migrant Farming Communities, a Health Center Cares for All. Direct Relief. 2018. Available from: directrelief.org/2018/11/in-puerto-ricos-migrant-farming-communities-a-heal th-center-cares-for-all/. Accessed 2020 May 19.

311. Peñaloza M, Allen G. Puerto Rico Harnesses the Power of the Sun for a Renewable Energy Future. All Things Considered. 2019. Available from: npr.org/2019/07/05/738164642/puerto-rico-harnesses-the-power-of-the-sun-fo r-a-renewable-energy-future. Accessed 2019 Jul 5.

312. Gabino Martínez MA, Sanjurjo Meléndez LE, Kantrow Vázquez M. Sustainable Renovation for Puerto Rico: Transparency Report. San Juan (Puerto Rico): Fundación Comunitaria de Puert Rico/Puerto Rico Community Foundation; 2018.

313. The Solar Foundation. Solar Saves Lives: Using Solar Energy and Storage to Build a Resilient Puerto Rico, Powered by the Sun: The Solar Foundation; u.d. Available from: thesolarfoundation.org/solar-saves-lives/. Accessed 2020 May 10.

314. The Solar Foundation. Puerto Rican Solar Business Accelerator u.d. Available from: thesolarfoundation.org/puerto-rican-solar-business-accelerator/. Accessed 2020 May 10.

315. Direct Relief, Clinton Foundation. The Puerto Rico Solar Map u.d. Available from: directrelief.maps.arcgis.com/apps/opsdashboard/index.html. Accessed 2020 May 10.

316. Puerto Rico Public-Private Partnerships Authority. Desirability and Convenience Study: Utility Scale Energy Storage Systems. San Juan (Puerto Rico): Puerto Rico Public-Private Partnerships Authority; 2018. p. 1-17. 
317. Kaufman AC. On Puerto Rico's 'Forgotten Island,' Tesla's Busted Solar Panels Tell a Cautionary Tale. HuffPost. 2019. Available from: huffpost.com/entry/elon-musk-tesla-puerto-rico-renewable-energy n 5ca51e 99e4b082d775dfec35. Accessed 2019 Dec 12.

318. Takruri D. Puerto Rico's Vieques Still Reels from Decades of U.S. Navy Bombing: $\quad \mathrm{Al} \quad$ Jazeera. $2019 . \quad$ Available from: aljazeera.com/blogs/americas/2019/06/puerto-rico-vieques-reels-decades-nav y-bombing-190626153309174.html. Accessed 2019 Sep 15.

319. Peet V. Residents of Vieques, Puerto Rico, are Struggling to Deal with a Public-Health Crisis. The Atlantic. 2016 Sep 3.

320. Small D, Bruce A, Macgill I, Raturi AK, Prakash VV. Delivery of Energy Services in Unfamiliar Contexts: Learnings from Fiji. Asia Pacific Solar Research Conference; 2018 Dec 4-6; Sydney, Australia. Sydney (Australia): Australian PV Institute; 2018. p. 1-15.

321. Berger T. Practical Constraints for Photovoltaic Appliances in Rural Areas of Developing Countries: Lessons Learnt from Monitoring of Stand-Alone Systems in Remote Health Posts of North Gondar Zone, Ethiopia. Energy Sustain Dev. 2017;40:68-76.

322. Turner B. Diffusion on the Ground: Rethinking the Logic of Scale and Access in Off-Grid Solar in Sri Lanka. Energy Res Soc Sci. 2019;50:1-6.

323. Sovacool BK, Griffiths S. The Cultural Barriers to a Low-Carbon Future: A Review of Six Mobility and Energy Transitions Across 28 Countries. Renew Sustain Energy Rev. 2020;119:1-12.

324. Sovacool BK, Drupady IM. Energy Access, Poverty, and Development: The Governance of Small-Scale Renewable Energy in Developing Asia. Surrey (UK): Ashgate; 2012.

325. Sharma A. 'We Do Not Want Fake Energy': The Social Shaping of a Solar Micro-Grid in Rural India. Sci Tech Soc. 2020;25(2):308-24.

326. Sovacool BK, D’Agostino AL, Bambawale MJ. The Socio-Technical Barriers to Solar Home Systems (SHS) in Papua New Guinea: “Choosing Pigs, Prostitutes, and Poker Chips Over Panels”. Energy Policy. 2011;39(3):1532-42.

327. Maclean R. 'Crazy Milk of the Desert' Transforming the Lives of Senegal's Dairy Farmers. The Guardian. 2016. Available from: theguardian.com/sustainable-business/2016/sep/24/crazy-millk-of-desert-sene gal-dairy-farmers-africa. Accessed 2020 Nov 2.

328. Puerto Rico Energy Bureau. Distribución Porcentual de la Generación de Energía por $2016 . \quad$ Tipo. Available from: energia.pr.gov/datos/distribucion-porcentual-de-la-generacion-de-energia-po r-tipo/. Accessed 2019 Dec 9.

329. Abbey C, Cornforth D, Hatziargyriou N, Hirose K, Kwasinski A, Kyriakides E, et al. Powering Through the Storm: Microgrids Operation for More Efficient Disaster Recovery. IEEE Power Energy Magaz. 2014;12(3):67-76.

330. Lugo AE. Social-Ecological-Technological Effects of Hurricane María on Puerto Rico: Planning for Resilience Under Extreme Events. Cham (Switzerland): Springer Nature; 2018. 
331. Muff K. The Collaboratory: A Common Transformative Space for Individual, Organizational and Societal Transformation. J Corp Citizen. 2016;62:91-108.

332. Ratcliffe S, editor. Concise Oxford Dictionary of Quotations. Oxford (UK): Oxford University Press; 2011.

333. Otten J. Phone meeting with Krantz D, Nietzold T, Patterson M. 2018 Aug 28. Unpublished material.

334. U.S. Census Bureau. Mayagüez Municipio, Puerto Rico: U.S. Census Bureau. 2019. Available from: data.census.gov/cedsci/profile?q=Mayagüez $\% 20$ Municipio,\%20Puerto\%20Rico\&g=0500000US72097. Accessed 2019 Dec 12.

335. U.S. Census Bureau. QuickFacts: Mayagüez Municipio, Puerto Rico: U.S. Census $\quad$ Bureau. 2020. Available from: census.gov/quickfacts/mayaguezmunicipiopuertorico. Accessed 2020 May 10.

336. Semega J, Kollar M, Creamer J, Mohanty A. Income and Poverty in the United States: 2018. Suitland (MD, US): U.S. Census Bureau; 2019 September.

337. Gobierno de Puerto Rico Municipio de Mayagüez (Municipal Government of Mayagüez Puerto Rico). Plan Territorial del Municipio de Mayagüez, Primera Revisión Integral: Fase I Memorial-Documento para Discusión en Vista Pública, 24 de Abril de 2018 (Territorial Plan of the Municipality of Mayagüez, First Comprehensive Review: Phase One Memorandum-Document for Public-Hearing Discussion, April 24, 2018). Mayagüez (Puerto Rico): Gobierno de Puerto Rico Municipio de Mayagüez (Municipal Government of Mayagüez, Puerto Rico); 2018. p. 1-192.

338. Officina de Generencia del Estado Libre Asociadode Puerto Rico (Management and Budget Office of the Commonwealth of Puerto Rico). La Autogestión y el Apoderamiento como Estrategia de Desarrollo Comunitario: OCEPR (Autogestión and Empowerment as a Community Development Strategy: OCEPR). San Juan (Puerto Rico): Officina de Generencia del Estado Libre Asociadode Puerto Rico (Management and Budget Office of the Commonwealth of Puerto Rico); 2004. p. 1-7.

339. Sharpless R. The History of Oral History. In: Charlton TL, Myers LE, Sharpless R, editors. Handbook of Oral History. Lanham (MD, US): AltaMira Press (Rowman \& Littlefield); 2006. p. 19-42.

340. Hirsch J. Before Columbia: The FWP and American Oral History Research. Oral History Rev. 2007;34(2):1-16.

341. Erekson KA. Method and Memory in the Midwestern" Lincoln Inquiry": Oral Testimony and Abraham Lincoln Studies, 1865-1938. Oral History Rev. 2007;34(2):49-72.

342. Kerr DR. Allan Nevins is Not My Grandfather: The Roots of Radical Oral History Practice in the United States. Oral History Rev. 2016;43(2):367-91.

343. McMahan EM. A Conversation Analytic Approach to Oral History Interviewing. In: Charlton TL, Myers LE, Sharpless R, editors. Handbook of Oral History. (MD, US): AltaMira Press (Rowman \& Littlefield); 2006. p. 336-56. 
344. Grele RJ, Terkel S, Vansina J, Tedlock D, Benison S, Kessler-Harris A. Envelopes of Sound: The Art of Oral History. 2nd ed. New York (NY, US): Praeger; 1991.

345. Starecheski A. Squatting History: The Power of Oral History as a History-Making Practice. Oral History Rev. 2014;41(2):187-216.

346. Kerr D. "We Know What the Problem Is": Using Oral History to Develop a Collaborative Analysis of Homelessness from the Bottom Up. Oral History Rev. 2003;30(1):27-45.

347. Kakar S. Leprosy in India: The Intervention of Oral History. In: Perks R, Thomson A, editors. The Oral History Reader. 2nd ed. London (UK): Routledge; 2006. p. 549-59.

348. Barton CP, Markert PG. Collaborative Archaeology, Oral History, and Social Memory at Timbuctoo, New Jersey. J Af Diaspora Archaeol Heritage. 2012;1(1):79-102.

349. Rogaly B, Qureshi K. 'That's Where My Perception of it All Was Shattered': Oral Histories and Moral Geographies of Food Sector Workers in an English City Region. Geoforum. 2017;78:189-98.

350. Hoffman M. Practicing Oral History to Improve Public Policies and Programs. MacKay N, editor. London (UK): Routledge; 2018.

351. Okihiro GY. Oral History and the Writing of Ethnic History: A Reconnaissance into Method and Theory. Oral History Rev. 1981;9(1):27-46.

352. Meadows D. Leverage Points: Places to Intervene in a System. Thinking in Systems: A Primer. White River Junction (VT, US): Chelsea Green Publishing; 2008. p. $145-65$.

353. Jacobs J. The Death and Life of Great American Cities. New York (NY, US): Random House; 1961.

354. Murphy BL. Locating Social Capital in Resilient Community-Level Emergency Management. Nat Hazards. 2007;41(2):297-315.

355. Berke PR, Chuenpagdee R, Juntarashote K, Chang S. Human-Ecological Dimensions of Disaster Resiliency in Thailand: Social Capital and Aid Delivery. J Environ Plan Manag. 2008;51(2):303-17.

356. Cox RS, Perry K-ME. Like a Fish Out of Water: Reconsidering Disaster Recovery and the Role of Place and Social Capital in Community Disaster Resilience. Am J Commun Psychol. 2011;48(3-4):395-411.

357. Thomas-Slayter BP, Fisher WF. Social Capital and AIDS-Resilient Communities: Strengthening the AIDS Response. Global Public Health. 2011;6(Supplement 3):S323-S43.

358. Aldrich DP. Social Capital in Post Disaster Recovery: Towards a Resilient and Compassionate East Asian Community. In: Sawada Y, Oum S, editors. Economic and Welfare Impacts of Disasters in East Asia and Policy Responses (ERIA Research Project Report 2011-8). Jakarta (Indonesia): ERIA (Economic Research Institute for ASEAN and East Asia); 2012. p. 157-78.

359. Marin A, Bodin Ö, Gelcich S, Crona B. Social Capital in Post-Disaster Recovery Trajectories: Insights from a Longitudinal Study of Tsunami-Impacted Small-Scale Fisher Organizations in Chile. Global Environ Change. 2015;35:450-62. 
360. Roque AD, Pijawka D, Wutich A. The Role of Social Capital in Resiliency: Disaster Recovery in Puerto Rico. Risk Hazards Crisis Public Policy. 2020;11(2):204-35.

361. Borrill C, West M, Shapiro D, Rees A. Team Working and Effectiveness in Health Care. Br J Healthc Manag. 2000;6(8):364-71.

362. Waldman DA. Interdisciplinary Research is the Key. Front Human Neurosci. 2013;7(562):1-3.

363. Bromham L, Dinnage R, Hua X. Interdisciplinary Research has Consistently Lower Funding Success. Nature. 2016;534(7609):684-7.

364. Max-Neef MA. Foundations of Transdisciplinarity. Ecol Econ. 2005;53(1):5-16.

365. Nicolescu B. Manifesto of Transdisciplinarity. Albany (NY, US): SUNY Press; 2002.

366. Ernst RR. Societal Responsibility of Universities: Wisdom and Foresight Leading to a Better World. In: Darbellay F, Cockell M, Billotte J, Waldvogel F, editors. A Vision of Transdisciplinarity: Laying Foundations for a World Knowledge Dialogue. Lausanne (Switzerland): EPFL Press; 2008. p. 121-36.

367. O’Hara K, Hall W. Web Science and Reflective Practice. In: Cockell M, Billotte J, Darbellay F, Waldvogel F, editors. Common Knowledge: The Challenge of Transdisciplinarity. Lausanne (Switzerland): EPFL Press; 2011. p. 205-18.

368. Robinson S-a. Climate Change Adaptation in SIDS: A Systematic Review of the Literature Pre and Post the IPCC Fifth Assessment Report. WIREs Climate Change. 2020:1-21.

369. Sumi A. New Initiatives of the University of Tokyo Toward Establishing a Strategy for Sustainability Through Knowledge Structuring and a Transdisciplinary Approach. In: Darbellay F, Cockell M, Billotte J, Waldvogel F, editors. A Vision of Transdisciplinarity: Laying Foundations for a World Knowledge Dialogue. Lausanne (Switzerland): EPFL Press; 2008. p. 167-72.

370. Slingerland EG. Consilience and the Status of Human-Level Truth. In: Darbellay F, Cockell M, Billotte J, Waldvogel F, editors. A Vision of Transdisciplinarity: Laying Foundations for a World Knowledge Dialogue. Lausanne (Switzerland): EPFL Press; 2008. p. 51-9.

371. Slingerland E, Collard M, editors. Creating Consilience: Integrating the Sciences and the Humanities. Oxford (UK): Oxford University Press; 2011.

372. Wilson EO. Consilience: The Unity of Knowledge. New York (NY, US): Vintage; 1999.

373. Grele RJ, Terkel S, Vansina J, Tedlock D, Benison S, Kessler-Harris A. A Surmisable Variety: Interdisciplinarity and Oral History. Envelopes of Sound: The Art of Oral History. 2nd ed. New York (NY, US): Praeger; 1991. p. 156-76.

374. Blainey J. Creating and Holding a Space: Learning Circles. In: Muff K, editor. The Collaboratory. Sheffield (UK): Greenleaf Publishing; 2014. p. 76-84.

375. Biernacki P, Waldorf D. Snowball Sampling: Problems and Techniques of Chain Referral Sampling. Soc Methods Res. 1981;10(2):141-63.

376. Williams RC. The Historian's Toolbox. Second ed. Armonk (NY, US): M.E. Sharpe; 2007. 
377. Cronin G, Briggle A. Applied Ecology Explained. Bull Pure Appl Sci Zool. 2018;37(2):75-84.

378. EnergySage. Average Solar Panel Size and Weight: EnergySage; 2020. Available from: news.energysage.com/average-solar-panel-size-weight/. Accessed 2020 Jan 15.

379. Wesoff E. Hanergy: From Thin-Film Solar Savior to Mass Layoffs at MiaSolé, Alta, Solibro and Global Solar. PV Magazine. 2019 Dec 13.

380. Wesoff E. MiaSole, Dormant Thin-Film Solar Company, Received More Than \$5 Million in PPP Loans. PV Magazine. 2020 Aug 26.

381. Wang Y-C, Wu T-T, Chueh Y-L. A Critical Review on Flexible Cu (In, Ga) Se2 (CIGS) Solar Cells. Mat Chem Phys. 2019;234:329-44.

382. Hutchins M. MiaSolé Breaks its Own Record for Flexible CIGS. PV Magazine. 2019 Nov 11.

383. Poortmans J, Arkhipov V, editors. Thin Film Solar Cells: Fabrication, Characterization and Applications. West Sussex (UK): John Wiley \& Sons; 2006.

384. Bhatia SC. Advanced Renewable Energy Systems. Boca Raton (FL, US): CRC Press; 2014.

385. MiaSolé. Lightweight Solar Modules for Solar Reservoir Covers: MiaSolé; 2019. Available from: miasole.com/miasole2017/wp-content/uploads/2019/ 02/flex-03w brochure reservoir 2.pdf. Accessed 2019 Dec 13.

386. MiaSolé. MiaSolé Flexible and Lightweight Solar Module Demonstrates Superior Resilience to Penetrative Damage PR Newswire. 2019. Available from: $\quad$ prnewswire.com/news-releases/miasole-flexible-and-lightweightsolar-module-demonstrates-superior-resilience-to-penetrative-damage-3009 00483.html. Accessed 2020 May 22.

387. Kullenberg C, Kasperowski D. What is Citizen Science? A Scientometric Meta-Analysis. PLOS ONE. 2016;11(1):1-16.

388. Forhringer Merchant E. Puerto Rico Legislature Approves 100 Percent Renewable Energy Target. Greentech Media. 2019.

389. Klein N. The Shock Doctrine: The Rise of Disaster Capitalism. 1st ed. New York (NY, US): Allen Lane; 2007.

390. Pont A. Precarious Decencies: Negotiating Creative (Im)mortalities, in Life, Together. Axon Creat Explor. 2016;6(10):1-18.

391. Langer E. Well-Being: Mindfulness Versus Positive Evaluation. In: Snyder CR, Lopez SJ, editors. Handbook of Positive Psychology. Oxford (UK): Oxford University Press; 2002. p. 214-30.

392. Bechtel RB, Berning A. The Third-Quarter Phenomenon: Do People Experience Discomfort After Stress has Passed? In: Harrison AA, Clearwater YA, McKay CP, editors. From Antarctica to Outer Space: Life in Isolation and Confinement. New York (NY, US): Springer-Verlag; 1991. p. 261-5.

393. Smith N, Sandal G. The Third-Quarter Phenomenon: The Psychology of Time in Space. ROOM Space J Asgardia. 2017;4(3):55-9.

394. Hulme D, Hanlon J, Barrientos A. Just Give Money to the Poor: The Development Revolution from the Global South. Sterling (VA, US): Kumarian Press; 2012. 
395. Mies M. Patriarchy and Accumulation on a World Scale: Women in the International Division of Labour. 3rd ed. London (UK): Zed Books; 2014.

396. Bell SE, Daggett C, Labuski C. Toward Feminist Energy Systems: Why Adding Women and Solar Panels is Not Enough. Energy Res Soc Sci. 2020;68:1-13.

397. Wilson S. Energy Imaginaries: Feminist and Decolonial Futures. In: Bellamy BR, Diamanti J, editors. Materialism and the Critique of Energy. Chicago (IL, US): MCMPrime Press; 2018. p. 377-412.

398. Stember M. Advancing the Social Sciences Through the Interdisciplinary Enterprise. Soc Sci J. 1991;28(1):1-14.

399. Boucher JL, Levenda AM, Morales-Guerrero J, Macias MM, Karwat DMA. Establishing a Field of Collaboration for Engineers, Scientists, and Community Groups: Incentives, Barriers, and Potential. Earth's Future. 2020;8:1-19.

400. Kagan S. Artful Sustainability in Transdisciplinary Spaces of Possibilities. Trans J Eng Sci. 2019;10:63-71.

401. Klein JT, Falk-Krzesinski HJ. Interdisciplinary and Collaborative Work: Framing Promotion and Tenure Practices and Policies. Res Policy. 2017;46(6):1055-61.

402. Cronin G. Transdisciplinary Scholarship: Integrating Boyer's Model of Scholarship with Transdisciplinary Research. Trans J Eng Sci. 2014;5:14-20.

403. Fritz L, Binder CR. Whose Knowledge, Whose Values? An Empirical Analysis of Power in Transdisciplinary Sustainability Research. Eur J Futures Res. 2020;8(1):1-21.

404. Sun Power Energy. Listado de Garantias. Aguada (Puerto Rico): Sun Power Energy; 2019. Unpublished Warranty.

405. Garofalo G. More Clients Shifting to Solar Energy as PREPA Concerns Grow. The Weekly Journal. 2020. Available from: theweeklyjournal.com/business/more-clients-shifting-to-solar-energy-as-pre pa-concerns-grow/article b51e97d2-4220-11ea-b7c5-5b12dc61a8f7.html. Accessed 2020 Jan 30.

406. Peters A. This Single Shipping Container can Start Powering a Small Renewable Grid in Less Than a Day. Fast Company. 2019 Nov 18.

407. BoxPower. Rapidly Deployable Microgrids for Emergency Response in Puerto Rico. BoxPower. 2020. Available from: boxpower.io/microgrids-emergency-response/. Accessed 2020 May 10.

408. BoxPower. Community Resilience in Mariana. BoxPower. 2020. Available from: boxpower.io/community-resilience-mariana/. Accessed 2020 Nov 10.

409. BoxPower. Solar Container: BoxPower; u.d. Available from: boxpower.io/products/solar-container/. Accessed 2020 May 10.

410. BoxPower. BoxPower MiniBox: BoxPower. Available from: boxpower.io/products/solar-battery-container/. Accessed 2020 May 10.

411. National Renewable Energy Laboratory. PVWatts Calculator: National Renewable Energy Laboratory; 2020. Available from: pvwatts.nrel.gov/pvwatts.php. Accessed 2020 May 10.

412. U.S. Environmental Protection Agency. Greenhouse Gas Equivalencies Calculator: U.S. Environmental Protection Agency. 2020. Available from: 
epa.gov/energy/greenhouse-gas-equivalencies-calculator. Accessed 2020 May 10.

413. Database of State Incentives for Renewables \& Efficiency. Puerto Rico-Net Metering Database of State Incentives for Renewables \& Efficiency: North Carolina Clean Energy Technology Center at North Carolina State University 2015. Available from: programs.dsireusa.org/system/program/detail/2846. Accessed 2020 May 10.

414. Simpson L, Wood L, Daws L. Community Capacity Building: Starting with People not Projects. Commun Dev J. 2003;38(4):277-86.

415. Kavlak G, McNerney J, Trancik JE. Evaluating the Causes of Cost Reduction in Photovoltaic Modules. Energy Policy. 2018;123:700-10.

416. Green MA. How Did Solar Cells Get So Cheap? Joule. 2019;3(3):631-3.

417. International Renewable Energy Agency. Solar PV Module Costs 2010-2018: International Renewable Energy Agency. 2020. Available from: resourceirena.irena.org/gateway/dashboard/?topic=3\&subTopic=32.

Accessed 2020 Jun 2.

418. International Renewable Energy Agency. Renewable Power Generation Costs in 2018. Abu Dhabi (United Arab Emirates): International Renewable Energy Agency; 2019.

419. Sovacool BK. The Cultural Barriers to Renewable Energy and Energy Efficiency in the United States. Tech Soc. 2009;31(4):365-73.

420. McCombie C, Jefferson M. Renewable and Nuclear Electricity: Comparison of Environmental Impacts. Energy Policy. 2016;96:758-69.

421. Prehoda EW, Pearce JM. Potential Lives Saved by Replacing Coal with Solar Photovoltaic Electricity Production in the U.S. Renew Sustain Energy Rev. 2017;80:710-5.

422. Mulvaney D, Bazilian MD. The Downside of Solar Energy. Scientific American. 2019.

423. Alinsky S. Rules for Radicals: A Pragmatic Primer for Realistic Radicals. New York (NY, US): Random House; 1971.

424. Yow V. “Do I Like Them Too Much?” Effects of the Oral History Interview on the Interviewer and Vice-Versa. Oral History Rev. 1997;24(1):55-79.

425. McCrea SM. Counterfactual Thinking Following Negative Outcomes: Evidence for Group and Self-Protective Biases. Eur J Soc Psychol. 2007;37(6):1256-71.

426. Galegher J, Kraut RE, Egido C, editors. Intellectual Teamwork: Social and Technological Foundations of Cooperative Work. New York (NY, US): Psychology Press; 1990.

427. Larson CE, LaFasto FMJ. Teamwork: What Must Go Right/What Can Go Wrong. Newbury Park (CA, US): Sage Publications; 1989.

428. Salas E, Goodwin GF, Burke CS, editors. Team Effectiveness in Complex Organizations: Cross-Disciplinary Perspectives and Approaches. New York (NY, US): Taylor \& Francis; 2008.

429. Salas E, Sims DE, Burke CS. Is There a "Big Five” in Teamwork? Small Group Res. 2005;36(5):555-99. 
430. Salas E, Burke CS, Cannon-Bowers JA. Teamwork: Emerging Principles. Int J Manag Rev. 2000;2(4):339-56.

431. West MA. Effective Teamwork: Practical Lessons from Organizational Research. 3rd ed. West Sussex (UK): John WIley \& Sons; 2012.

432. Bozeman B, Gaughan M, Youtie J, Slade CP, Rimes H. Research Collaboration Experiences, Good and Dad: Dispatches from the Front Lines. Sci Public Policy. 2016;43(2):226-44.

433. Primack RB, Cigliano JA, Parsons ECM. Coauthors Gone Bad; How to Avoid Publishing Conflict and a Proposed Agreement for Co-Author Teams. Biol Conserv. 2014;176(August):277-80.

434. Stebbins S. These are the Poorest Cities in Every State in the U.S. USA Today. 2019 May 7; Sect. 24/7 Wall Street.

435. Stein P. D.C.'s Poorer Residents are Increasingly Concentrated East of the Anacostia The Washington Post. 2015 Apr 14.

436. Ikejemba ECX, Schuur PC. Analyzing the Impact of Theft and Vandalism in Relation to the Sustainability of Renewable Energy Development Projects in Sub-Saharan Africa. Sustainability. 2018;10(3):1-17.

437. Galbraith K. Solar Panels are Vanishing, Only to Reappear on the Internet. The New York Times. 2008 Sep 23.

438. Cialdini RB. Basic Social Influence is Underestimated. Psychol Inquiry. 2005;16(4):158-61.

439. U.S. Department of Energy. SETO FY2018-Photovoltaics Washington: U.S. Department of Energy. 2019. Available from: energy.gov/eere/solar/seto-fy2018-photovoltaics. Accessed 2020 Jun 2.

440. Rivera Matos Y. Solar Energy Innovation Ecosystem, Community Solar Development, and Energy-Poverty Nexus: Insights from Puerto Rico. QESST Presentation Expo; 2 June; Zoom. 2020.

441. Koirala BP, Koliou E, Friege J, Hakvoort RA, Herder PM. Energetic Communities for Community Energy: A Review of Key Issues and Trends Shaping Integrated Community Energy Systems. Renew Sustain Energy Rev. 2016;56:722-44.

442. Santayana G. Reason in Common Sense. London (UK): A. Constable and Co. Ltd.; 1906.

443. Durant W, Durant A. The Lessons of History. New York (NY, US): Simon \& Schuster; 1968.

444. Haraway D. Anthropocene, Capitalocene, Plantationocene, Chthulucene: Making Kin. Env Hum. 2015;6(1):159-65.

How to cite this article:

Krantz D. Solving Problems like Maria: A Case Study and Review of Collaborative Hurricane-Resilient Solar Energy and Autogestión in Puerto Rico. J Sustain Res. 2021;3(1):e210004. https://doi.org/10.20900/jsr20210004 